\title{
RADAR NOWCASTING OF TOTAL LIGHTNING OVER THE KENNEDY SPACE CENTER
}

\author{
A Thesis \\ by \\ GREGORY NICHOLAS SEROKA
}

Submitted to the Office of Graduate Studies of Texas A\&M University

in partial fulfillment of the requirements for the degree of

MASTER OF SCIENCE

May 2011

Major Subject: Atmospheric Sciences 
Radar Nowcasting of Total Lightning over the Kennedy Space Center Copyright 2011 Gregory Nicholas Seroka 


\title{
RADAR NOWCASTING OF TOTAL LIGHTNING OVER THE KENNEDY SPACE CENTER
}

\author{
A Thesis \\ by \\ GREGORY NICHOLAS SEROKA
}

Submitted to the Office of Graduate Studies of Texas A\&M University in partial fulfillment of the requirements for the degree of

MASTER OF SCIENCE

Approved by:

Chair of Committee, Richard Orville

Committee Members, Courtney Schumacher

Mark Everett

Head of Department, $\quad$ Kenneth Bowman

May 2011

Major Subject: Atmospheric Science 


\author{
ABSTRACT \\ Radar Nowcasting of Total Lightning over the \\ Kennedy Space Center. (May 2011) \\ Gregory Nicholas Seroka, B.S., Pennsylvania State University \\ Chair of Advisory Committee: Dr. Richard Orville
}

The NASA Kennedy Space Center (KSC) is situated along the east coast of central Florida, where a high frequency of lightning occurs annually. Although cloud-to-ground (CG) lightning forecasting using radar echoes has been thoroughly analyzed, few studies have examined intracloud (IC) and/or total $(\mathrm{IC}+\mathrm{CG})$ lightning. In addition to $\mathrm{CG}$ lightning, IC flashes are of great concern to KSC launch operations.

Four years (2006-2009) of summer (June, July, August) daytime (about 14-00 Z) Weather Surveillance Radar - 1988 Doppler data for Melbourne, FL were analyzed. Convective cells were tracked using a modified version of the Storm Cell Identification and Tracking (SCIT) algorithm and then correlated to CG lightning data from the National Lightning Detection Network (NLDN), as well as grouped IC flash data acquired from the KSC Lightning Detection and Ranging (LDAR) networks I and II. Pairs of reflectivity values $(30,35$, and $40 \mathrm{dBZ})$ at isothermal levels $\left(-10,-15,-20\right.$ and updraft $\left.-10^{\circ} \mathrm{C}\right)$, as well as a vertically integrated ice (VII) product were used to optimize criteria for radar-based forecasting of both IC and CG lightning within storms. 
Results indicate that the best radar-derived predictor of CG lightning according to CSI was $25 \mathrm{dBZ}$ at $-20^{\circ} \mathrm{C}$, while the best reflectivity at isothermal predictor for IC was 25 $\mathrm{dBZ}$ at $-15^{\circ} \mathrm{C}$. Meanwhile, the best VII predictor of CG lightning was the $30^{\text {th }}$ percentile $\left(0.840 \mathrm{~kg} \mathrm{~m}^{-2}\right)$, while the best VII predictor of IC was the $5^{\text {th }}$ percentile $\left(0.143 \mathrm{~kg} \mathrm{~m}^{-2}\right)$, or nearly 6 times lower than for CG!

VII at both CG and IC initiation was higher than at both CG and IC cessation. VII was also found to be lower at IC occurrence, including at initiation, than at CG occurrence. Seventy-six percent of cells had IC initiation before CG initiation; using the first IC flash as a predictor of CG occurrence also statistically outperformed other predictors of CG lightning. Even though average lead time for using IC as a predictor of CG was only 2.4 minutes, when taking into account automation processing and radar scan time for the other methods, lead times are much more comparable. 


\section{TABLE OF CONTENTS}

ABSTRACT …..............................................................................

TABLE OF CONTENTS ...........................................................................

LIST OF FIGURES …..................................................................... vii

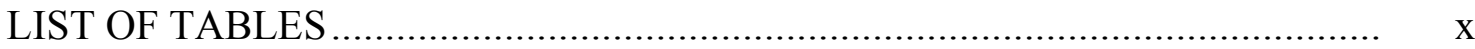

1. INTRODUCTION ...........................................................................

1.1 General background and motivation........................................ 1

1.2 Previous studies ......................................................................... 4

1.3 Objectives .......................................................................... 8

2. DATA AND METHODS …............................................................. 10

$2.1 \quad$ Radar data........................................................................... $\quad 10$

2.2 Lightning data...................................................................... 11

2.3 Sounding data ................................................................. 23

2.4 CAPPI-SCIT algorithm.................................................... 24

2.5 Correlation of lightning data to cells ........................................ 25

$2.6 \quad$ Final steps............................................................................ 26

3. RESULTS ................................................................................... 31

3.1 Overview .......................................................................... 31

3.2 IC:CG ratio overview....................................................... 32

3.3 Diagnostic comparisons between IC vs. CG initiation, cessation ....... 35

3.4 Optimization of total lightning forecasting ................................. 46

3.5 Sensitivity to horizontal resolution....................................... 60

3.6 Sensitivity to range and track count............................................. 60

3.7 More on interannual variation ................................................. 61

4. CONCLUSIONS AND FUTURE WORK ............................................... 66

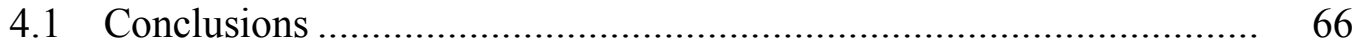

4.2 Future work ......................................................................... 69 


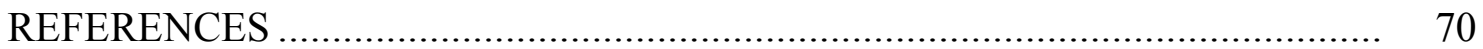

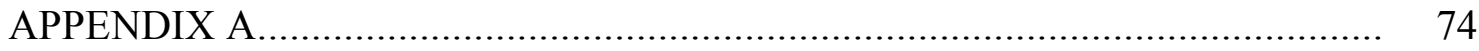

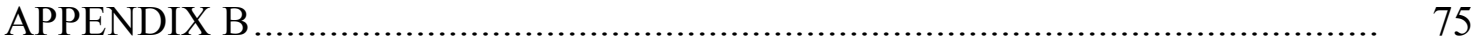

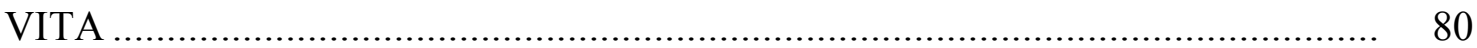




\section{LIST OF FIGURES}

FIGURE Page

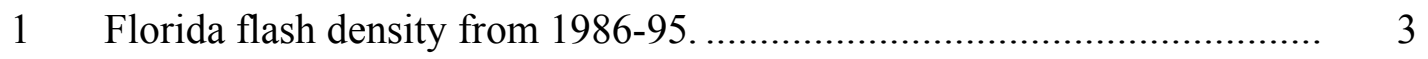

2 LDAR-I and LDAR-II site locations ........................................ 13

3 Various estimates of LDAR-I flash detection efficiency versus range ...... 14

$4 \quad$ LDAR-II flash detection efficiency versus range.................................. 15

5 An example of the reduction in radial smearing in LDAR-II as compared to LDAR-I .......................................................................... 16

$6 \quad$ LDAR flash-grouping ellipse diagram ...................................... 20

7 Example of matching process of CG flashes from NLDN to LDAR

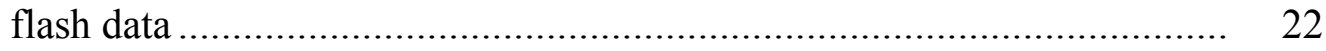

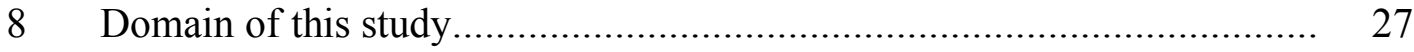

9 Overview Venn diagram of cells within database............................. 31

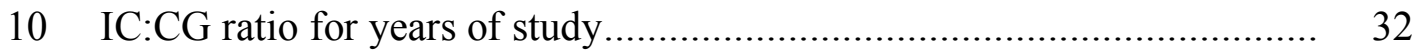

11 Intracloud to cloud-to-ground ratio after NLDN detection efficiency correction as computed by Cummins et al. (1998) (after Boccippio et al., 2001a)

12 Monthly IC:CG ratio........................................................... 35

13 Lightning initiation depicted in a pie chart .................................... 36

14 Same as in Figure 13, but for lightning cessation .............................. 37

15 Distributions of IC to $\mathrm{CG}$ initiation time difference in minutes and $\mathrm{CG}$ to IC cessation time difference......................................................... 39 
16 Left image is cumulative distribution function (CDF) of both IC to CG initiation time difference in minutes (black) and CG to IC cessation time difference (blue). Right image is zoomed in to show where CDFs cross 0 minutes

17 Box and whisker plots of VII at time of CG initiation and cessation (blue/light blue), and IC initiation and cessation

18 IC: $\mathrm{CG}$ ratio at the time of $\mathrm{CG}, \mathrm{IC}$ initiation and cessation......

19 Critical Success Index (CSI) for the five best dBZ group predictors of CG lightning.....

20 Critical Success Index (CSI) for the six best dBZ group predictors of IC lightning

21 Time series of POD, FAR, CSI, and bias for best dBZ predictor for CG: $25 \mathrm{dBZ} @-20^{\circ} \mathrm{C}$

22 Time series of POD, FAR, CSI, and bias for best $\mathrm{dBZ}$ predictor for IC: $25 \mathrm{dBZ} @-15^{\circ} \mathrm{C}$.

23 Lead time from the five best $\mathrm{dBZ}$ group predictors to first $\mathrm{CG}$ flash 52

24 Lead time from the six best dBZ group predictors to first IC flash .......... 53

25 Critical Success Index (CSI) for VII percentiles for both CG and IC....... 55

26 Time series of POD, FAR, CSI, and bias for best VII predictor for CG: 30th percentile

27 Time series of POD, FAR, CSI, and bias for best VII predictor of IC: 5 th percentile

28 Lead time from VII percentiles to first CG and first IC flash 58

29 Time series of POD, FAR, CSI, and bias for IC as predictor of CG........ 59

30 JJA 2006-2009 aerial precipitation for Florida 
FIGURE Page

31 Monthly (JJA) precipitation totals (inches) for the six closest available observation stations to the area of study versus number of monthly (JJA) total lightning $(\mathrm{IC}+\mathrm{CG})$ flashes within $100 \mathrm{~km}$ of the LDAR network

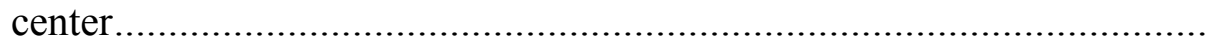




\section{LIST OF TABLES}

TABLE

Page

1 Results from previous studies of lightning forecasting with radar reflectivity.

2 VII medians $\left(\mathrm{kg} \mathrm{m}^{-2}\right)$, differences between means, and $\mathrm{p}$-values for CG initiation vs. cessation, IC initiation vs. cessation, CG vs. IC initiation, and $\mathrm{CG}$ vs. IC cessation

3 VII percentiles at both CG and IC occurrence across the entire dataset .... 


\section{INTRODUCTION}

\subsection{General background and motivation}

In recent years, much effort in meteorological research has focused on developing the predictability of hurricanes, tornadoes, and, to some extent, flash and river floods. The commonality among these types of weather events is the magnitude of their impacts, felt by many in one place at one time. These research efforts are important, especially when considering the damage inflicted by each type of event. However, when approaching the matter by fatality rate per year, a type of weather-related event becomes significant: lightning.

Lightning usually kills in scattered instances throughout the year, rather than in one large event, as with a hurricane, tornado, or flash flood. Nevertheless, the number of lightning fatalities in a year, on average, is sizeable. According to Curran et al. (2000), lightning ranked second only to river and flash floods in weather-related deaths per year in the United States, from 1959 to 1991 . A more recent glance at the 30-year average, from 1980-2009, shows lightning remaining second only to floods, with 57 fatalities per year (The 2009 NWS Weather Fatalities, Injury, and Damage Statistics, http://www.nws.noaa.gov/om/hazstats.shtml).

While examining storms over Central Florida, Holle et al. (1992) determined that most casualties from lightning occur either during the time of thunderstorm initiation or

This thesis follows the style of Weather and Forecasting. 
while the thunderstorm is decaying. At these critical times the public is not fully aware of the threat of lightning. Therefore, forecasting for lightning initiation and cessation within thunderstorms is vital in protecting lives.

Lightning poses the greatest threat amongst all the states to Florida. Coined the "lightning capital" of the United States, the state's maritime influences and the persistence of tropical air masses provide an environment often conducive to the formation of lightning. Florida has greater than twice the number of lightning deaths as any other state (Curran et al., 2000), with at least two-thirds of casualties (fatalities plus injuries) occurring during the summer months of June, July and August. Furthermore, two-thirds of casualties occur between 12 and 18 Local Standard Time (LST), during the climatological diurnal maximum of thunderstorm activity and peak of outdoor human activity.

Within Florida, a band of maximum annual cloud-to-ground (CG) lightning flash densities has been found, with an area of 10-12 flashes $\mathrm{km}^{-2}$ stretching from Tampa Bay to Cape Canaveral (Figure 1). During the warm season months of June, July and August, this flash density maximum is locally enhanced by diabatic processes and subsequent formation of sea breeze convergence zones, especially along the west and east coasts of the central peninsula. Not only does this Central Florida maximum align with the highly populated cities of Tampa, Orlando, and Melbourne along Interstate 40, but the area also houses the Kennedy Space Center (KSC) and its critical daily operations. 


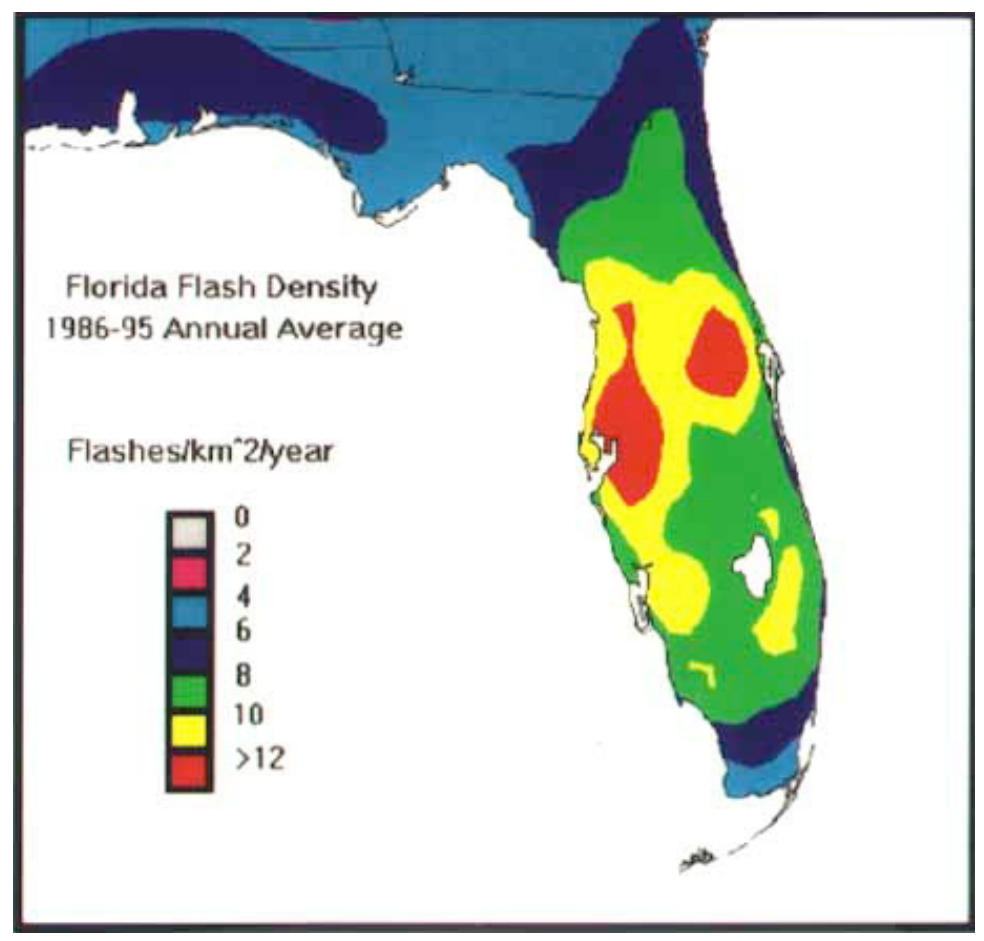

Figure 1. Florida flash density from 1986-95. Note the band of maximum CG flash density from Tampa to Melbourne (after Hodanish et al., 1997).

In summary, lightning has been the second largest weather-related killer over the past 30 years, with most deaths from lightning occurring at the start and end of thunderstorms, when the threat to humans may not be as evident. Many of these fatalities occur in Florida - specifically in the central peninsula — during the afternoons of summer months. This research focuses on summer months over KSC, striving to refine techniques developed in past studies on lightning initiation and cessation forecasting and to develop new insights into this important topic. 


\subsection{Previous studies}

In order to optimize radar-based lightning forecast predictors, Mosier et al. (2010) examined ten years (1997-2006) of summer (June, July, August) daytime (14-00 Z)

Weather Surveillance Radar - 1988 Doppler data for Houston, TX. The result was 65,399 unique thunderstorm cells that were analyzed to produce robust statistical characteristics on the best lightning forecast criteria. Besides Wolf (2006) (1,100 cells), lightning forecasting studies prior to Mosier et al. (2010) examined many fewer unique cells, typically 50 or fewer: Buechler and Goodman (1990), Michimoto (1991), Hondl and Eilts (1994), Gremillion and Orville (1999), Vincent et al. (2003), and Clements and Orville (2008); these studies relied mainly on investigation of individual storms. Table 1 provides a summary of similar previous studies. The second column in this table, or the number of cells in each study, ranges from 20-50 to upwards of thousands of cells.

Table 1. Results from previous studies of lightning forecasting with radar reflectivity.

Table 1. Results from previous studies of lightning forecasting with radar reflectivity.

\begin{tabular}{|c|c|c|c|c|c|c|c|c|}
\hline \multirow[t]{2}{*}{ Study } & \multirow[t]{2}{*}{ Num. of Cells } & \multirow[t]{2}{*}{ Location } & \multicolumn{2}{|c|}{ Criteria } & \multirow[t]{2}{*}{ POD } & \multirow[t]{2}{*}{ FAR } & \multirow[t]{2}{*}{ CSI } & \multirow[t]{2}{*}{ Lead Time } \\
\hline & & & Reflectivity & Isotherm & & & & \\
\hline Buechler and Goodman (1990) & 20 & $\mathrm{FL}, \mathrm{AL}, \mathrm{NM}$ & $40 \mathrm{dBZ}$ & -10 & 1.00 & 0.20 & 0.80 & $4-33$ minutes \\
\hline Michimoto (1991) & & Japan & $30 \mathrm{dBZ}$ & -20 & & & & 5 minutes \\
\hline Hondl and Eilts (1994) & 23 & $\mathrm{FL}$ & $10 \mathrm{dBZ}$ & -10 & 1.00 & 0.18 & 0.82 & 15 minutes \\
\hline \multirow[t]{2}{*}{ Gremillion and Orville (1999) } & 39 & $\mathrm{FL}$ & $40 \mathrm{dBZ}^{*}$ & -10 & 0.84 & 0.07 & 0.79 & 7.5 minutes \\
\hline & & & $25 \mathrm{dBZ}$ & -15 & 0.84 & 0.24 & 0.67 & 14.8 minutes \\
\hline \multirow{2}{*}{ Vincent et al (2003) } & 50 & $\mathrm{NC}$ & $35 \mathrm{dBZ}$ & -10 & 1.00 & 0.41 & 0.59 & 17.5 minutes \\
\hline & & & $40 \mathrm{dBZ}$ & -15 & 0.86 & 0.31 & 0.63 & 11.0 minutes \\
\hline Wolf (2006) & 1,100 & $\mathrm{FL}, \mathrm{GA}$ & $40 \mathrm{dBZ}$ & U-10" & 0.96 & 0.11 & 0.86 & $n / a$ \\
\hline Clements and Orville (2008) & 37 & $T X$ & $30 \mathrm{dBZ}$ & -10 & & & & 16.14 minutes \\
\hline Mosier et al. $(2010)^{\cdots \cdot \cdots}$ & 65,399 & TX & $30 \mathrm{dBZ}$ & -20 & & & 0.71 & 16.9 minutes $\cdots$ \\
\hline \multicolumn{9}{|l|}{$\begin{array}{l}\text { "Met for two consecutive scans } \\
\text { "Updraft }-10^{\circ} \mathrm{C} \text { isotherm }\end{array}$} \\
\hline
\end{tabular}


All of these studies used isothermal reflectivity values, e.g. $40 \mathrm{dBZ}$ at $-10^{\circ} \mathrm{C}$, to forecast lightning. The results from this table indicate the best predictor of lightning in terms of Critical Success Index (CSI) is $40 \mathrm{dBZ}$ at $-10^{\circ} \mathrm{C}$. These isothermal reflectivity values will be explained further in Section 2.6.3, and statistical measures such as Probability of Detection (POD), False Alarm Ratio (FAR) and CSI are explained in Appendix A.

To illustrate the need for further study of large sample sizes, statistical analyses for determining sample size were conducted. Sample sizes for a confidence interval about a single mean, $\mu$, were determined (Montgomery and Runger, 2006). For example, let $\mu=$ mean lead time between time of forecast and first occurrence of lightning. Then,

$$
n \geq\left(\frac{t_{\alpha / 2, d f}}{\Delta} \tilde{\sigma}\right)^{2}
$$

where $\mathrm{n} \quad=$ sample size,

$\alpha \quad=$ maximum chance of a false positive - $\mathrm{a}$ hit falsely recognized as good (1$\alpha=$ confidence level),

df $=$ degrees of freedom,

$t_{\alpha / 2, d f}=\mathrm{t}$-statistic of the Student's t-distribution (value looked up in statistical table),

$\Delta \quad=$ desired maximum size of the error bound, and

$\tilde{\sigma}=$ rough guess of the population standard deviation

$(\sim 1 / 4$ of the anticipated range of the data).

The Student's t-distribution was used for this calculation because it provides a more accurate measure of error of population standard deviation, and thus a decreased chance of an erroneous conclusion. The above inequality provides a formula for determining the amount of data (sample size $n$ ) required to achieve an error bound approximately equal to $\Delta$. Initially using: 


$$
\begin{array}{ll}
\alpha & =0.05(1-\alpha=0.95, \text { or } 95 \% \text { confidence }) \\
\mathrm{df} & =\infty, \\
t_{\alpha / 2, d f} & =t_{0.025, \infty}=1.960, \\
\Delta & = \pm 0.5 \text { minutes }, \text { and } \\
\tilde{\sigma} \quad=8 \text { minutes }
\end{array}
$$

we get

$$
n \geq\left(\frac{1.960}{0.5} 8\right)^{2}=984
$$

Then, we repeat the calculation with $\mathrm{df}=\mathrm{n}-1=983$. Thus, ${ }_{\alpha / 2, d f}=t_{0.025,983}=1.962$, and

$$
n \geq\left(\frac{1.962}{0.5} 8\right)^{2}=986
$$

This means that we would need to analyze a minimum of about 1,000 cells to estimate mean forecast lead time to within 0.5 minutes with $95 \%$ confidence! It is apparent that further research involving more thunderstorm cells and thus larger sample sizes is required in order to confidently arrive at a mean lead time for a sample that is close to the true mean value of the entire population of cells.

Furthermore, most past studies have been limited to only cloud-to-ground (CG) lightning forecasting, with very few using intracloud (IC) and/or total (IC + CG) lightning: Clements and Orville (2008) and Motley (2006). Total lightning, by its very nature, provides a more complete inspection of the factors contributing to CG flashes. Boccippio et al. (2001a) states that the ratio of IC to CG lightning over the continental United States is 2.64-2.94. As a result, for every one CG flash, there are nearly three IC flashes. Monitoring of total lightning will also allow the potential use of IC flash detection as a predictor of ground-strike occurrence (Murphy and Cummins, 2000; Weber et al., 1998). 
The addition of IC lightning in this study may provide another benefit. Most past studies have limited the use of meteorological quantities (e.g. vertically integrated iceVII) to be predictors of only CG lightning. However, there is no apparent reason to restrict analysis to CG lightning other than perhaps because CG flash data are readily accessible. Consequently, it is advantageous to extend previous studies to include IC lightning, as certain meteorological parameters may be related to total and/or IC lightning rather than only CG lightning. The National Aeronautics and Space Administration (NASA) Kennedy Space Center (KSC) is situated along the east coast of central Florida, where a high frequency of lightning occurs which poses a hazard to the daily operations of the center. As stated above, CG lightning initiation forecasting using radar echoes has been thoroughly analyzed, but very few studies have examined IC lightning. While CG lightning may be of most importance to ground operations, IC lightning is also of great concern to KSC launch operations.

Vertically integrated ice (VII), mentioned above, has shown promise as a predictor of CG lightning in recent years. This quantity was developed by Carey and Rutledge (2006) and used by Gauthier et al. (2006), Motley (2006), and Mosier et al. (2010). The formula for VII is as follows:

$$
V I I=1000 \pi \rho_{i} N_{0}^{3 / 7}\left(\frac{5.28 \times 10^{-18}}{720}\right) \int_{H_{-10}}^{4 / 7 H_{-40}} Z^{4 / 7} d H
$$

where

$$
\begin{aligned}
& \rho_{\mathrm{i}} \quad=\text { density of ice }\left(917 \mathrm{~kg} \mathrm{~m}^{-3}\right) \text {, } \\
& \mathrm{N}_{0}: \quad=\text { intercept } \text { parameter }\left(4 \times 106 \mathrm{~m}^{-4}\right) \text {, } \\
& \mathrm{Z} \quad=\text { reflectivity, and } \\
& \mathrm{H}_{-10}, \mathrm{H}_{-40}=\text { height of }-10,-40^{\circ} \mathrm{C} \text { levels }(\mathrm{m})(\sim 7,11 \mathrm{~km} \\
& \text { climatologically). }
\end{aligned}
$$


Because VII is a good proxy for precipitation ice mass within a cloud, it has been found to be a useful predictor of lightning occurrence. This is due to the fact that graupel and hail, as well as ice crystals - all considered precipitation ice mass - are required in the most widely accepted thunderstorm charging mechanism: the non-inducting charging theory (NIC). The NIC theory does not require an initial electric field but rather suggests that charge separation occurs as the result of the collision of large hail and graupel and small ice crystals in the presence of supercooled water droplets within a thunderstorm updraft.

\subsection{Objectives}

This study has a three-fold objective: 1) to determine optimal radar-derived lightning forecast predictors for $\mathrm{KSC}, 2$ ) to compare $\mathrm{CG}$ and $\mathrm{IC}$ initiation and cessation, the study of which has been sparse across literature, and 3) to comprehensively analyze the timing difference between IC and CG lightning initiation and cessation within thunderstorm cells over KSC, and thus the usefulness of IC flash detection as a predictor of CG occurrence.

The first objective will specifically involve calculating statistical measures, including but not limited to probability of detection (POD), false alarm ratio (FAR), the critical success index (CSI), and bias (Gremillion, 1999; Wilks, 1995). POD is the probability that an event would be forecast, given that it occurred. FAR is the fraction of forecast events that turn out to have occurred. The CSI is the ratio of the number of correctly forecasted events to the sum of the total number of predicted events plus the incorrectly predicted nonevents. Bias is the proportion of the number of yes forecasts to the 
number of yes observations; bias greater than one indicates overforecasting, while bias less than one indicates underforecasting. See Appendix A for more details on these statistics.

These statistics will be computed in order to objectively and exhaustively determine both the best radar reflectivity value $(30,35$, and $40 \mathrm{dBZ})$ at certain temperature levels $\left(-10,-15,-20^{\circ} \mathrm{C}\right.$, and updraft $\left.-10^{\circ} \mathrm{C}\right)$ as a predictor of lightning, as well as the best VII predictor of lightning. In addition, lead times between the time of forecast and the first occurrence of lightning in each cell will be calculated, which will act as another method to quantify the best radar reflectivity and VII predictors for both CG and IC lightning.

The second objective will involve providing a closer look at those cells that contained both CG and IC lightning. Comparisons between VII at CG, IC initiation and cessation will be performed. The third objective will require calculating the timing difference between the first IC and CG flash occurrence within cells. These time differences will be analyzed to ascertain the percentage of cells in which IC lightning occurred first, the percentage in which CG occurred first, and the full distribution of $+/$ lead/lag times between the two. 


\section{DATA AND METHODS}

\subsection{Radar data}

Four years (2006-2009) of summer (June, July, August) daytime (about 14-00 Z) Weather Surveillance Radar - 1988 Doppler (WSR-88D) Level II data for Melbourne, FL (KMLB) were obtained from the National Climatic Data Center (NCDC). The Melbourne radar, operated by the National Weather Service (NWS), is part of the Next Generation Radar (NEXRAD) network that consists of 159 WSR-88D sites throughout the United States and some overseas locations.

Volume Coverage Patterns (VCPs) are used by the NWS to direct which elevation angles are used on the WSR-88D; they are automated methods that repetitively scan the atmosphere at predefined elevation angles, antenna rotation rates, and pulse characteristics (OFCM, 2008). A sequence of these scans is called a volume scan. There exist a total of nine VCPs, each having its own function for a given weather situation (e.g. "Clear-air", “Precipitation”, “Severe Weather"). VCP 11 provides the best vertical resolution and is mainly used for severe and non-severe convective events. Although previous studies (Gauthier et al., 2006; Motley, 2006) considered VCP, this study did not include or exclude any radar data based solely on VCP. It is assumed that a VCP with sufficient vertical sampling was operated during the events important to this study, which mainly occurred due to severe and non-severe convection. Thus, this study did not require any subjective filtering regarding VCP within the radar database.

In order to transform the radar data into a format useful for this analysis, the native Level II KMLB radar data were first converted to Universal Format (UF, Barnes, 1980) 
and then interpolated onto a $300 \times 300 \times 20 \mathrm{~km}$ Cartesian grid using the National Center for Atmospheric Research (NCAR) REORDER software package (Mohr et al., 1986; Oye and Case, 1995). Both horizontal (x, y) and vertical (z) resolutions of $1 \mathrm{~km}$ were used in the REORDER interpolation scheme, which uses a three-dimensional Cressman interpolation scheme (Cressman, 1959) with $\mathrm{x}, \mathrm{y}$, and $\mathrm{z}$ radii of influence of $1.25,1.25$, and $1.75 \mathrm{~km}$, respectively. Although a $2 \mathrm{~km}$ horizontal resolution is common in previous radarbased lightning forecasting studies (e.g. Gauthier et al., 2006; Mosier et al., 2010), $1 \mathrm{~km}$ horizontal resolution was used in this study. Sensitivity tests performed on horizontal resolution, which will be described in Section 3.4.4, indicated that a horizontal resolution of $1 \mathrm{~km}$ may outperform $2 \mathrm{~km}$ horizontal resolution. Vertical resolutions must balance successful differentiation between temperature levels and the creation of false features through interpolation. Mosier et al. (2010) performed sensitivity tests and determined that a $1 \mathrm{~km}$ vertical resolution generally performed better than $0.5 \mathrm{~km}$ vertical resolution over Houston, TX. Therefore, $1 \mathrm{~km}$ vertical resolution was chosen for this study over Melbourne, FL.

\subsection{Lightning data}

\subsubsection{National Lightning Detection Network (NLDN)}

The National Lightning Detection Network (NLDN) consists of over 100 sensors across the United States, providing both real-time and historical lightning data to the NWS, the energy industry, and other users since 1989 (Cummins et al., 1998). The NLDN network uses a combination of magnetic direction finding (MDF) and time of arrival (TOA) for detection of lightning. For this study, CG flash data provided by the NLDN 
were used. Positive flashes with peak current less than $+15 \mathrm{kA}$ were omitted from this study, following the suggestion of Biagi et al. (2007) who found that some weak positive flashes were actually IC flashes in their study. They generally concluded that the number of false $\mathrm{CG}$ detections equaled the number of correct $\mathrm{CG}$ reports at around $+15 \mathrm{kA}$. After removing potential IC flashes, flash data were then correlated to storm cells for analysis. Correlation of CG flashes will be described more in depth in section 2.4 of Data and Methods.

\subsubsection{Lightning Detection and Ranging (LDAR)}

The KSC Lightning Detection and Ranging (LDAR) system, located on the east coast of Florida just north of Melbourne, is a three-dimensional lightning mapping system consisting of radio antennas that detect Very High Frequency (VHF) emissions from lightning breakdown and channel formation processes at a frequency of about $60-66 \mathrm{MHz}$ (Murphy et al., 2008). The network then uses TOA techniques to detect the time and location of both intracloud flashes and components of cloud-to-ground flashes. The KSC LDAR-I system, which operated from the early 1990s to June 2008, consisted of six to seven VHF radio antennas, with the center latitude and longitude of the network at $28.5387^{\circ} \mathrm{N}$ and $80.6428^{\circ} \mathrm{W}$. The upgraded LDAR-II system has operated since April 2008 and consists of nine new VHF radio antennas covering an area 2.5 times the width of the previous LDAR-I system, with its center location essentially the same as LDAR-I (Roeder, 2010). Figure 2 shows the LDAR-I and LDAR-II sensor locations. It is apparent that the LDAR-II system covers a much larger area than the previous system. 


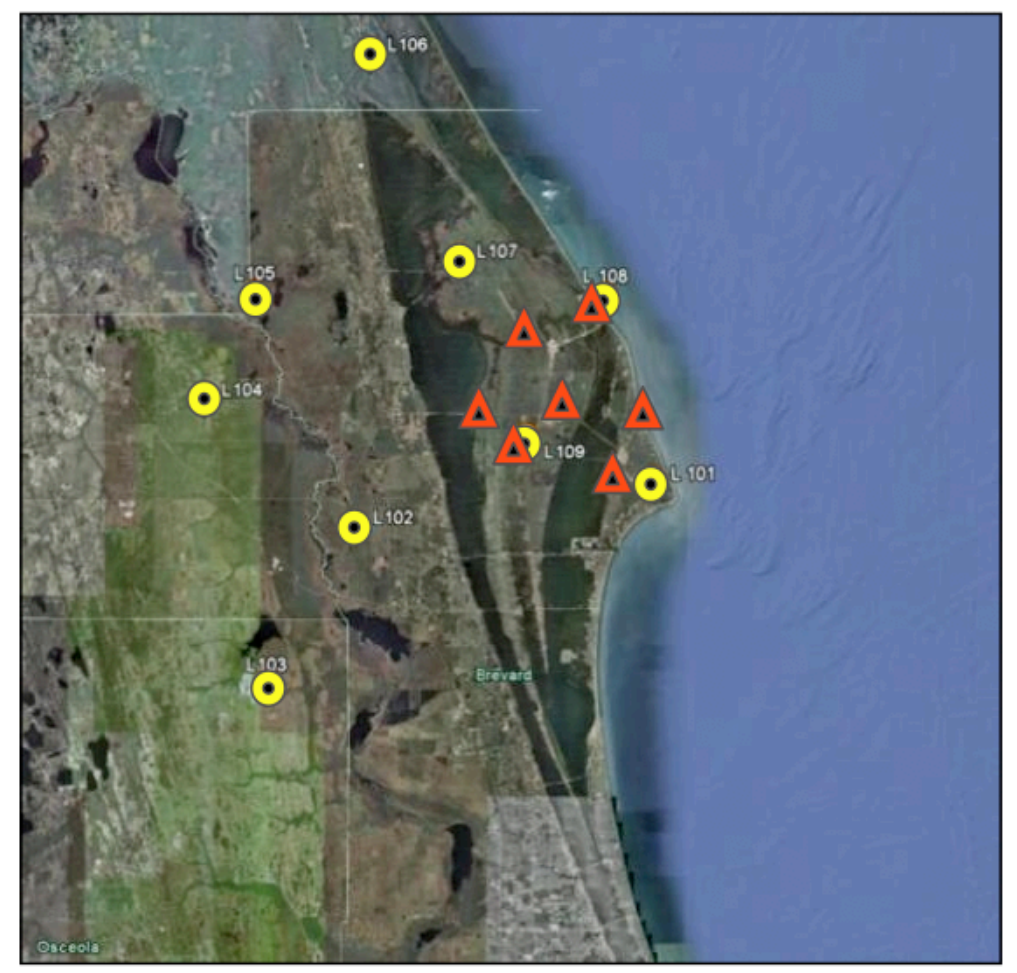

Figure 2. LDAR-I (red triangles) and LDAR-II (yellow circles) site locations. The LDAR-II network is about 2.5 times wider than the LDAR-I network (from Roeder personal communication, 2010).

Because of the increase in number of sensors and aerial extent of the network, LDAR-II has had an increase in detection efficiency and several other benefits over the previous LDAR-I. Subjective comparisons between LDAR systems during the summer 2007 lightning season found that LDAR-II detected about 40\% more VHF sources than LDAR-I (Murphy et al., 2008). Note that a typical lightning flash produces on the order of ten to 100 VHF sources (Murphy et al., 2008). Flash detection efficiency was at least $90 \%$ out to $90 \mathrm{~km}$ for LDAR-I (Boccippio et al., 2001c), whereas flash detection efficiency for LDAR-II is at least $90 \%$ out to $115 \mathrm{~km}$ (Murphy et al., 2008). Figures 3 and 4 depict flash 
detection efficiency vs. range for both LDAR-I and LDAR-II, respectively. It is apparent that the LDAR-II network has much higher flash detection efficiencies at longer ranges, especially greater than about $120 \mathrm{~km}$.

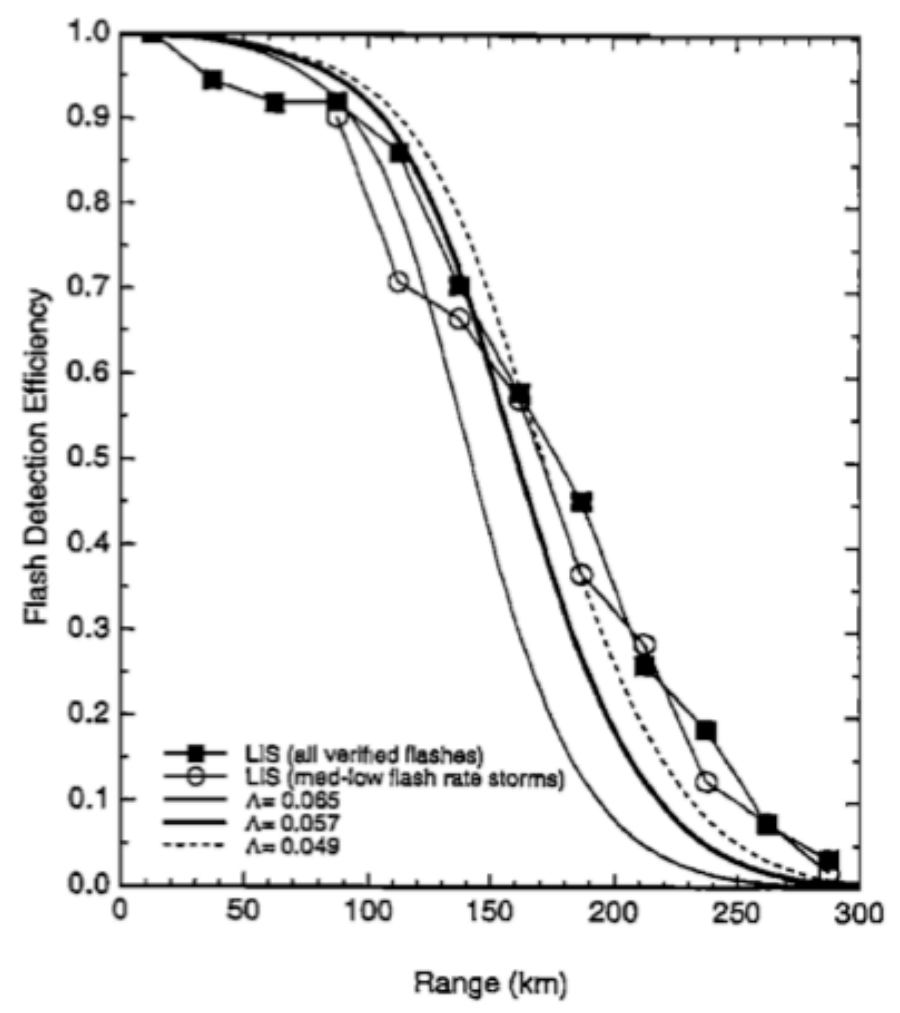

Figure 3. Various estimates of LDAR-I flash detection efficiency versus range (after Boccippio et al., 2001b). 


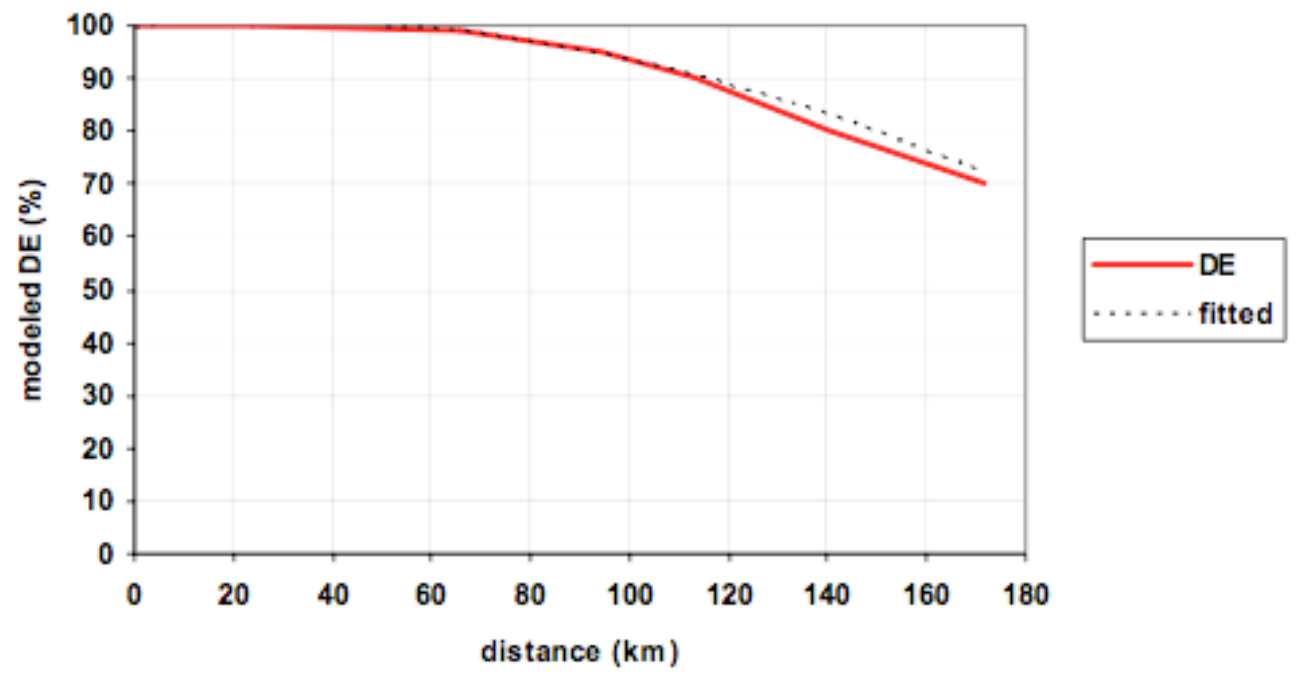

Figure 4. LDAR-II flash detection efficiency versus range (after Murphy et al., 2008).

In LDAR-I, radial location error increased much more quickly with range than azimuthal error, producing an effect known as "radial smearing." This error has been minimized with the LDAR-II system by virtue of its larger aerial extent. Due to increased detection efficiency and the reduction in radial smearing, the LDAR-II system can provide a more detailed representation of lightning branching and even detect lightning in small new thunderstorm cells before LDAR-I (Roeder, 2010). Lastly, LDAR-II has eliminated the detection of electrostatic discharges from aircraft flying through precipitation clouds, thus lowering the false alarm ratio (FAR). Figure 5 depicts data retrieved from the LDAR-I and LDAR-II networks at the same date and time. Both Figures 5a and 5b plot LDAR data in dots, NLDN data in minus symbols, and composite radar data in color. Note the reduction in radial smearing in LDAR-II, highlighted by the red ovals. 

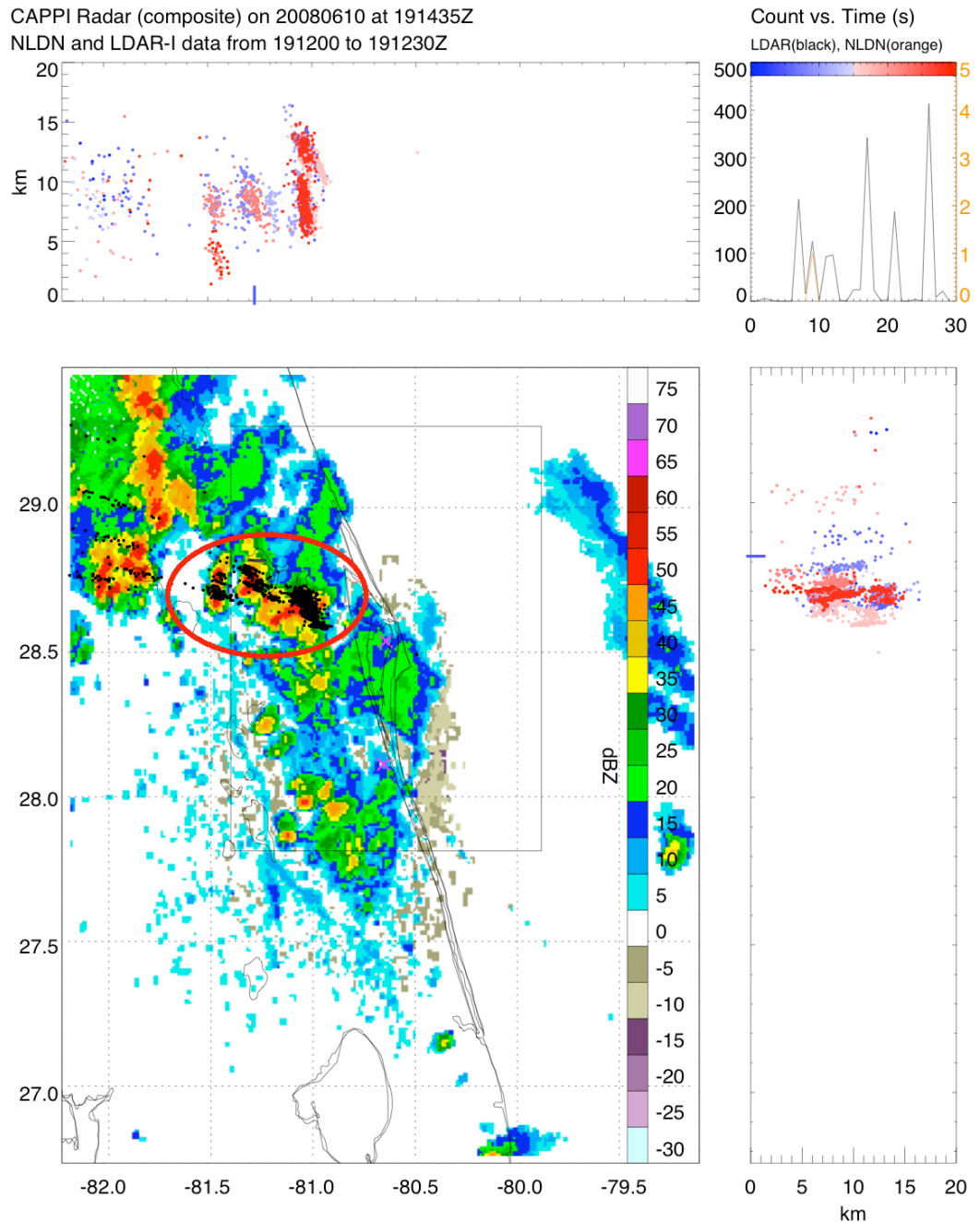

Figure 5. An example of the reduction in radial smearing in LDAR-II as compared to LDAR-I.

a) A plot of LDAR-I data (black dots in plane view; blue to red dots, according to time, in vertical plots), NLDN data (grey minus in plane view, blue minus in vertical plots), and composite radar data contoured in color. Note the red oval highlighting radially-smeared LDAR-I data. 

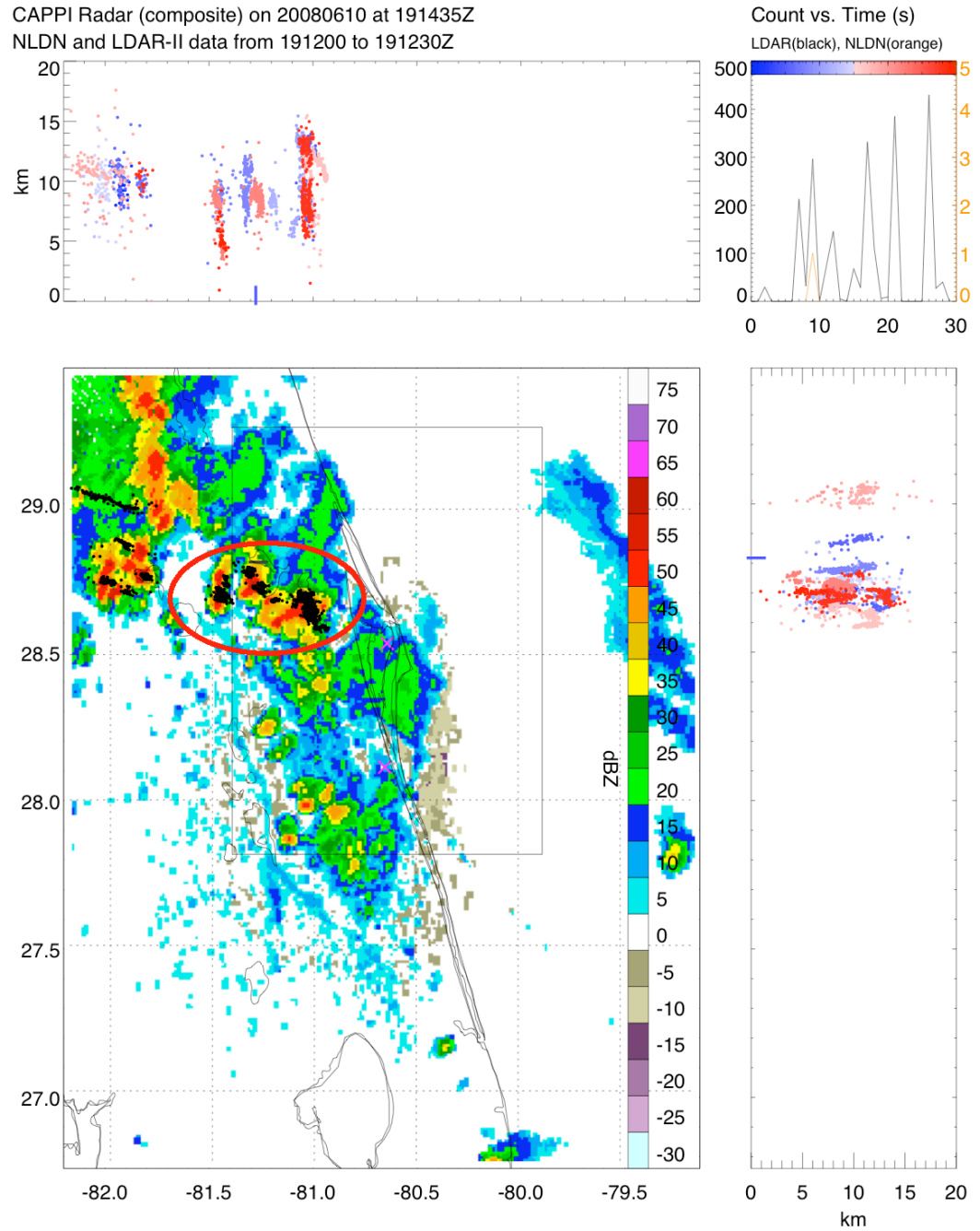

Figure 5 continued.

b) The same date and time as in plot (a), but with LDAR-II data. The reduction in radial smearing (highlighted by the red oval) is apparent not only in the plane view but in the vertical, as well.

In this study, VHF source data are used from both the LDAR-I and LDAR-II networks. The summer months of June, July, August during 2006 and 2007 represent the LDAR-I dataset, while the same summer months during 2008 and 2009 represent the 
LDAR-II dataset. In this way, lightning forecast statistics can be directly compared between the two systems, providing a fairly straightforward approach to quantifying the upgrade of the LDAR-II system. It is important to note that natural variations in lightning among years may exist, thus altering any conclusions that may result. A cursory examination of the number of CGs that occurred within a $100 \mathrm{X} 100 \mathrm{~km}$ box centered over the LDAR networks in June, July and August (JJA) of each year was performed. It was found that the ratio of total number of CGs during JJA 2008 and 2009 to the total number of CGs during JJA 2006 and 2007 was about 1.59. This increase may have resulted from natural variability, from physical modifications of the NLDN that took place in 2006 and/or 2008 — outlined in Orville et al. (2010) —, or a combination of both.

\subsubsection{LDAR flash grouping algorithm}

As stated above, a lightning flash regularly produces tens to hundreds of VHF sources. In order to transform the LDAR VHF sources into data of value to this study, a flash-grouping algorithm — outlined by Murphy et al. (2000) and written by Nelson (2002) — was used to group the data into distinct lightning flashes. Several other algorithms, listed in Stano et al. (2010), have been used in previous studies to group VHF sources into flashes. Murphy (2006) evaluated the various flash-grouping algorithms and found that all have difficulty during high flash rates, especially events with greater than 30 flashes per minute.

First, the LDAR datasets were purged of any calibration data. A transmitter located 1,318 meters south and 1,609 meters west of the center of the LDAR-I network sends out a continuous series of pulses to validate the operational status of the LDAR system. The 
LDAR-I system could not distinguish these simulated lightning events from real events. Therefore, the flash-grouping algorithm removed any LDAR-I data located within $200 \mathrm{~m}$ in the $\mathrm{x}$ - and $\mathrm{y}$-directions from and up to $900 \mathrm{~m}$ above this transmitter site. In contrast, the LDAR-II system is able to distinguish the calibration data from real data, so the calibration data was simply removed prior to grouping the LDAR-II data into flashes.

Next, individual VHF sources were grouped into flashes according to specific temporal and spatial constraints. A VHF source must occur within $3 \mathrm{~s}$ of the first observed source (the flash's initiation point) to be included in the flash. In addition, each source must occur within $0.5 \mathrm{~s}$ of the previous source in the flash (Nelson, 2002). The flash grouping algorithm considered the LDAR system's radial and azimuthal errors by creating an ellipse around the VHF source in question. This ellipse is defined by 1) a minor axis of $5000 \mathrm{~m}$ plus the azimuthal error (1 degree times the range for LDAR-I both and LDAR-II) and 2$)$ a major axis of $5000 \mathrm{~m}$ plus the range error $(12 \%$ of the range for LDAR-I, azimuthal error plus $10 \%$ for LDAR-II). If this ellipse contains any sources that are already grouped in the current flash, then the VHF source in question is grouped into that flash. Figure 6 depicts the ellipse concept used in the algorithm. Every flash must also contain at least 3 VHF sources (Nelson, 2002). 


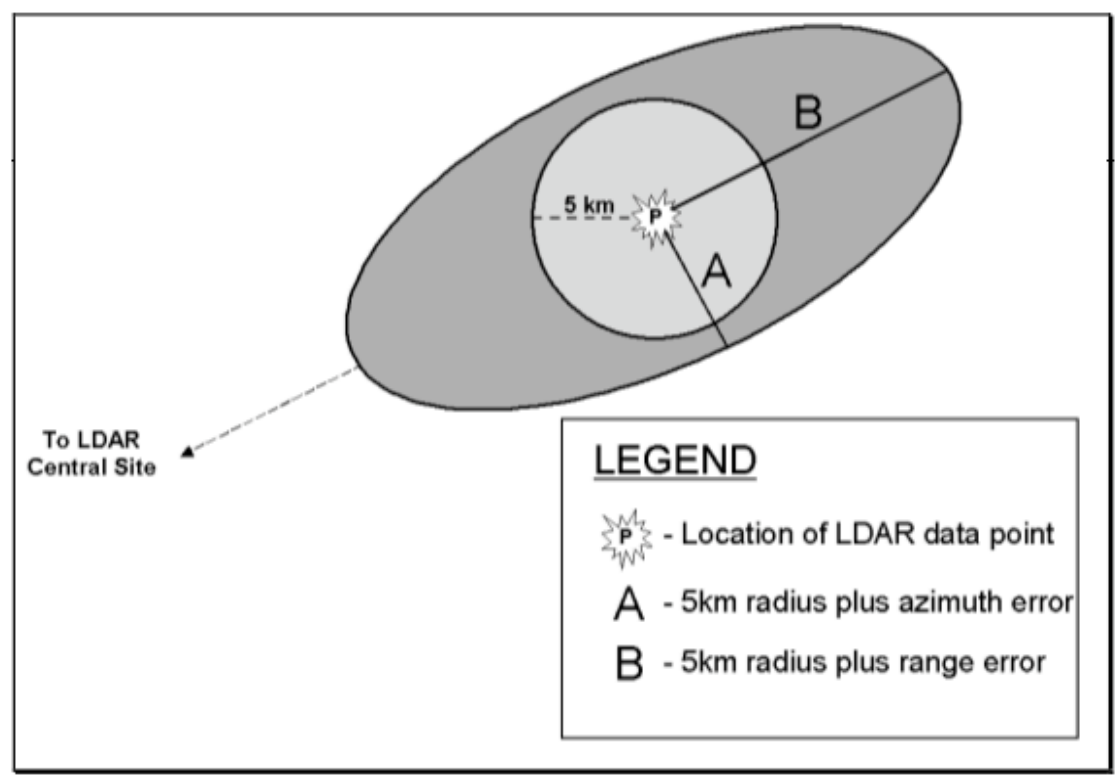

Figure 6. LDAR flash-grouping ellipse diagram. The minor axis (A) is defined by the azimuthal error of the network, while the major axis $(B)$ is defined by the radial error of the network (after Nelson, 2002).

The flash-grouping algorithm also further grouped flashes into branches, but at this point only flash information was used in this study. A complete description of the algorithm is included in Nelson (2002).

\subsubsection{Creating the intracloud array}

One of the goals of this study is collect statistics comparing cloud-to-ground to intracloud lightning initiation. A very reliable CG lightning dataset was already available via NLDN, but a purely IC lightning dataset must be created.

LDAR's capability is limited to detecting VHF radiation emitted from channel formation and branching processes in both IC and CG lightning. In addition, at close ranges, LDAR seems more skillful at detecting VHF sources from the upper branching of 
IC channels than from the lower branching of IC channels or from CG channels (Boccippio et al., 2001c). Finally, CG flashes at longer ranges are more likely to remain undetected by LDAR due to the Earth's curvature.

Ideally, a technique that removes any likely CG flashes from the LDAR flash dataset is desired; this technique would leave only IC flashes. Therefore, this study matches LDAR flash data with NLDN CG ground strike locations according to methods originally created by McNamara (2002) and used by Stano et al. (2010).

In this matching process, an LDAR VHF source must be within $1 \mathrm{~s}$ and $15 \mathrm{~km}$ (horizontally) of a CG ground contact point in order for it to be matched and identified as part of a CG flash. The temporal constraint of $1 \mathrm{~s}$ was used by both Stano et al. (2010) and McNamara (2002). Rakov and Uman (2003) also confirm that a $1 \mathrm{~s}(0.5 \mathrm{~s})$ flash duration includes all but $5 \%$ of the longest duration negative (positive) flashes. A spatial constraint of $10 \mathrm{~km}$ was initially suggested through discussions with Orville (personal communication, 2010) and was empirically refined to $15 \mathrm{~km}$ after further examination of cases. This examination consisted of inspecting three days in August 2007; it was found that increasing the spatial constraint from 10 to $15 \mathrm{~km}$ resulted in a $1-2 \%$ increase in the number of accurate CG to LDAR flash matches.

Figure 7 portrays the matching process used in this study. Flash 1 (triangles) is within the temporal constraint of $1 \mathrm{~s}$ but outside of the spatial constraint of $15 \mathrm{~km}$. Therefore, Flash 1 was not matched with the NLDN CG flash. Both Flash 2 (circles) and Flash 3 (squares) are within the temporal and spatial criteria. In this instance, all VHF sources for each flash under consideration (Flash 2 and 3) are examined. The flash with the 
closest VHF source (horizontally) to the NLDN CG ground contact point is then chosen. In this case, Flash 3 was matched to the NLDN CG flash.

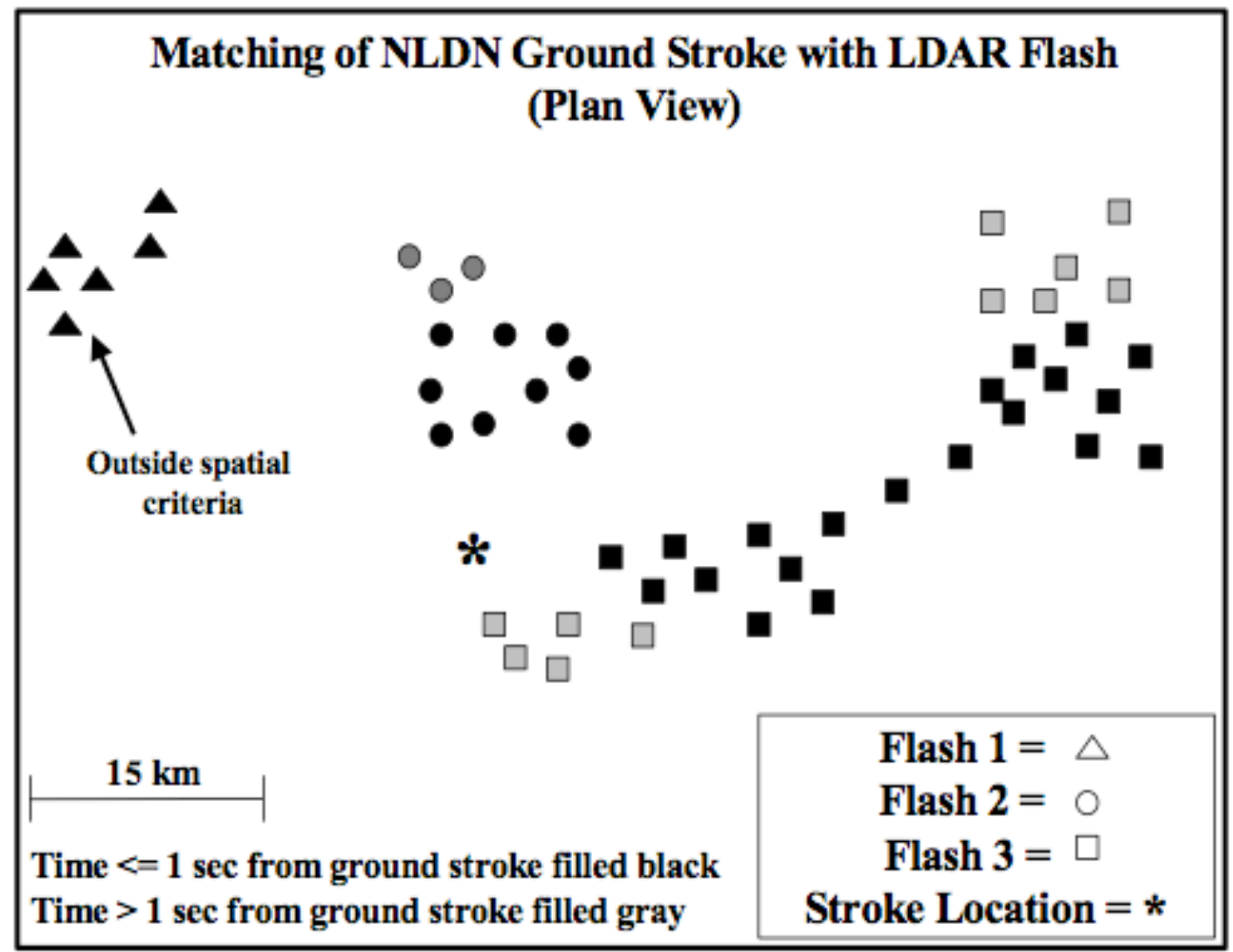

Figure 7. Example of matching process of CG flashes from NLDN to LDAR flash data. Flash 3 is matched to the CG flash, denoted by *. Note that data and scale is not real, but fabricated to portray how the matching process operates (after McNamara, 2002).

Each NLDN CG flash can be matched to one and only one LDAR flash, and vice versa. The results of this matching process consist of 1) LDAR flashes considered CG and 2) LDAR flashes considered IC, which are those not correlated to an NLDN CG flash. 
This resulting second array will act as the IC array for which all further methods and analysis will be based. The IC flash data were then correlated to storm cells for analysis. Correlation of IC flashes will be described more in depth in section 2.4 of Data and Methods.

\subsection{Sounding data}

A large part of this study deals with optimizing radar-based lightning forecast criteria, and more specifically reflectivity values (e.g. 30, 35, and $40 \mathrm{dBZ}$ ) at certain isothermal levels $\left(-10,-15,-20^{\circ} \mathrm{C}\right.$ and updraft $\left.-10^{\circ} \mathrm{C}\right)$. In order to obtain the heights of

these isothermal levels at the times requested, radiosonde soundings from Cape Canaveral (XMR) were used. Three XMR soundings (1000, 1500, and 2300 UTC) are typically launched during the warm season over Cape Canaveral. These launch times are different than the standard launch times used at National Weather Service (NWS) offices due to various $45^{\text {th }}$ Weather Squadron (45 WS) requirements-one being an 1100 UTC daily planning forecast (Lambert et al., 2005).

Only soundings between 1000 and 1500 UTC are used in this study. These soundings usually occur prior to convective initiation and are less likely to be contaminated by afternoon convective circulations. Afternoon soundings have also been disregarded in numerous previous studies (Vincent et al., 2003; Lambert et al., 2005; Stano et al., 2010; Clements and Orville, 2008). 


\subsection{CAPPI-SCIT algorithm}

As stated in the introduction, it is apparent that analysis of larger sample sizes-on the order of 1,000 cells - is needed so as to arrive at statistically significant conclusions regarding the best lightning forecast criteria. This type of large-scale investigation would be impossible without the use of an automated method for identifying and tracking storm cells. Therefore, this study uses a modified version of the Storm Cell Identification and Tracking (SCIT, Johnson et al., 1998) algorithm called Constant Altitude Plan Position Indicator (CAPPI)-SCIT. CAPPI-SCIT was developed by Mosier et al. (2010) to automate storm tracking in Cartesian coordinates rather than polar coordinates.

CAPPI-SCIT modifies the SCIT algorithm in three ways, which are outlined in more detail in Mosier et al. (2010). In summary, these changes attempt to more accurately group 1D storm segments into 2D storm cells, vertically associate 2D storm cells into 3D cell centroids, and track 3D cells through time.

This study modifies the original CAPPI-SCIT algorithm to improve cell identification and tracking at longer ranges—greater than about $100 \mathrm{~km}$-from the radar. Although CAPPI radar scans are useful in this study for various reasons-one being the ease of reflectivity identification at a given altitude-, there are also several issues that result from the use of this interpolated form of radar data. One of the major issues arises at longer ranges from the radar. Here, interpolation onto the CAPPI scheme results in radar data gaps at low heights. To mitigate this problem, a composite reflectivity grid was calculated by determining, at each grid point, the highest reflectivity value at any height. This composite reflectivity grid temporarily replaced reflectivity at $1 \mathrm{~km}$ so as to extend 
cell boundaries where needed. After cell boundaries were identified using this composite grid, then the reflectivity at $1 \mathrm{~km}$ was reverted back to its original reflectivity. This modification not only visibly improved cell identification at long ranges, but also improved correlation of lightning data to cells. This second benefit will be discussed further in the next section.

\subsection{Correlation of lightning data to cells}

Lightning initiation forecasting is most easily accomplished through cell-based prediction. The main goal is to determine those thunderstorm cells that are lightning producers, and those that are not. In order to achieve this goal, both cloud-to-ground and intracloud flashes were correlated to those cells identified by CAPPI-SCIT. The CG correlation process for one radar scan period began by identifying all CG flashes within $150 \mathrm{~km}$ of the KMLB radar and between the start times of consecutive radar scans (about 5 minutes for VCP 11). Each CG flash is then correlated to a cell by first determining if the CG flash was within a cell's $30-\mathrm{dBZ}$ boundary. If this has occurred, then that CG flash is correlated to that cell. If not, then the distance between the 30-dBZ boundaries of each cell and the CG flash was calculated; the CG flash was then correlated to the cell with the shortest distance.

In general, it is reasonable to assume that the most accurate method for correlating a lightning flash to a storm cell is by using the flash's initiation point. While this information was not available for CG flash correlation via the NLDN dataset, initiation points were available for IC flashes via our previous methods. This study used the first detected VHF source of a flash as its initiation point. Therefore, each IC flash initiation 
point is used for correlation of IC lightning to storm cells, which was performed in the same manner as described above for CG flashes. Furthermore, an IC flash initiation point is correlated to a cell if and only if it is within $20 \mathrm{~km}$ from that cell's $30-\mathrm{dBZ}$ boundaries (Orville personal communication, 2010). A spatial constraint of $50 \mathrm{~km}$ was initially suggested in order to prevent correlation of noise (e.g. aircraft signatures) to nearby cells. The $50 \mathrm{~km}$ restriction was subsequently evaluated through the examination of several cases and was empirically refined to $20 \mathrm{~km}$.

CG correlation could be performed at the lowest height available $(1 \mathrm{~km})$, which is logical given that CG lightning data from the NLDN consists of ground contact points. However, flash initiation points - which were used in IC correlation — can occur at many heights throughout the column of the troposphere. Therefore, it is not logical to perform IC correlation at the lowest height. It is also not logical to perform the correlation at the height of each flash initiation point, because many initiation points can occur at heights above the highest $30-\mathrm{dBZ}$ boundary for a cell. Therefore, the $30-\mathrm{dBZ}$ composite reflectivity boundaries were used for both CG and IC flash correlation, so as to eliminate the question of height.

\subsection{Final steps}

\subsubsection{Research domain}

Using the location of the KMLB radar and LDAR-I and LDAR-II networks, a radius of $100 \mathrm{~km}$ extending from the center of the LDAR networks was used as the primary outer boundary of this study (Figure 8). Flash detection efficiencies for both the LDAR-I and LDAR-II systems within this range were $80-90 \%$ and above. In addition, the 
northernmost extent of the $100 \mathrm{~km}$ range lies within the range of the KMLB radar.

Secondary radii of 60 and $80 \mathrm{~km}$ were also used for further statistical comparison. The results of analyses will be discussed in Section 3.4.5.

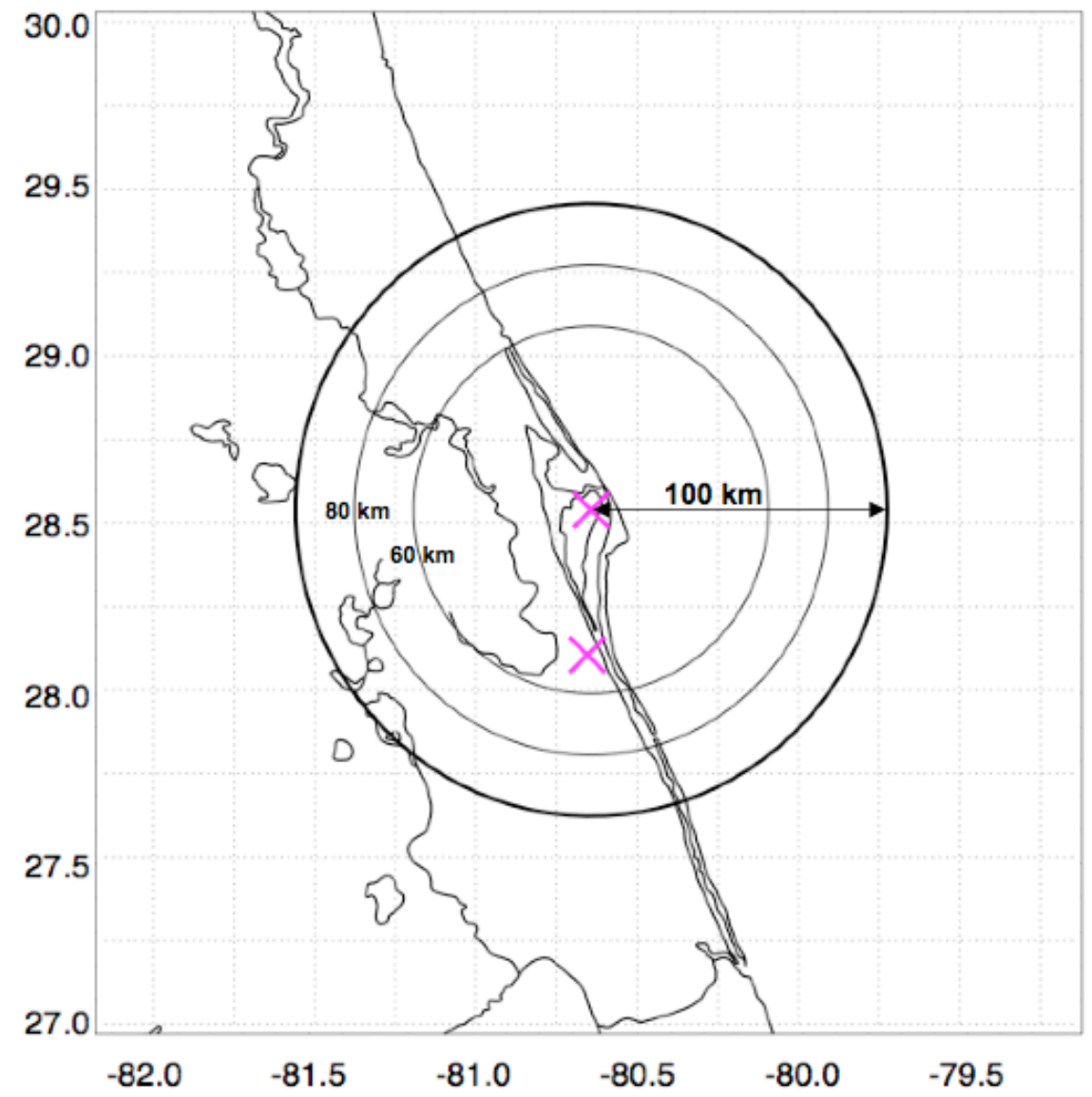

Figure 8. Domain of this study. Latitude and longitude are plotted on the ordinate and abscissa, respectively. Top magenta X denotes center location of LDAR networks, while bottom magenta $\mathrm{X}$ denotes KMLB radar location. This study focuses on cells occurring within $100 \mathrm{~km}$ of the LDAR network center (outer ring). Inner radii of 60 and $80 \mathrm{~km}$ will also be used secondarily. 


\subsubsection{Determining time ranges to process}

Methods were developed that would conserve data processing time. Only days with active lightning were used. This was determined by creating a box extending $80 \mathrm{~km}$ horizontally and vertically from the center of the LDAR networks. If at least one CG flash occurred within this box between 1400 and $0000 \mathrm{Z}$ on a given day, then that day was further analyzed to find which times to process. A range of times to process for that day was determined by simply using the time of the first CG flash and the time of the last CG flash, and adding one hour on each end of this time range to allow for the inclusion of storm development and decay. Note that some start times did include times between 1300 and $1400 \mathrm{Z}$, but all end times stopped at 2359Z.

\subsubsection{Radar-derived forecast predictors}

Radar-derived forecast predictors used in this study include both the temperature level-reflectivity pairs and cell-based VII values. The standard environmental temperature levels $\left(-10,-15\right.$, and $\left.-20^{\circ} \mathrm{C}\right)$ are calculated directly from a sounding. These environmental temperature levels have been used in several previous studies outlined in Mosier et al. (2010). The updraft level $\left(-10^{\circ} \mathrm{C}\right)$ is calculated by using a sounding to determine the temperature a parcel would be in a thunderstorm updraft. This updraft level was used for comparison with both Mosier et al. (2010) and Wolf (2006). Reflectivity values (30, 35, 40 dBZ) used in this study have also been used in the previous studies outlined in Mosier et al. (2010). Sensitivity tests (described in Section 3.4.5) were performed on range from the LDAR network center (60 and $80 \mathrm{~km}$ versus $100 \mathrm{~km}$ ) and track count, or the number of radar volumes the cell was tracked by the CAPPI-SCIT algorithm ( 0 versus 1 and 2 
volumes). Cell-based VII forecasts entailed calculating the distribution of VII values throughout the entire dataset. Percentiles in increments of 5\% from this distribution were then used as forecast criteria.

A summary of the methods to create a cell-based lightning forecast is given here. These steps are modeled after techniques used by Mosier et al. (2010). The summary is as follows: 1) CAPPI-SCIT was processed on all radar volumes occurring within determined time ranges, in order to identify and track cells; 2) the environmental temperature and updraft levels were calculated from the XMR sounding; 3) for each cell in the radar volume, the reflectivity levels were determined at the environmental and updraft levels; 4) for each cell, if the reflectivity reached the predetermined thresholds, then a "yes" forecast was made; 5) for each cell, if the VII reached the predetermined percentiles, then a "yes" forecast was made.

Two methods were used to measure the skill of each radar-based forecast predictor. The first method involves using statistical measures-POD and CSI for forecast accuracy and FAR for forecast reliability. The second method involves using lead times between the time of forecast and the first occurrence of lightning in each cell. This study calculates lead time by using the difference between the start time of the radar scan during which the forecast was made and the time of the first IC flash and first CG flash. This calculation is consistent with previous studies (Gremillion and Orville, 1999; Clements and Orville, 2008; Mosier et al., 2010). However, it is important to note that actual operational lead time of each forecast is much longer, consisting of both the time it takes for the radar to complete its scan as well as the time it takes for the entire algorithm to run (CAPPI-SCIT 
processing, LDAR flash grouping, etc). Therefore, lead times in this study should not be used operationally; here, they are used strictly for comparison and evaluation of forecasts, both within this study and to similar past studies.

\subsubsection{IC as predictor of $C G$}

Can IC flash detection be used as a predictor of CG occurrence? To answer this question, the time of the first IC flash and the time of the first CG flash were determined

for each cell. The full distribution of positive and negative lead times between the two was analyzed. Furthermore, the percentage of cells in which an IC flash occurred first, and the percentage in which a CG flash occurred first, was determined. 


\section{RESULTS}

\subsection{Overview}

A summary of the entire database acquired, at a range of $100 \mathrm{~km}$ or less from the LDAR network and spanning from the summer months of 2006 through 2009 is given in the format of a Venn diagram below (Figure 9). Out of 17,649 total cells, 39\% contained lightning (at least one flash). Of the cells with lightning, $60 \%$ contained both CG and IC flashes. Interestingly, over 700 cells (4\% of total cells, $10 \%$ of cells with lightning) produced only CG flashes.

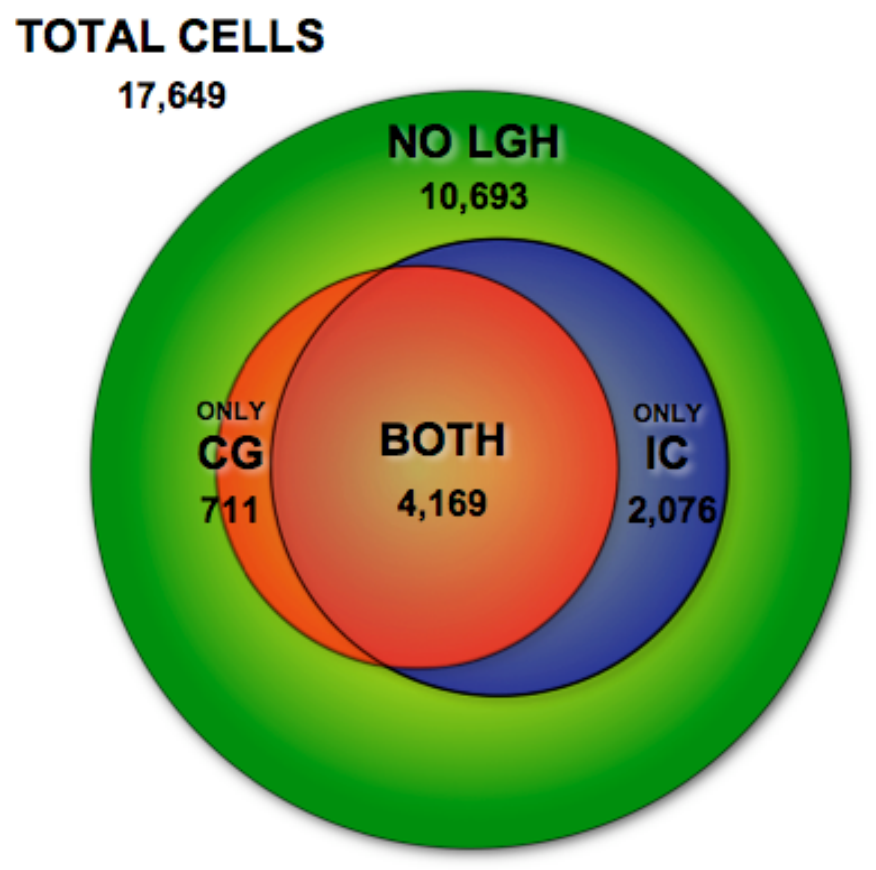

Figure 9. Overview Venn diagram of cells within database. Sizes of circles are proportional to number of cells. Cells with no lightning (NO LGH) are depicted in green. Cells with both CG and IC lightning (BOTH) are depicted in dark red. Cells with only CG lightning are depicted in orange, and cells with only IC lightning are depicted in blue. 


\subsection{IC:CG ratio overview}

Because a dataset of both CG and IC lightning was readily available, the relative proportion of intracloud to cloud-to-ground lightning (IC:CG ratio) was calculated, for both ground truth verification of and comparison to past local, regional and global studies investigating the ratio. In order to calculate IC: $\mathrm{CG}$ ratio, all IC and CG flashes that occurred within $100 \mathrm{~km}$ of the LDAR network center were tallied. As shown in Figures 2 and 3, mean flash detection efficiencies within $100 \mathrm{~km}$ are $85-90 \%$ or higher for LDAR-I, while at least $90 \%$ or higher for LDAR-II. Thus, the $100 \mathrm{~km}$ distance restriction prevents any detection efficiency differences between the LDAR-I and LDAR-II networks from significantly affecting the overall IC count for each year. Ratio results are shown below in Figure 10.

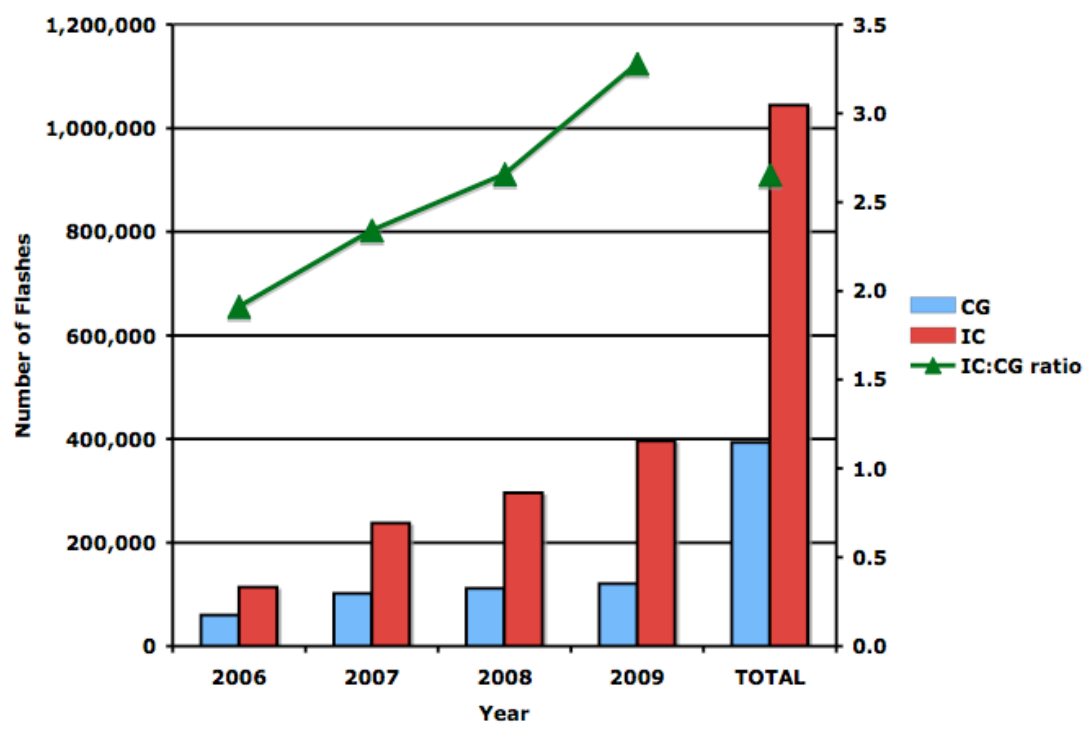

Figure 10. IC:CG ratio for years of study. Number of flashes for each year and total number of flashes in blue and red. IC:CG ratio for each year, and average IC:CG ratio in green. 
The number of IC flashes increased at a large rate over the four years of study, whereas the number of CG flashes increased at a much lower rate. Therefore, IC:CG ratio increased throughout the time of study, from 1.91 in 2006 to 3.28 in 2009. Average IC:CG ratio for the whole period was 2.65, which is consistent with Boccippio et al. (2001a) showing a ratio of between 2 and 2.5 over central portions of the Floridian peninsula (Figure 11). Coincidentally, their analysis found a continental mean IC:CG ratio of 2.64 .

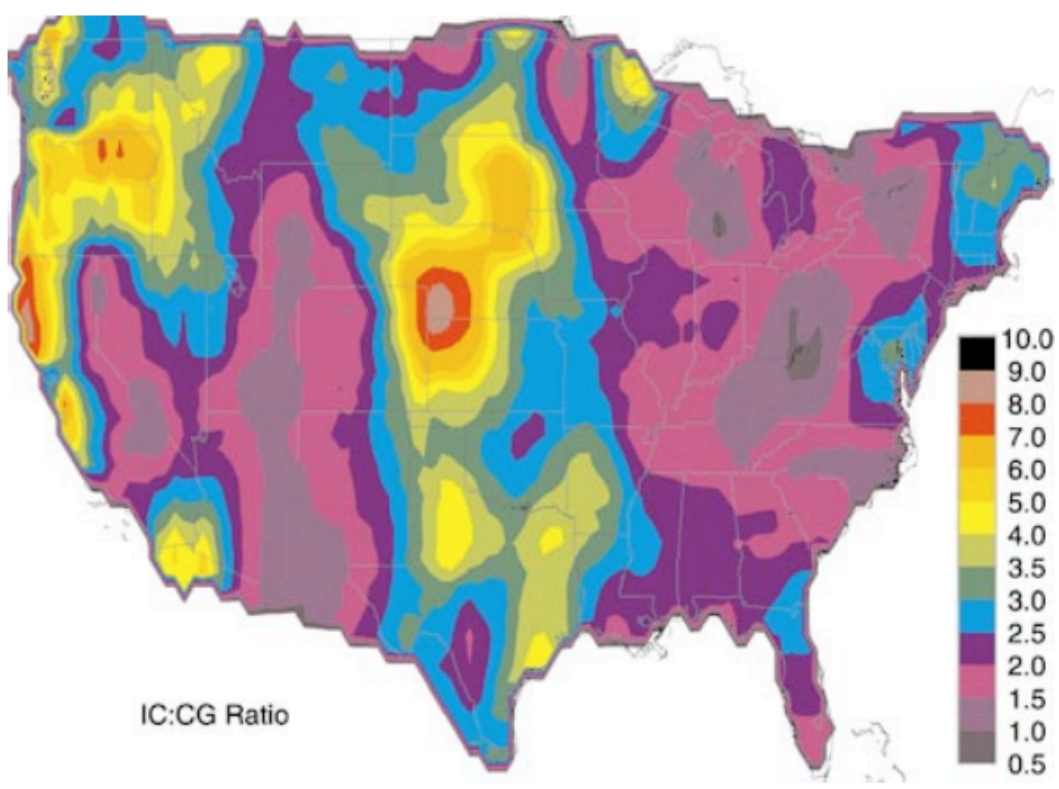

Figure 11. Intracloud to cloud-to-ground ratio after NLDN detection efficiency correction as computed by Cummins et al. (1998) (after Boccippio et al., 2001a). 
Further analysis was performed in order to ascertain possible reasons for increase in IC flash count, and thus IC:CG ratio through the time of study. First, to provide a more detailed analysis of lightning trends, monthly counts of both IC and CG flashes were calculated, both within a range of $100 \mathrm{~km}$ and $60 \mathrm{~km}$ from the LDAR network center. The shorter range of $60 \mathrm{~km}$ was used to determine if LDAR flash detection efficiency was a factor in the overall increase in IC counts. Figure 12 below depicts these monthly analyses at each range. A general increase in IC:CG ratio is evident at both ranges, due to overall higher IC counts and relatively constant CG counts beginning in July 2007. Because an increase in IC counts from 2006-09 is still apparent at $\leq 60 \mathrm{~km}$, the increase in flash detection efficiency from the LDAR-I to LDAR-II system, especially at longer ranges, is not likely a large factor. Natural causes to observed interannual trending and variability will be addressed in Section 3.4.6. 


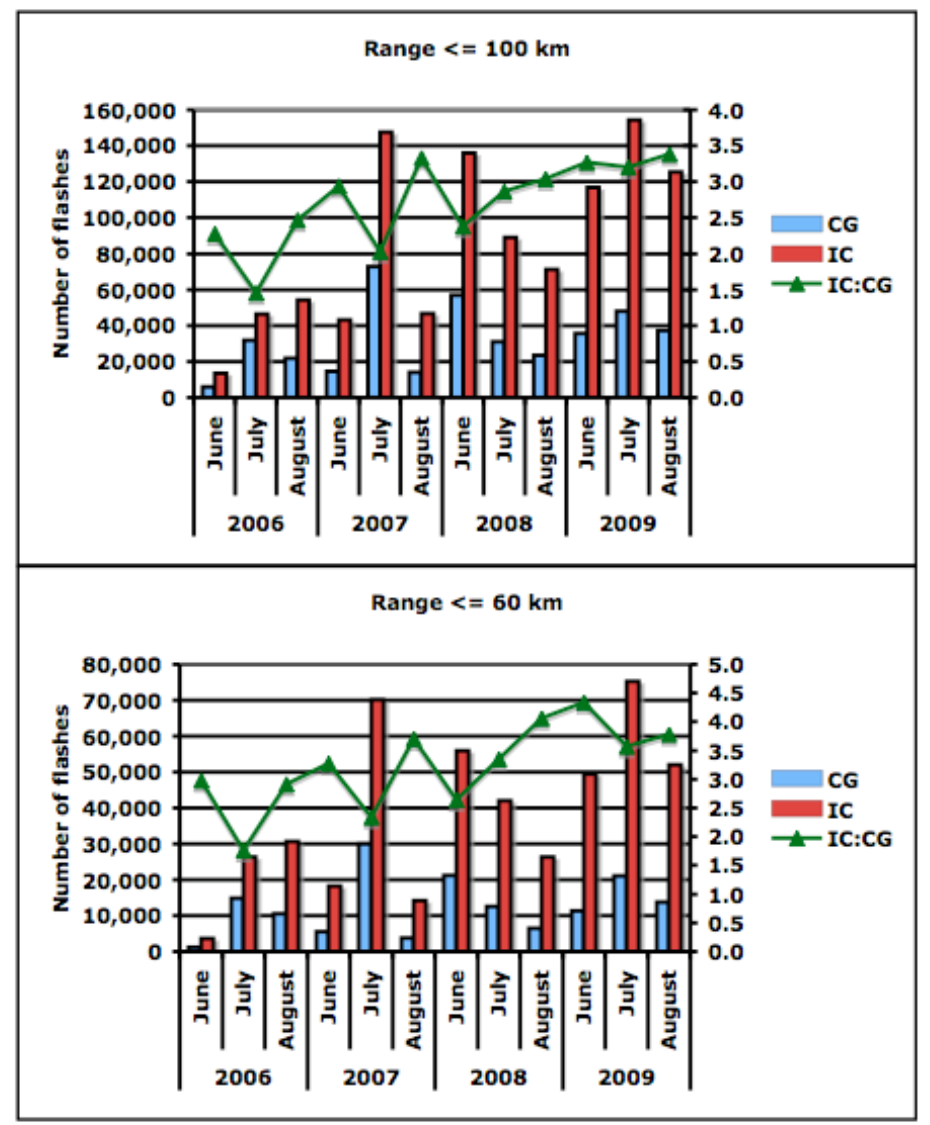

Figure 12. Monthly IC: $\mathrm{CG}$ ratio. Top figure is for lightning within a range of 100 $\mathrm{km}$ from the LDAR network, while bottom figure is for lightning within $60 \mathrm{~km}$.

\subsection{Diagnostic comparisons between IC vs. CG initiation, cessation}

As shown in Figure 9, 4,169 cells within $100 \mathrm{~km}$ of the LDAR network center contained both IC and CG lightning. A closer look at these cells can provide us some interesting insight into the similarities and differences between IC and CG initiation and cessation within thunderstorm cells. Although some inference can be gained, such as regarding IC lightning as a predictor of $\mathrm{CG}$, it is important to note that the following 
analyses are purely diagnostic comparisons and do not convey any information as to the accuracy of IC as a predictor. This information will be presented in Section 3.4.

\subsubsection{Initiation}

Every one of these cells with both lightning types was analyzed to determine the time of IC initiation and CG initiation. Figure 13 presents an overview of lightning initiation in cells by type. Note that greater than three-quarters of all cells produced an intracloud flash first, whereas less than a quarter produced a cloud-to-ground flash first. This gives us some confidence that IC lightning could be a predictor of CG flashes, at least for a large majority of storms.

\section{Lightning Initiation (\% of cells)}

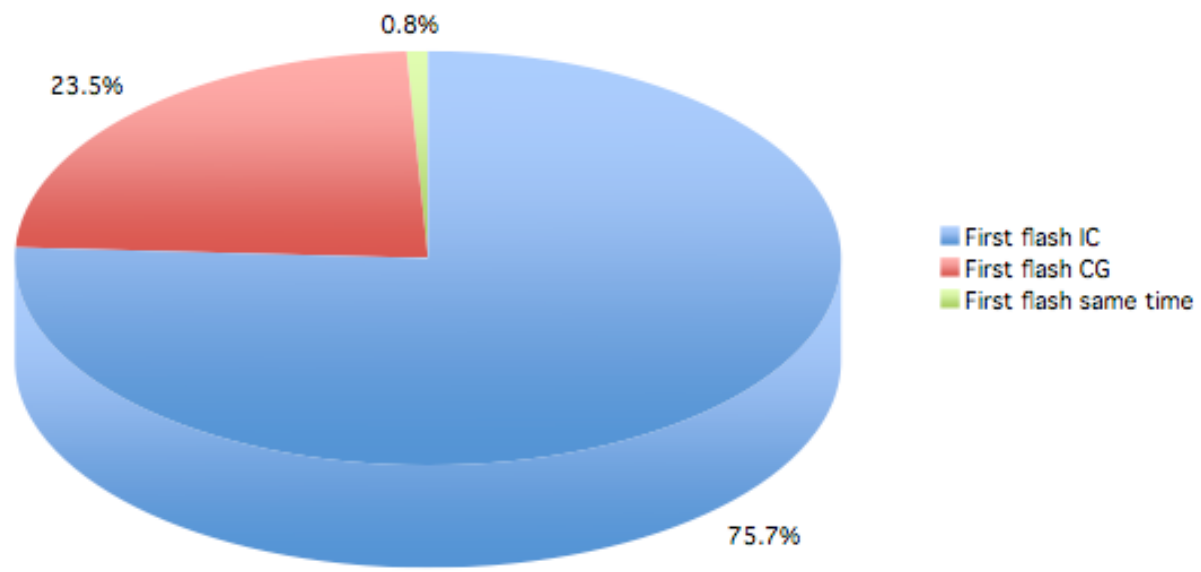

Figure 13. Lightning initiation (\% of cells with both IC and CG flashes) depicted in a pie chart. Blue represents cells with IC first, red represents cells with CG first, and green represents cells with first IC and first CG flash at same time. 


\subsubsection{Cessation}

A similar analysis was performed for lightning cessation within cells. Figure 14 depicts these results. Less than two-thirds of all cells produced an IC flash as the last flash. In contrast, CG lightning was last in about $36 \%$ of all cells, which is consistent with $30 \%$ found by Clements and Orville (2008) in their analysis of 37 ordinary thunderstorms over Houston, Texas. This initial illustration provides less credence but still holds to the hypothesis that, in general, storms decay at a steady rate, producing primarily IC lightning and fewer CG flashes as they dissipate.

\section{Lightning Cessation (\% of cells)}

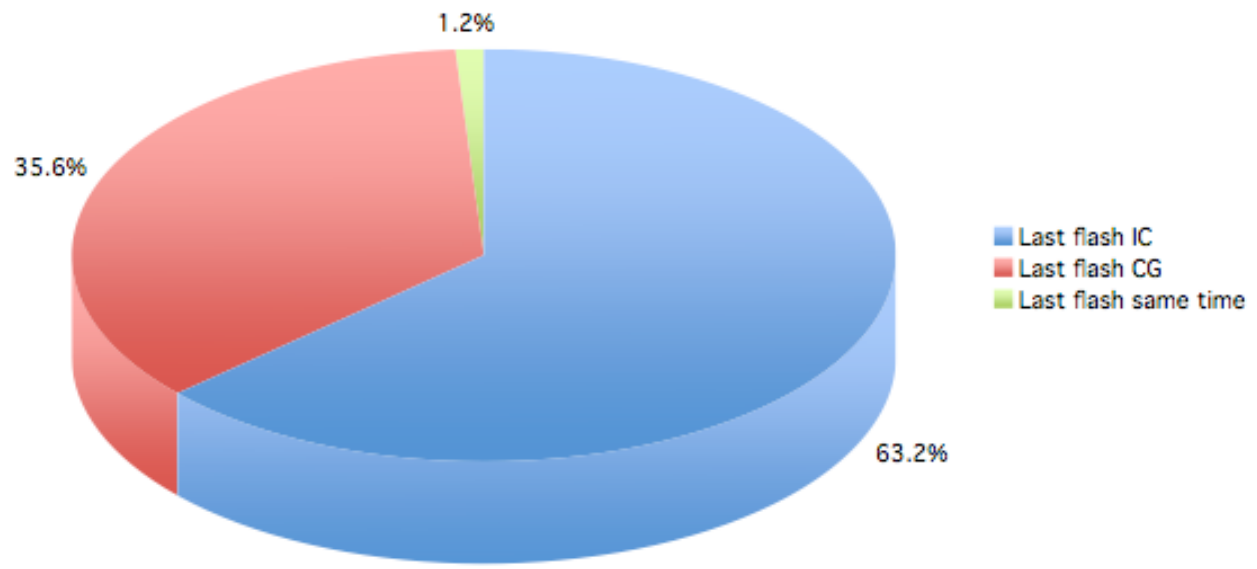

Figure 14. Same as in Figure 13, but for lightning cessation. 


\subsubsection{Time differences}

After the times of IC, CG initiation and cessation were determined, time differences between each type were calculated. Figure 15 shows the distribution of time differences between IC and CG initiation in minutes (black), and between CG and IC cessation (blue). Positive values for initiation correspond to the first IC lightning flash occurring prior to the first CG in a cell; negative values for initiation correspond to $\mathrm{CG}$ occurring before IC. Note that mean initiation time difference is about 2.4 minutes, whereas the median initiation time difference is only about 1 minute.

Positive time difference values for cessation, on the other hand, correspond to the last IC flash occurring after the last CG flash in a cell, whereas negative values represent the last CG occurring after the last IC flash. Mean cessation time difference is about 1.6 minutes, while median cessation time difference is almost 0.5 minutes. 


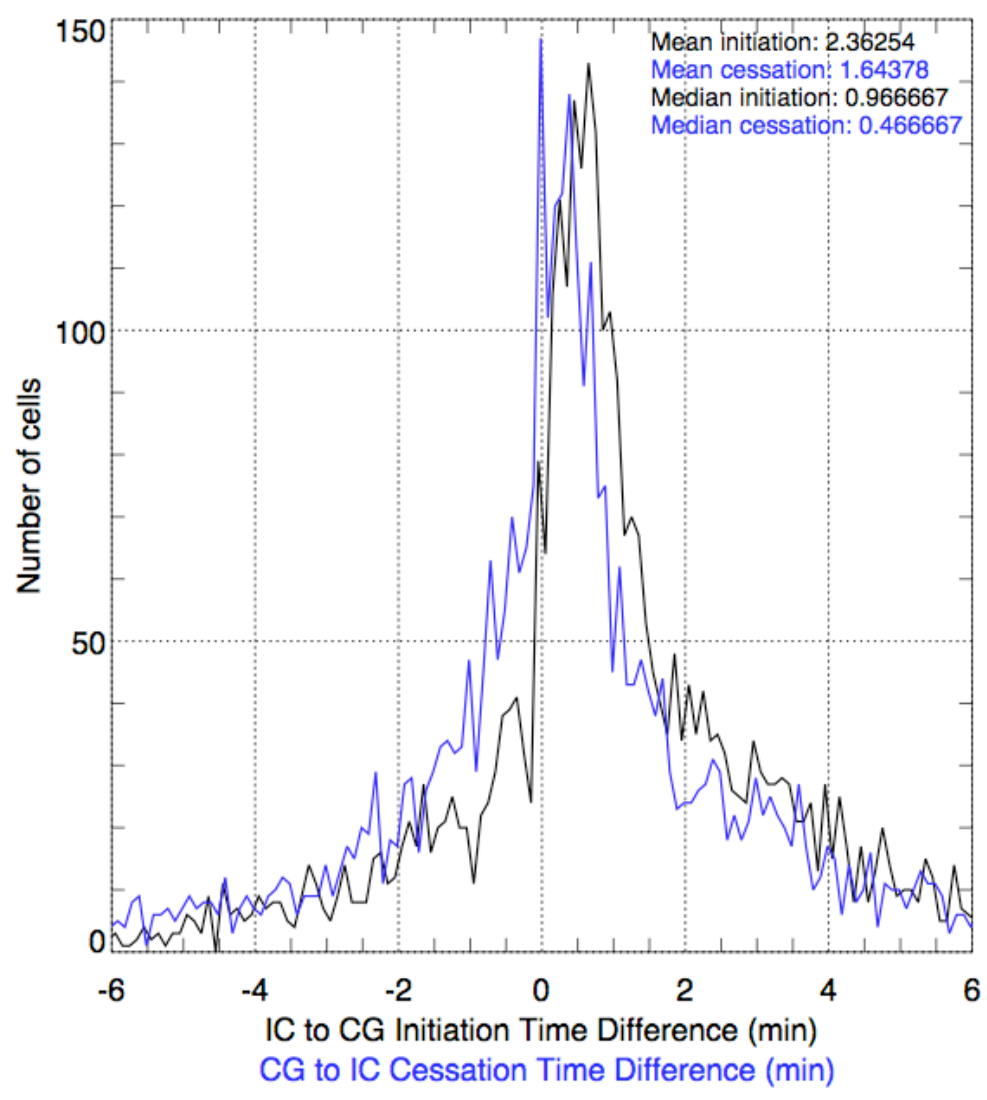

Figure 15. Distributions of IC to CG initiation time difference in minutes (black) and CG to IC cessation time difference (blue).

Cumulative distribution functions (CDF) for both IC to CG initiation time difference and CG to IC cessation time difference were also produced. Figure 16 below shows both CDFs, with an additional close-up view of the CDF's intersection with the 0minute line. According to this $\mathrm{CDF}$, about $25 \%$ of all cells have a negative lead time from IC to CG initiation (black), closely matching Figure 12 's value of $23.5 \%$ of cells with first flash as CG. In addition, Figure 15 closely matches the 36\% value shown in Figure 14 for which cells have CG as the last flash. It is also interesting to note that almost $60 \%$ of cells 
have between a 0 and +5 minute lead time from the first IC flash to the first CG flash, with about $70 \%$ of cells having a lead time from first IC to first CG between 0 and +20 minutes. Furthermore, in about $10 \%$ of cells with lightning, the first intracloud flash provided at least 10 minutes warning time before the first CG flash (consistent with Murphy and Cummins, 2000). Similar values can be seen for cessation as well.

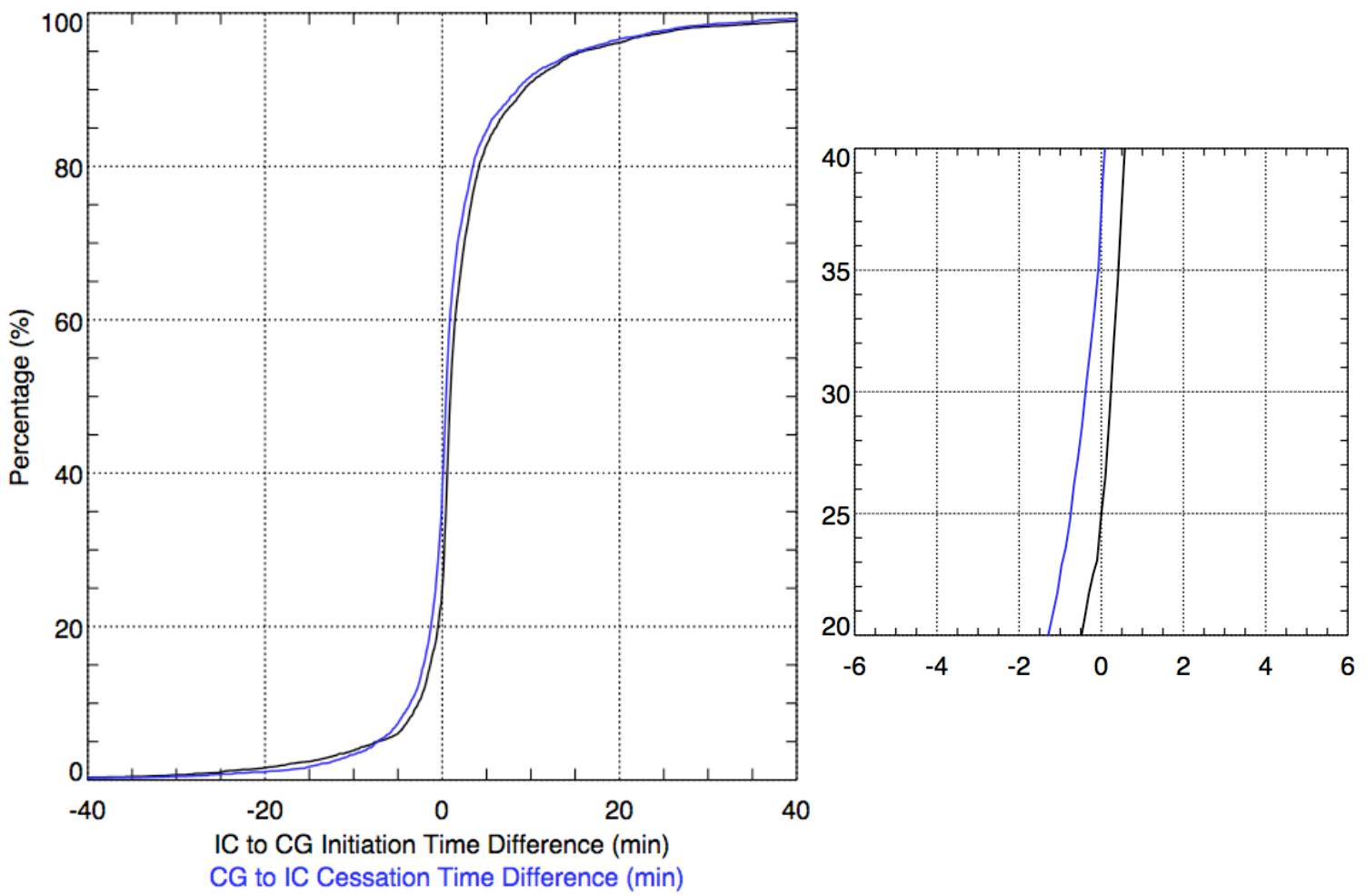

Figure 16. Left image is cumulative distribution function (CDF) of both IC to $\mathrm{CG}$ initiation time difference in minutes (black) and CG to IC cessation time difference (blue). Right image is zoomed in to show where CDFs cross 0 minutes.

\subsubsection{Vertically Integrated Ice (VII)}

To provide further insight into the comparison between CG and IC lightning occurrence within thunderstorm cells, vertically integrated ice was calculated at each radar 
scan coinciding with each type of lightning initiation and cessation. Box and whisker plots providing a complete picture of the distributions of each initiation and cessation type are shown below in Figure 17. Several notable features are addressed here. First, VII at the time of initiation, for both CG and IC lightning, is significantly higher than VII at cessation. This difference is especially evident when comparing the upper portion of the distributions, specifically the upper quartiles and top whiskers. For CG lightning, the upper quartile of initiation $\left(\sim 3 \mathrm{~kg} \mathrm{~m}^{-2}\right)$ is nearly $1 \mathrm{~kg} \mathrm{~m}^{-2}$ higher than that of cessation $\left(\sim 2 \mathrm{~kg} \mathrm{~m}^{-}\right.$ ${ }^{2}$ ); the top whisker end of initiation (nearly $7 \mathrm{~kg} \mathrm{~m}^{-2}$ ) is $2 \mathrm{~kg} \mathrm{~m}^{-2}$ greater than that of cessation $\left(\sim 5 \mathrm{~kg} \mathrm{~m}^{-2}\right)$. Similar comparisons can be made between IC initiation and cessation, with slightly less difference.

Second, median VII at the time of CG initiation $\left(\sim 1.2 \mathrm{~kg} \mathrm{~m}^{-2}\right)$ is noticeably higher than median VII at the time of IC initiation $\left(\sim 1 \mathrm{~kg} \mathrm{~m}^{-2}\right)$; median VII at CG cessation $(\sim 0.8$ $\left.\mathrm{kg} \mathrm{m}^{-2}\right)$ is slightly higher than median VII at IC cessation $\left(\sim 0.65 \mathrm{~kg} \mathrm{~m}^{-2}\right)$. 


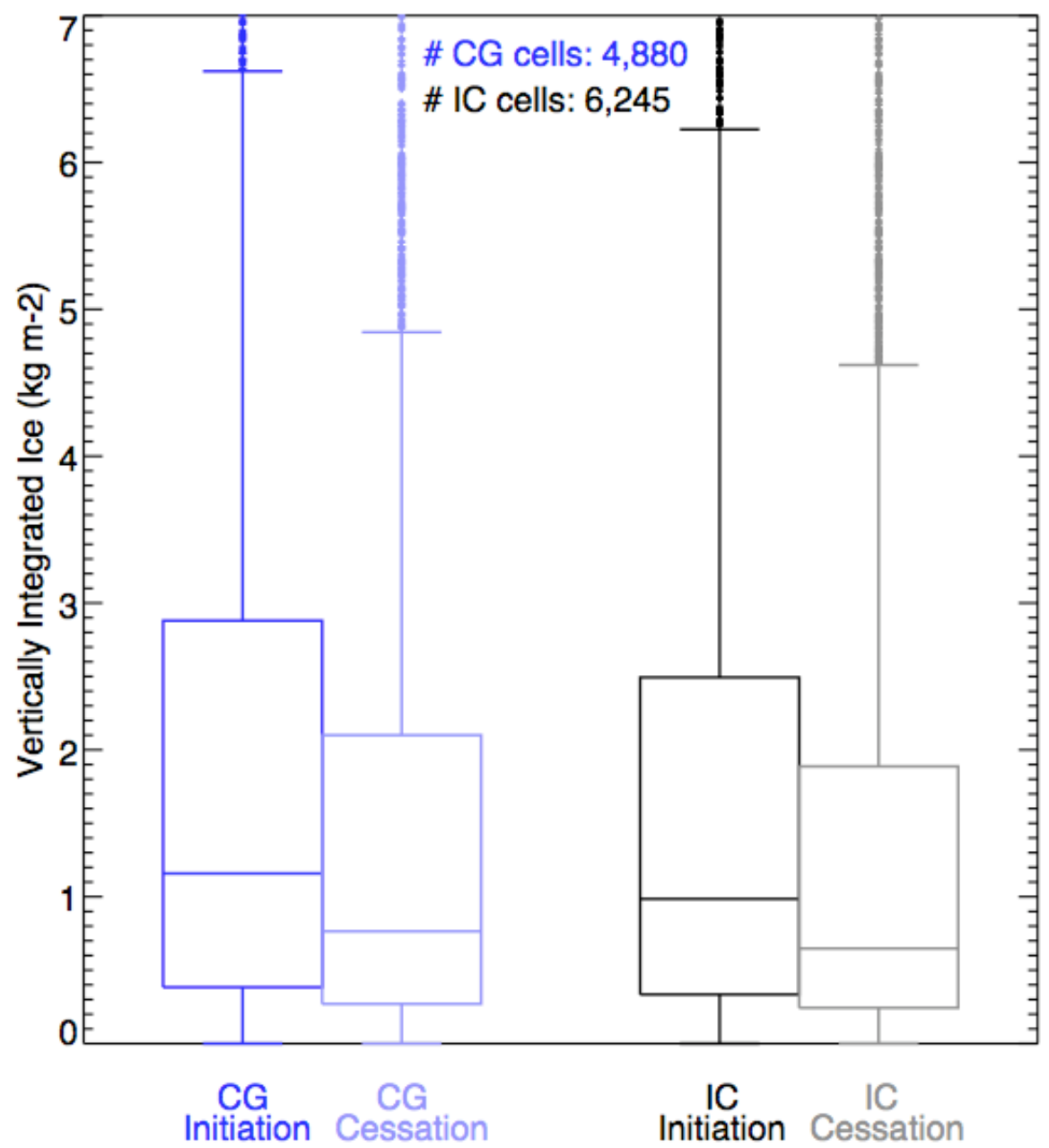

Figure 17. Box and whisker plots of VII at time of CG initiation and cessation (blue/light blue), and IC initiation and cessation (black/gray).

To determine, with confidence, that each of these differences is statistically significant - that is, to ascertain if the populations come from different distributions - the Kruskal-Wallis Test was performed on each of these comparisons. The Kruskal-Wallis Test makes no assumptions about the distributions of the data, including normality. The test, which compares differences of medians, works well for our data because our 
distributions may not be Gaussian. An example of this test is now given. To determine if the difference between VII at CG initiation and VII at CG cessation is statistically significant, we use the hypothesis test:

$\boldsymbol{H}_{\boldsymbol{o}}$ : both populations (VII at CG initiation, cessation) have the same distribution $\boldsymbol{H}_{1}:$ VII from one population tend to be larger than VII from the other population

Then, using the methods of the Kruskal-Wallis Test, a p-value is obtained, which we compare to a significance level, which we set at 0.001 . If the p-value is lower than our significance level, then we reject the null hypothesis and conclude that the populations are different. Table 2 depicts results from our statistical tests. The first three differences are statistically significant, providing evidence that 1) VII at CG initiation is higher than VII at CG cessation, 2) VII at IC initiation is higher than VII at IC cessation, and 3) VII at CG initiation is higher than VII at IC initiation. The last difference, between VII at CG cessation and VII at IC cessation, has a p-value greater than our significance level, so we do not reject the null hypothesis. We would likely need a larger sample size to determine if this difference is statistically significant.

Table 2. VII medians $\left(\mathrm{kg} \mathrm{m}^{-2}\right)$, differences between means, and $\mathrm{p}$-values for CG initiation vs. cessation, IC initiation vs. cessation, $C G$ vs. IC initiation, and CG vs. IC cessation. P-values computed from Kruskal-Wallis Test.

\begin{tabular}{|cccc|}
\hline & \multicolumn{3}{c|}{ CG $(\mathbf{n}=\mathbf{4 , 8 8 0})$} \\
Median & Dif & p-value \\
Initiation & 1.158 & & \\
& & 0.393 & $<0.0001$ \\
Cessation & 0.765 & & \\
\hline
\end{tabular}


Table 3 continued.

\begin{tabular}{|c|c|c|c|}
\hline \multicolumn{4}{|c|}{ IC $(n=6,245)$} \\
\hline \multirow{3}{*}{ Initiation } & Median & Dif & p-value \\
\hline & 0.985 & & \\
\hline & & 0.338 & $<0.0001$ \\
\hline Cessation & 0.647 & & \\
\hline
\end{tabular}

\begin{tabular}{|cccc|}
\hline \multicolumn{5}{c|}{$\begin{array}{c}\text { CG vs. IC } \\
\text { Initiation } \\
\text { Median }\end{array}$} & Dif & p-value \\
CG & 1.158 & 0.173 & 0.001 \\
IC & 0.985 & & \\
\hline \multicolumn{5}{c}{$\begin{array}{c}\text { Cessation } \\
\text { CG } \\
\text { CG }\end{array}$} & $\begin{array}{c}0.765 \\
\text { IC }\end{array}$ & 0.647 & 0.118 & 0.0121 \\
\hline
\end{tabular}

\subsubsection{IC:CG ratio}

Another variable — IC:CG ratio—was tracked during each cell's lifetime, in order to determine its value in the diagnostic comparisons between $\mathrm{CG}$, IC initiation and cessation. Unfortunately, analysis of this variable can be difficult. This is especially the case during times of low or no CG activity, when IC:CG would approach infinity.

Therefore, the ratio at each type of initiation and cessation was calculated by using the numbers of each flash that occurred during the radar scan in which initiation or cessation took place. Although this method worked in all instances of $\mathrm{CG}$ initiation and cessation, it did not eliminate the possibility of IC:CG being undefined at IC initiation or cessation. These instances at which IC:CG was undefined-i.e. when no CG flashes occurred-could not be included in the analysis. Results are shown below in box and whisker plot form in 
Figure 18. Note that about 2,000 cells $(\sim 32 \%)$ could not be included in IC initiation and cessation because no CG flashes occurred at those times. Thus, in theory, IC:CG ratios would be higher for both IC initiation and cessation, if the "undefined" cases were treated as very large numbers. As a result, direct comparisons between CG and IC cannot be presented with this diagnostic variable. Furthermore, no significant conclusions can be made regarding differences between initiation and cessation for both flash types.

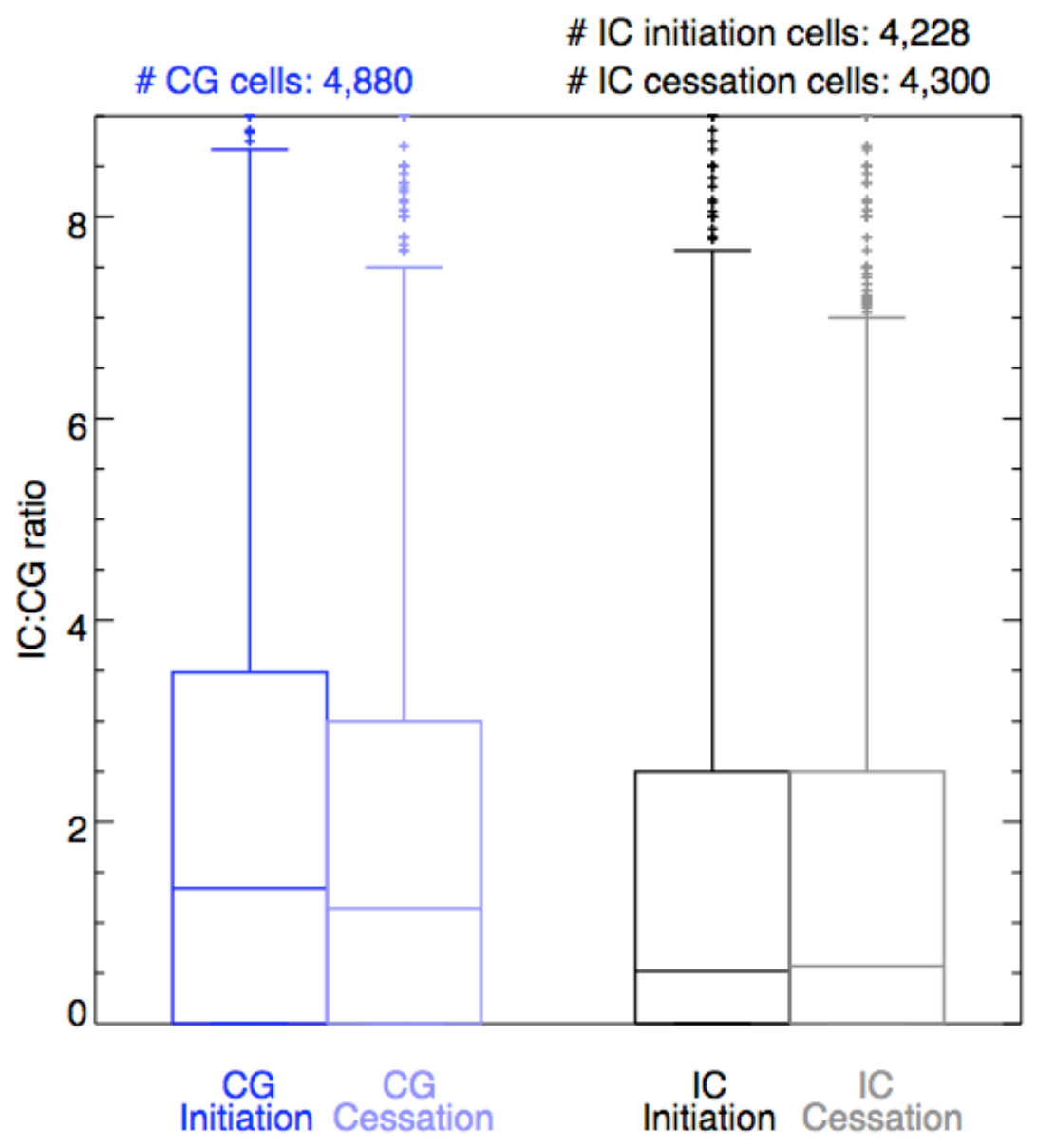

Figure 18. IC:CG ratio at the time of CG, IC initiation and cessation. 


\subsection{Optimization of total lightning forecasting}

Three techniques were used to nowcast both CG and IC lightning within thunderstorm cells. Each predictor was analyzed for accuracy and utility through the use of statistical measures (POD, FAR, CSI) and lead time in minutes. Because we have performed these analyses for both $\mathrm{CG}$ and IC lightning, further diagnostic comparisons can be made between flash type. The following three sections provide results from these investigations.

\subsubsection{Radar reflectivity method}

Numerous past studies have used radar reflectivity at certain isothermal levels to predict the initiation of CG lightning within storm cells. We do the same for our cell database of nearly 18,000 cells to determine, with statistical significance, the best predictor of lightning initiation — not only for CG flashes but for IC flashes as well.

\subsubsection{Statistics}

\section{i. Cloud-to-ground}

To determine our best radar reflectivity predictor of CG lightning within our database, POD, FAR, and CSI were computed for each pairing of dBZ level with isothermal level. The five best $\mathrm{dBZ}$ levels were chosen according to highest CSI, and statistics for each pairing were plotted. Figure 19 depicts CSI for the five best dBZ group predictors of CG lightning: 20, 25, 30, 35 and $40 \mathrm{dBZ}$, each at $-10,-15,-20$, and updraft $10^{\circ} \mathrm{C}$ level. Overall, the best predictor of CG lightning was $25 \mathrm{dBZ}$ at $-20^{\circ} \mathrm{C}$, with a CSI of 0.469. This predictor balanced comparatively high POD (0.780) with lower FAR (0.460). Other predictors with high CSI were (CSI in parentheses): $35 \mathrm{dBZ}$ at $-15^{\circ} \mathrm{C}(0.465), 30$ 
$\mathrm{dBZ}$ at $-20^{\circ} \mathrm{C}(0.462)$, and $30 \mathrm{dBZ}$ at $-15^{\circ} \mathrm{C}(0.462)$. Figures depicting POD and FAR for the same five best dBZ group predictors of CG lightning are included in Appendix B.

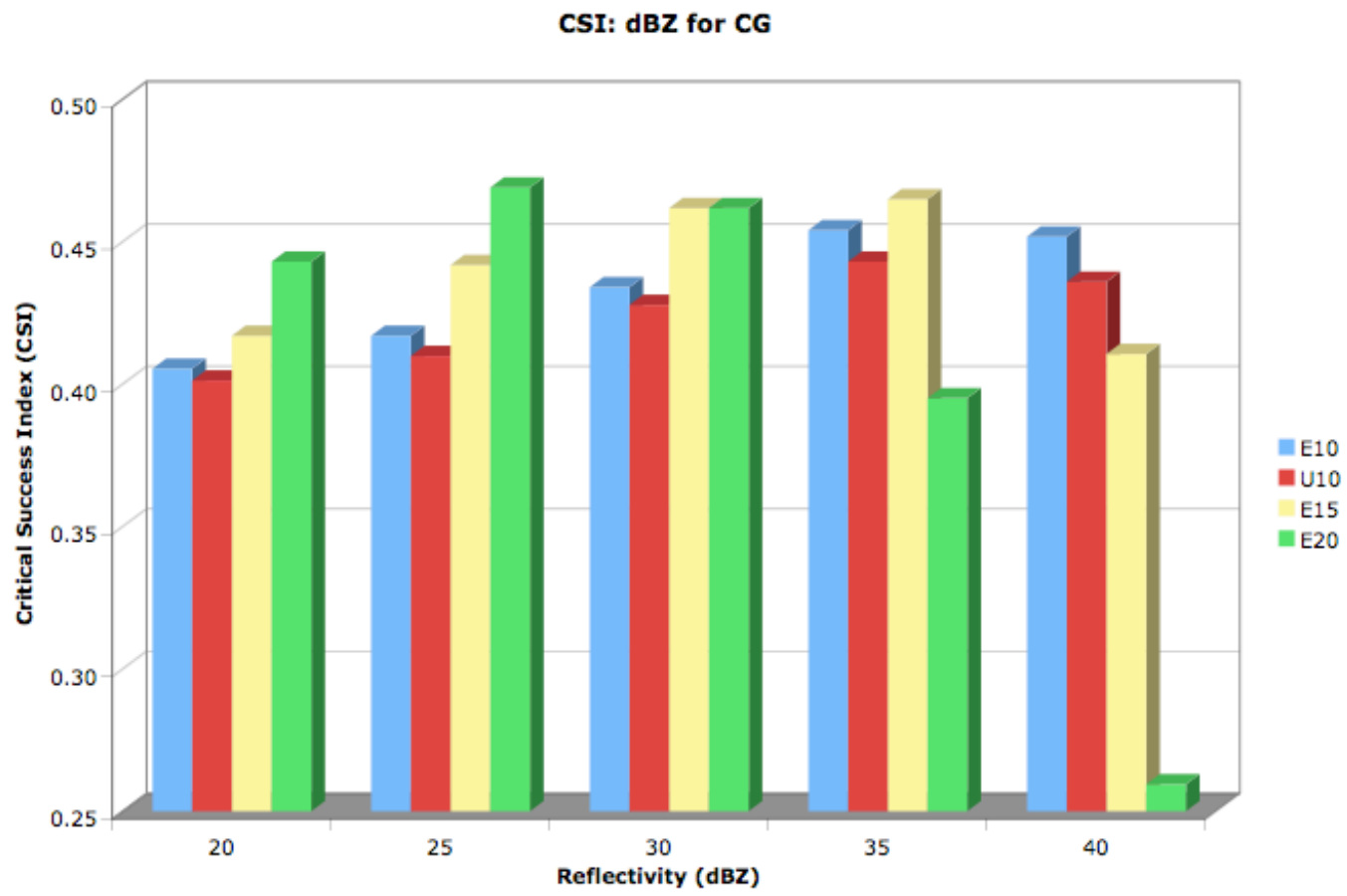

Figure 19. Critical Success Index (CSI) for the five best dBZ group predictors of CG lightning.

\section{ii. Intracloud}

The same radar reflectivity at isothermal level analysis was performed for intracloud lightning prediction, as well. Figure 20 shows CSI for the six best dBZ group predictors, each at $-10,-15,-20$, and updraft $-10^{\circ} \mathrm{C}$ levels. Note that, in general, CSI is higher for IC prediction than that for CG prediction, due to both an increase in POD and decrease in FAR for each predictor. In addition, the six best $\mathrm{dBZ}$ levels were significantly 
lower than that for $\mathrm{CG}$ prediction-5, 10, 15, 20, 25, and $30 \mathrm{dBZ}$ for IC, as compared to $20,25,30,35$, and $40 \mathrm{dBZ}$ for CG. The best predictor of IC flashes, according to CSI, was $25 \mathrm{dBZ}$ at $-15^{\circ} \mathrm{C}$ (CSI of 0.579$)$. Other good predictors include $25 \mathrm{dBZ}$ at $-10^{\circ} \mathrm{C}(0.578)$, $20 \mathrm{dBZ}$ at $-15^{\circ} \mathrm{C}(0.577)$, and $15 \mathrm{dBZ}$ at $-20^{\circ} \mathrm{C}(0.576)$. Again, figures of POD and FAR for each of the six best $\mathrm{dBZ}$ group predictors of IC are included in Appendix B.

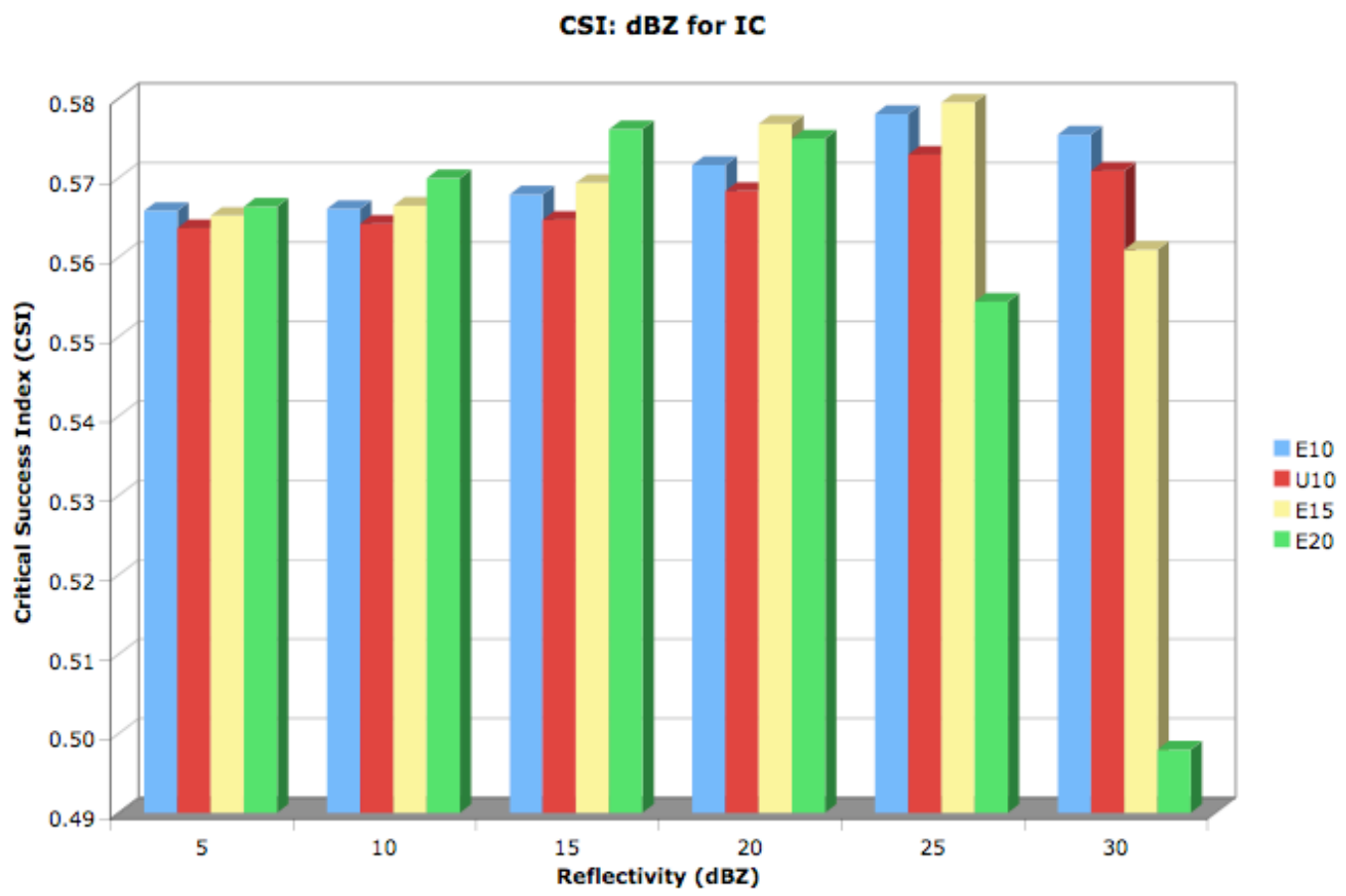

Figure 20. Critical Success Index (CSI) for the six best dBZ group predictors of IC lightning. 
iii. Total lightning

The same statistics were calculated for total lightning prediction-i.e. predicting either an IC or CG flash to occur. It was found that, in general, CSI was higher for total lightning prediction than for just CG or just IC lightning, mainly due to significantly lower FAR for each predictor. The best predictors of total lightning, according to CSI, were 20 $\mathrm{dBZ}$ at $-15^{\circ} \mathrm{C}(\mathrm{CSI}$ of 0.642 , FAR of 0.341 , POD of 0.962$)$ and $25 \mathrm{dBZ}$ at $-10^{\circ} \mathrm{C}(\mathrm{CSI}$ of 0.642 , FAR of 0.338 , POD of 0.955$)$.

iv. Time series for yearly comparison

In order to ascertain if any variability in statistical measures occurred through the years of study, and to perhaps quantify the upgrade of the LDAR-II upgrade over LDAR-I, time series of each statistic as well as bias were plotted. Figure 21 portrays the time series of the best $\mathrm{dBZ}$ predictor of $\mathrm{CG}-25 \mathrm{dBZ}$ at $-20^{\circ} \mathrm{C}$. It is evident that both POD and CSI decreased, and FAR and bias increased, from 2006 to 2009, but it is difficult to make any conclusions regarding these interannual changes. 
Best dBZ predictor for CG: 25 dBZ @ -20C

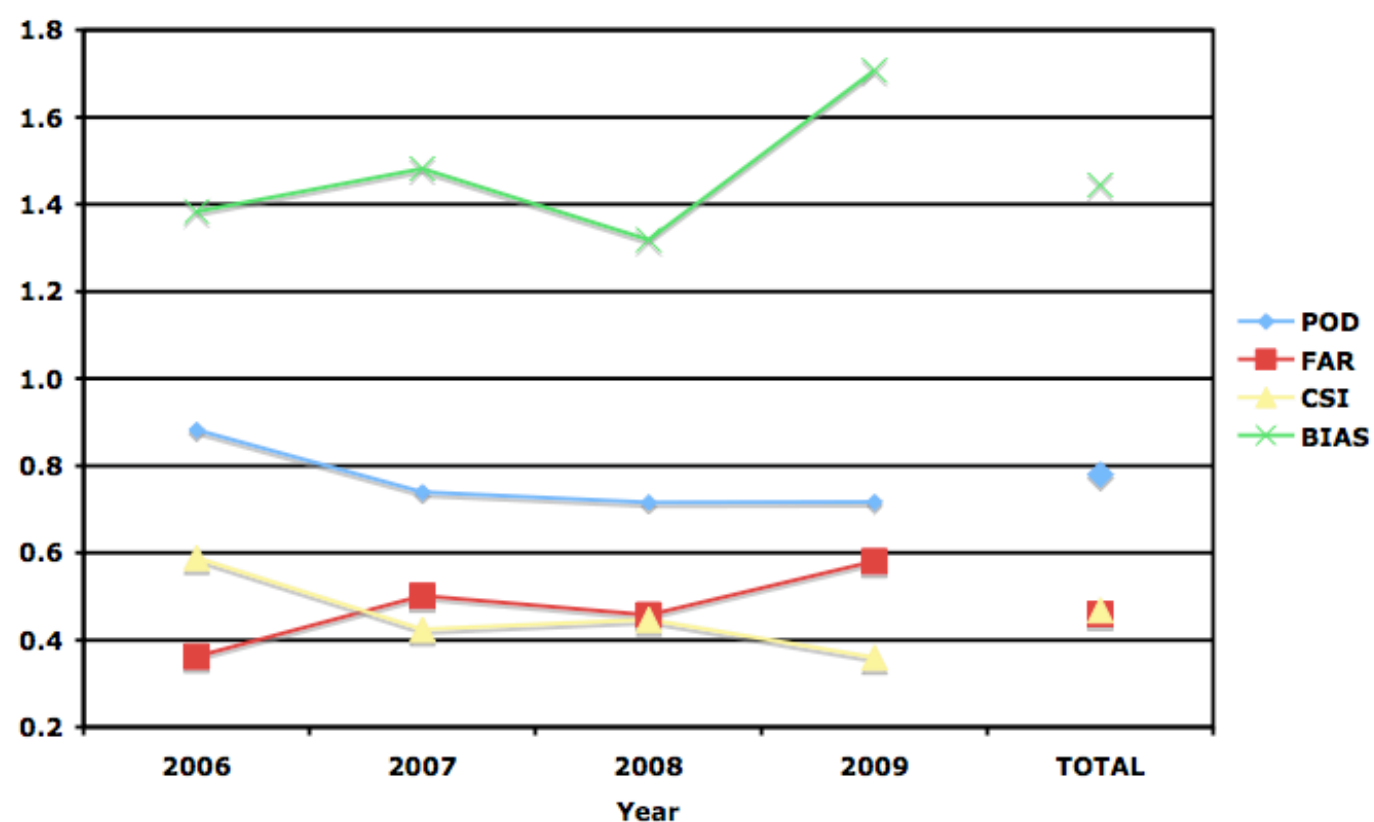

Figure 21. Time series of POD, FAR, CSI, and bias for best dBZ predictor for CG: $25 \mathrm{dBZ} @-20^{\circ} \mathrm{C}$.

Figure 22 portrays the time series of the best $\mathrm{dBZ}$ predictor for IC $-25 \mathrm{dBZ} @$ $15^{\circ} \mathrm{C}$. Significantly higher bias and FAR in 2006 led to a decrease in 2007, but a slight increase thereafter. CSI reflects these changes, but in the opposite direction. Again, no conclusions regarding the interannual variability in forecast statistics are made. Note that further discussion regarding interannual variability and trending, including radar calibration and yearly precipitation, will be presented at the end of the Results section. 
Best dBZ predictor for IC: $25 \mathrm{dBZ} @-15 \mathrm{C}$

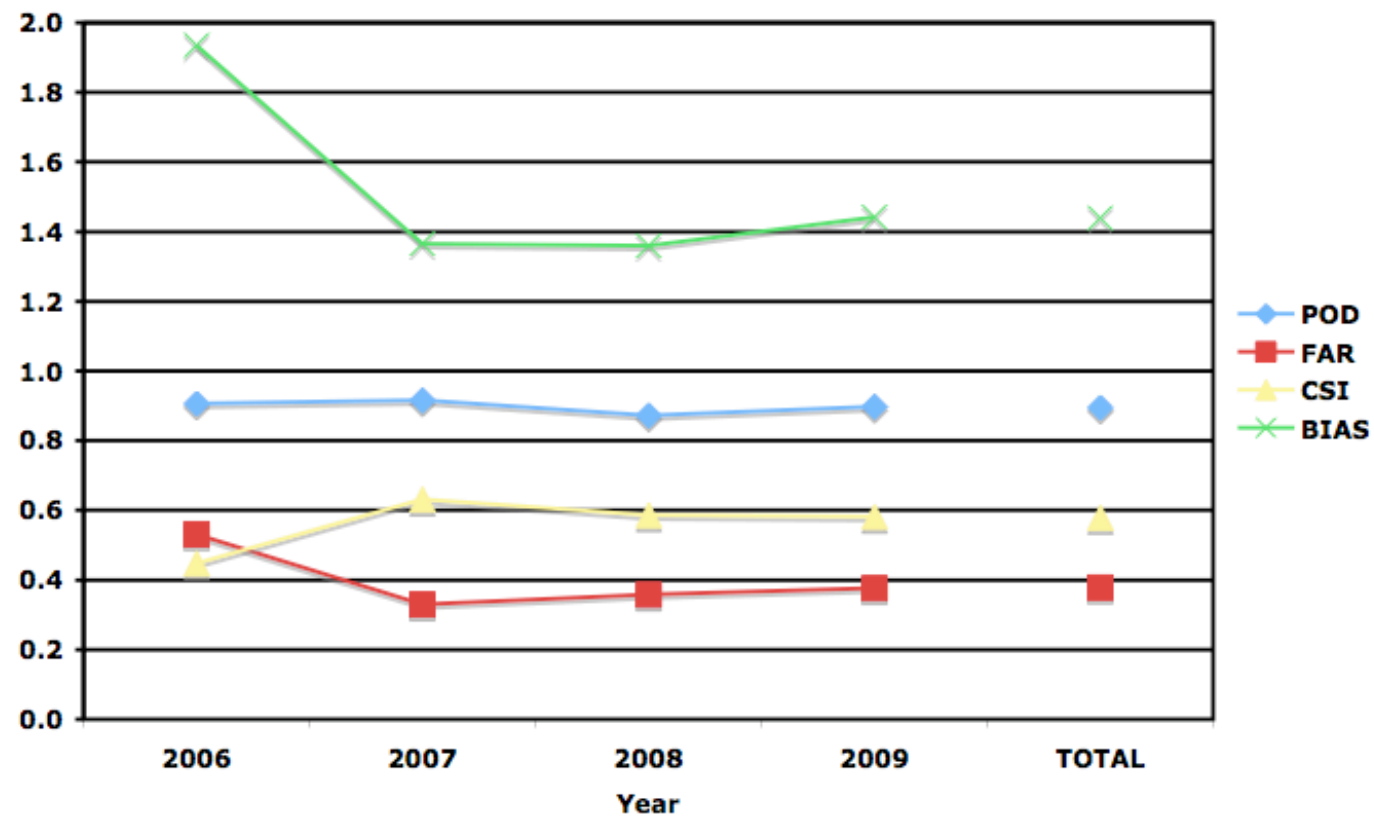

Figure 22. Time series of POD, FAR, CSI, and bias for best dBZ predictor for IC: 25 dBZ@-15².

\subsubsection{Lead time}

A second technique to analyze utility of radar-derived forecast predictors was to calculate lead time from each predictor to the occurrence of CG and IC lightning. As discussed above, lead times were calculated through the time difference between the start time of the radar scan in which the forecast occurred to the time of the first CG and first IC flash. It is important to note that algorithm processing and radar scan time would significantly decrease these lead times in an operational setting, so these lead times should be only used for research comparison within this study and to other similar automated studies. Figures 23 and 24 depict lead time for the five best (according to highest CSI) dBZ 
group predictors of $\mathrm{CG}$ and six best $\mathrm{dBZ}$ group predictors of IC, respectively. Lead times for IC predictors are lower by more than a minute; this is consistent with median time difference from IC to CG initiation, which is about one minute, shown in Figure 15. The best $\mathrm{CG}$ predictor according to highest $\mathrm{CSI}-25 \mathrm{dBZ}$ at $-20^{\circ} \mathrm{C}-$ had an average lead time of about 6.4 minutes, whereas the best IC predictor- $-25 \mathrm{dBZ}$ at $-15^{\circ} \mathrm{C}$ - had an average lead time of about 6.1 minutes.

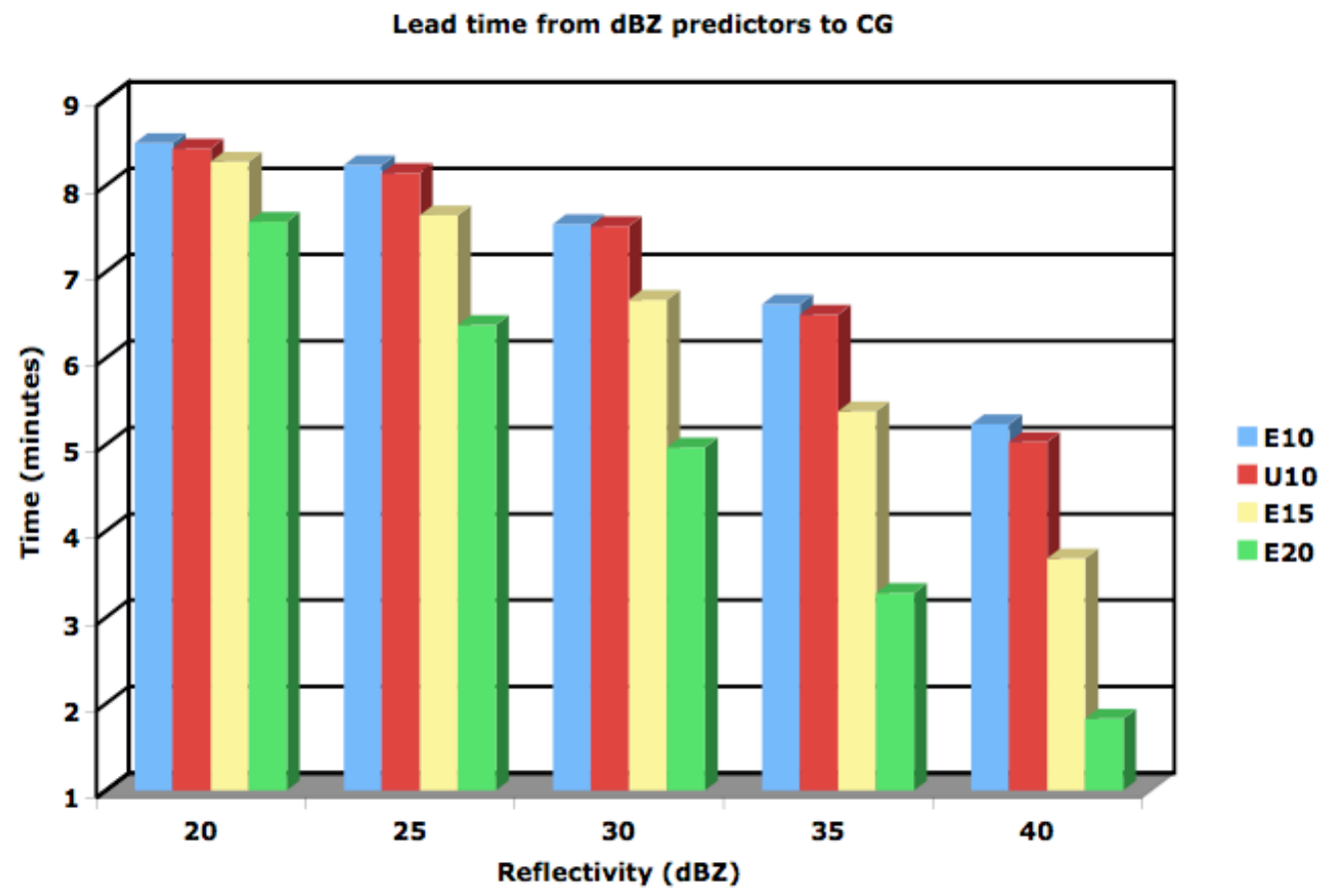

Figure 23. Lead time from the five best $\mathrm{dBZ}$ group predictors to first CG flash. 


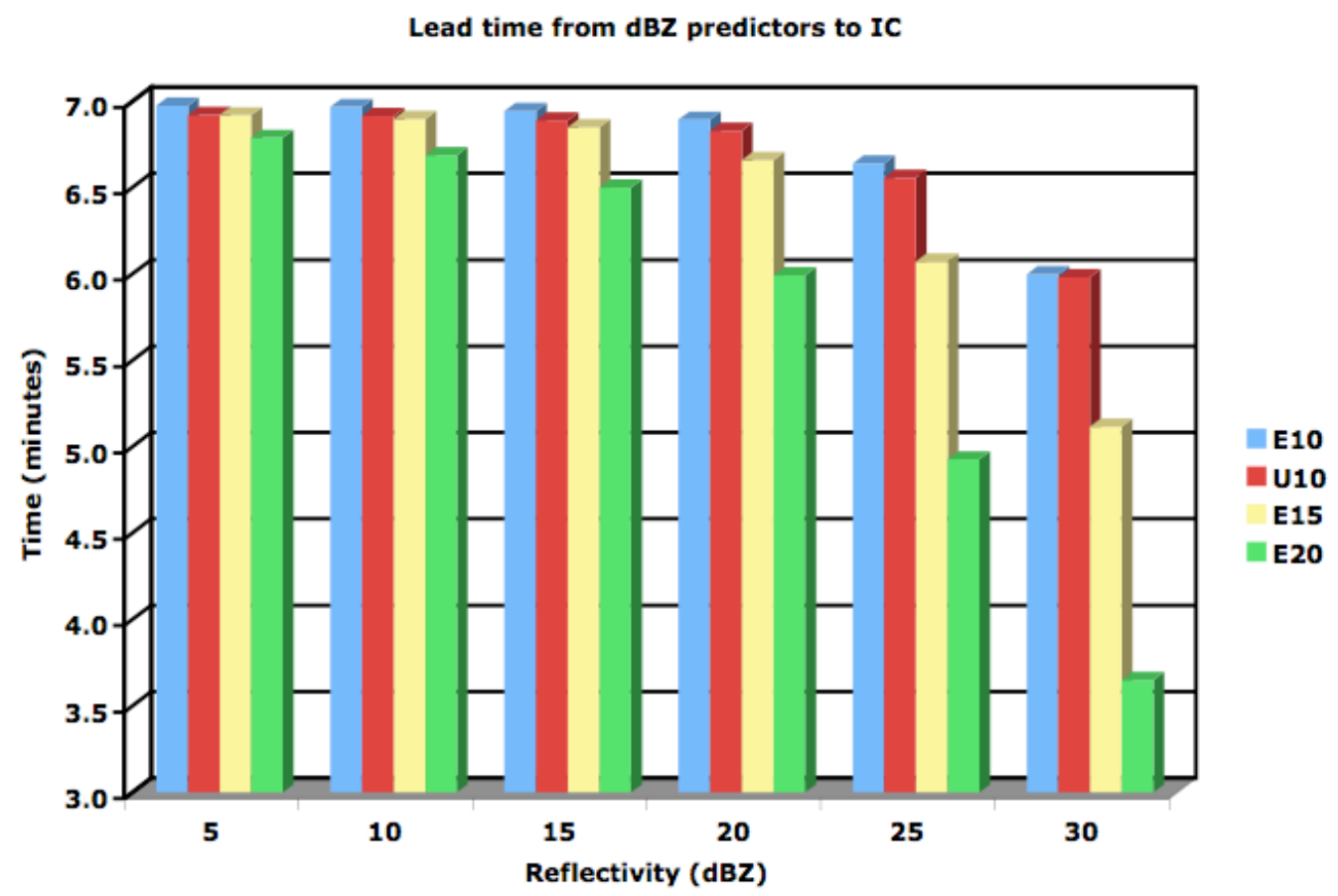

Figure 24. Lead time from the six best dBZ group predictors to first IC flash.

\subsubsection{VII percentile method}

Vertically integrated ice (VII) was used as another method of predicting lightning initiation with cells. VII percentiles at both CG and IC occurrence across the entire dataset were used as the forecast predictors of this method. These percentiles are displayed in Table 3. Note that percentiles at IC occurrence are consistently lower than those at CG occurrence, which is consistent with conclusions drawn from Figure 17 showing VII lower at IC initiation and cessation than at CG initiation and cessation, with statistical significance. 
Again, forecast verification statistics - POD, FAR, and CSI—were computed, and lead times for each percentile predictor were calculated, in order to evaluate forecast utility.

Table 3. VII percentiles $\left(\mathrm{kg} \mathrm{m}^{-2}\right)$ at both $\mathrm{CG}$ and IC occurrence across the entire dataset.

\section{Cloud-to-ground VII percentiles $[\mathrm{kg} \mathrm{m}$ -}

2]

\begin{tabular}{|c|c|}
\hline Percentile & VII \\
\hline 0 & 0 \\
\hline 5 & 0.157 \\
\hline 10 & 0.238 \\
\hline 15 & 0.344 \\
\hline 20 & 0.484 \\
\hline 25 & 0.651 \\
\hline 30 & 0.840 \\
\hline 35 & 1.032 \\
\hline 40 & 1.257 \\
\hline 45 & 1.529 \\
\hline 50 & 1.836 \\
\hline 55 & 2.177 \\
\hline 60 & 2.572 \\
\hline 65 & 3.063 \\
\hline 70 & 3.603 \\
\hline 75 & 4.300 \\
\hline 80 & 5.131 \\
\hline 85 & 6.276 \\
\hline 90 & 7.918 \\
\hline 95 & 10.778 \\
\hline 100 & 548.010 \\
\hline
\end{tabular}

Intracloud VII percentiles $[\mathbf{k g}$ m-2]

\begin{tabular}{|c|}
\hline MEAN \\
3.186 \\
\hline MEDIAN \\
1.836 \\
\hline
\end{tabular}

\begin{tabular}{|c|c|}
\hline Percentile & VII \\
\hline 0 & 0 \\
\hline 5 & 0.143 \\
\hline 10 & 0.208 \\
\hline 15 & 0.290 \\
\hline 20 & 0.395 \\
\hline 25 & 0.532 \\
\hline 30 & 0.683 \\
\hline 35 & 0.861 \\
\hline 40 & 1.058 \\
\hline 45 & 1.286 \\
\hline 50 & 1.557 \\
\hline 55 & 1.878 \\
\hline 60 & 2.250 \\
\hline 65 & 2.669 \\
\hline 70 & 3.178 \\
\hline 75 & 3.793 \\
\hline 80 & 4.630 \\
\hline 85 & 5.722 \\
\hline 90 & 7.368 \\
\hline 95 & 10.196 \\
\hline 100 & 548.010 \\
\hline
\end{tabular}

\subsubsection{Statistics}

Figure 25 illustrates CSI for each VII percentile predictor, for both CG and IC

lightning. Refer to Appendix B for POD and FAR for each VII percentile predictor. Note 
that VII CG percentiles were used and shown for CG lightning prediction, while VII IC percentiles were used and shown for IC lightning prediction. CSI is higher for IC prediction than for CG prediction for the majority of percentiles. The best VII percentile predictor of CG is shown to be the $30^{\text {th }}$ percentile $\left(0.840 \mathrm{~kg} \mathrm{~m}^{-2}\right)$, with a CSI of 0.467 . The best VII percentile predictor of IC was the $5^{\text {th }}$ percentile $\left(0.143 \mathrm{~kg} \mathrm{~m}^{-2}\right)$, with a CSI of 0.578. Thus, the best VII predictor of IC lightning is significantly lower than the best for CG lightning — a VII value nearly 6 times lower! This may be due to the apparent requirement of lower VII for IC flash initiation as compared to CG initiation.

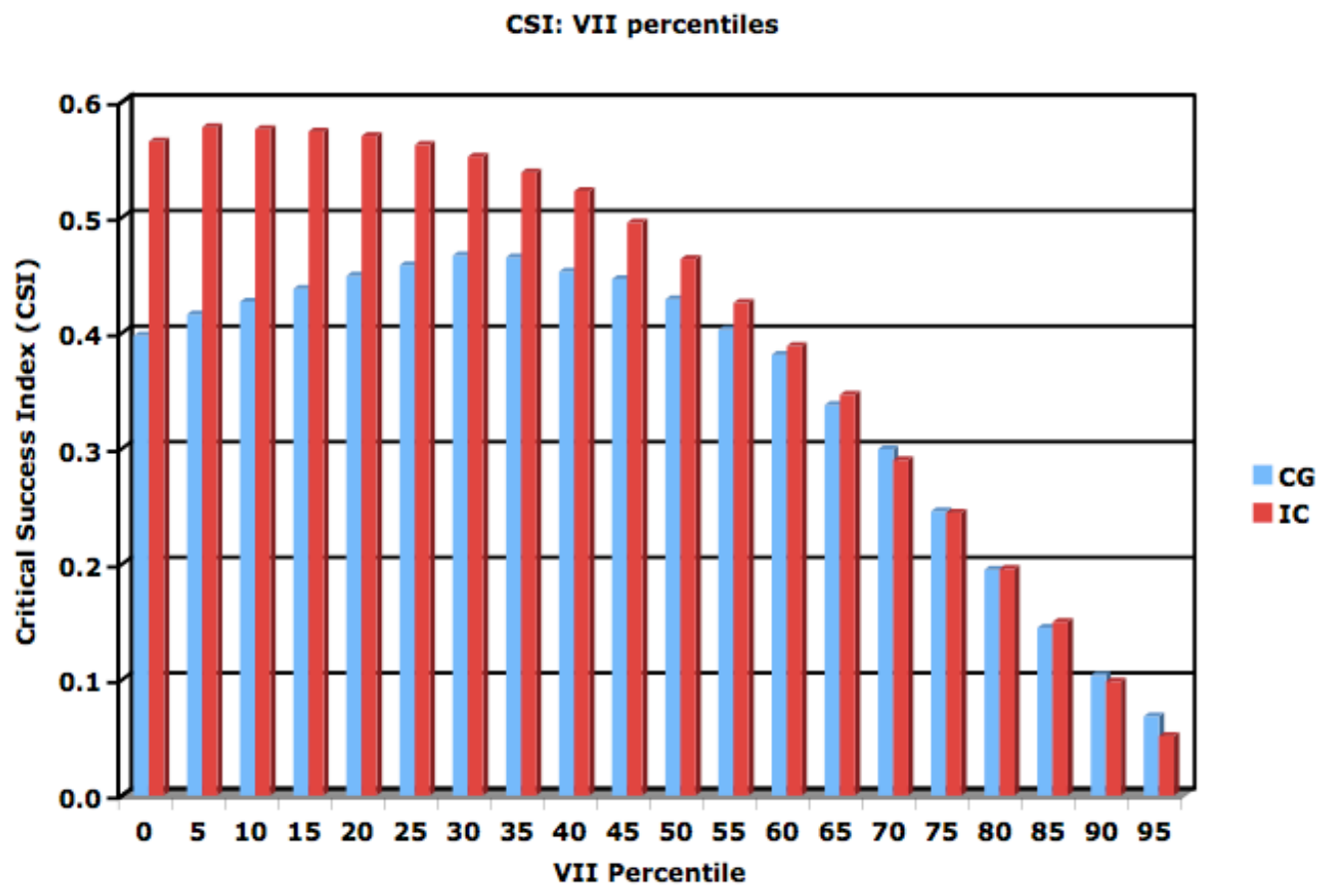

Figure 25. Critical Success Index (CSI) for VII percentiles for both CG and IC. 
The time series of the best VII predictor of CG $\left(30^{\text {th }}\right.$ percentile $)$ and of IC $\left(5^{\text {th }}\right.$ percentile) are shown in Figures 26 and 27, respectively. Similar patterns to the same time series shown in Figures 20 and 21 are evident: 1) a general increase in FAR and bias, and a general decrease in POD and CSI, for CG, and 2) a sudden drop in bias and FAR from 2006 to 2007, and a slow increase thereafter, with CSI behaving in the opposite manner, for IC. Again, no conclusions regarding these patterns are made, but the fact that the time series are consistent between types of predictors provides more confidence in assessing any further insight.

Best VII predictor for CG: 30th percentile

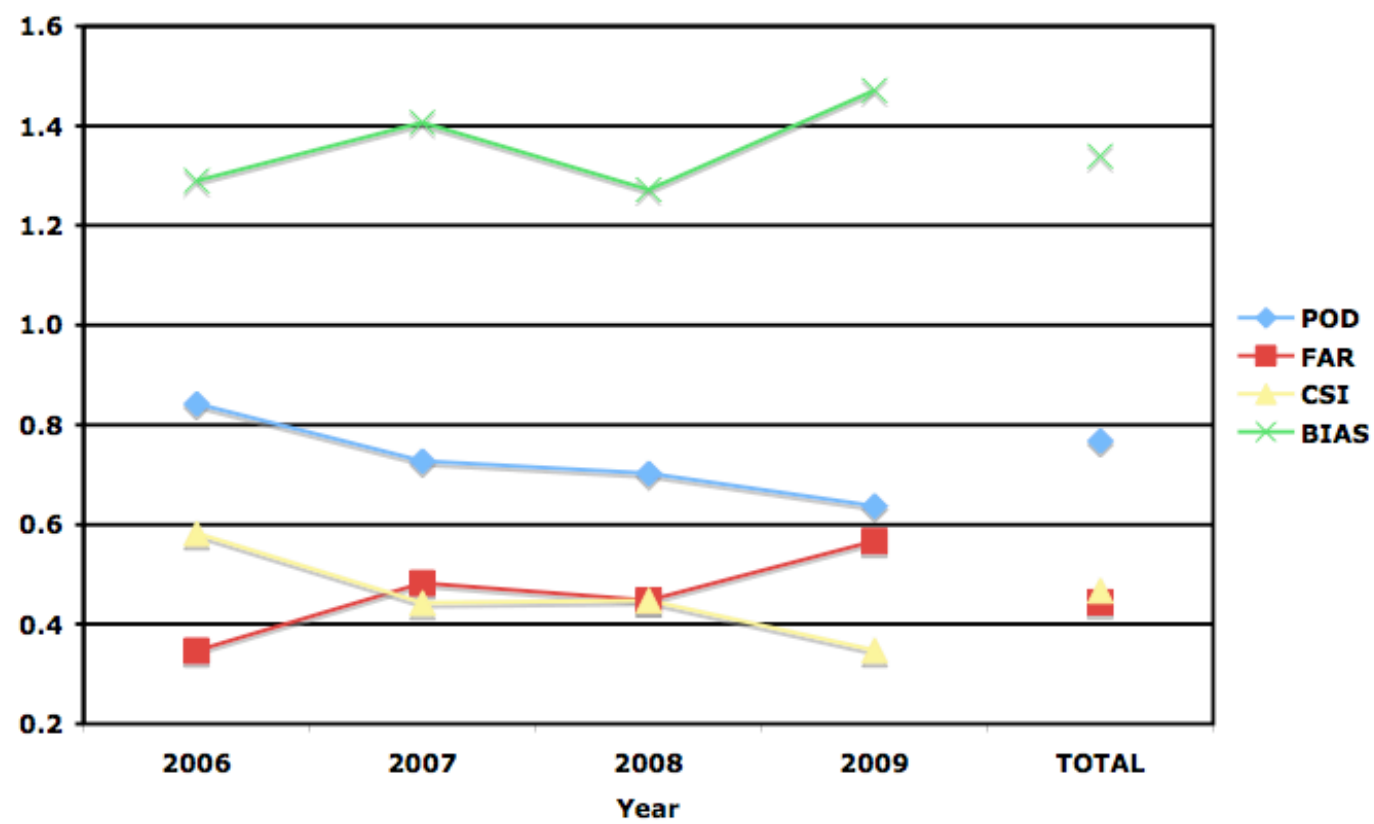

Figure 26. Time series of POD, FAR, CSI, and bias for best VII predictor for CG: 30th percentile. 
Best VII predictor for IC: 5th percentile

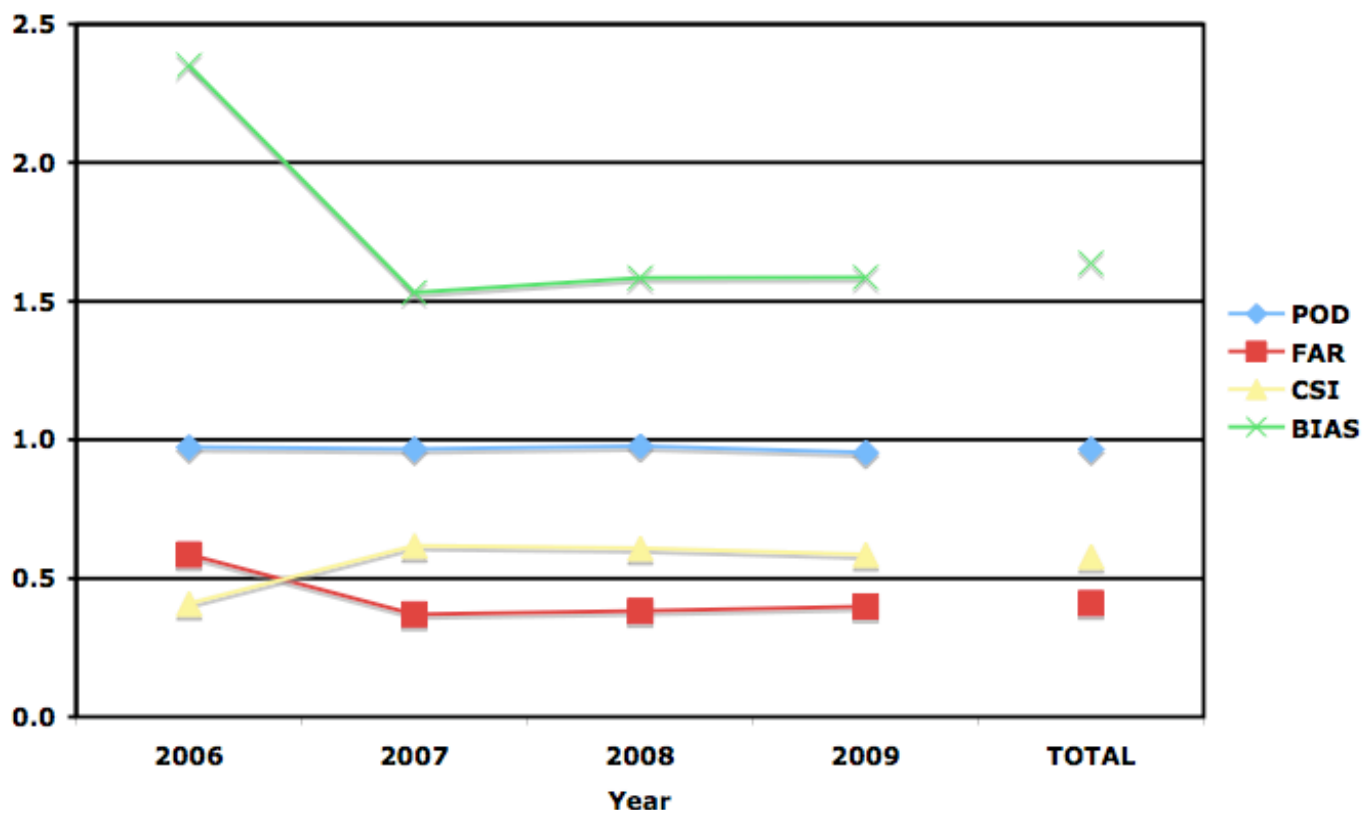

Figure 27. Time series of POD, FAR, CSI, and bias for best VII predictor of IC: 5th percentile.

\subsubsection{Lead time}

Lead time was calculated for the VII percentile method in the same way as for the radar reflectivity method. Figure 28 displays the lead times for both CG and IC lightning. Lead time for CG lightning as consistently higher than lead time for IC lightning due to higher VII values required for CG initiation. The best VII percentile predictor of CG according to CSI $-30^{\text {th }}$ percentile — had an average lead time of 6.1 minutes, while the best VII percentile predictor of $\mathrm{IC}-5^{\text {th }}$ percentile — had an average lead time of 6.7 minutes. Therefore, using the best VII predictor of lightning for each type of flash actually provides more time warning to predict IC lightning as compared to CG lightning. 


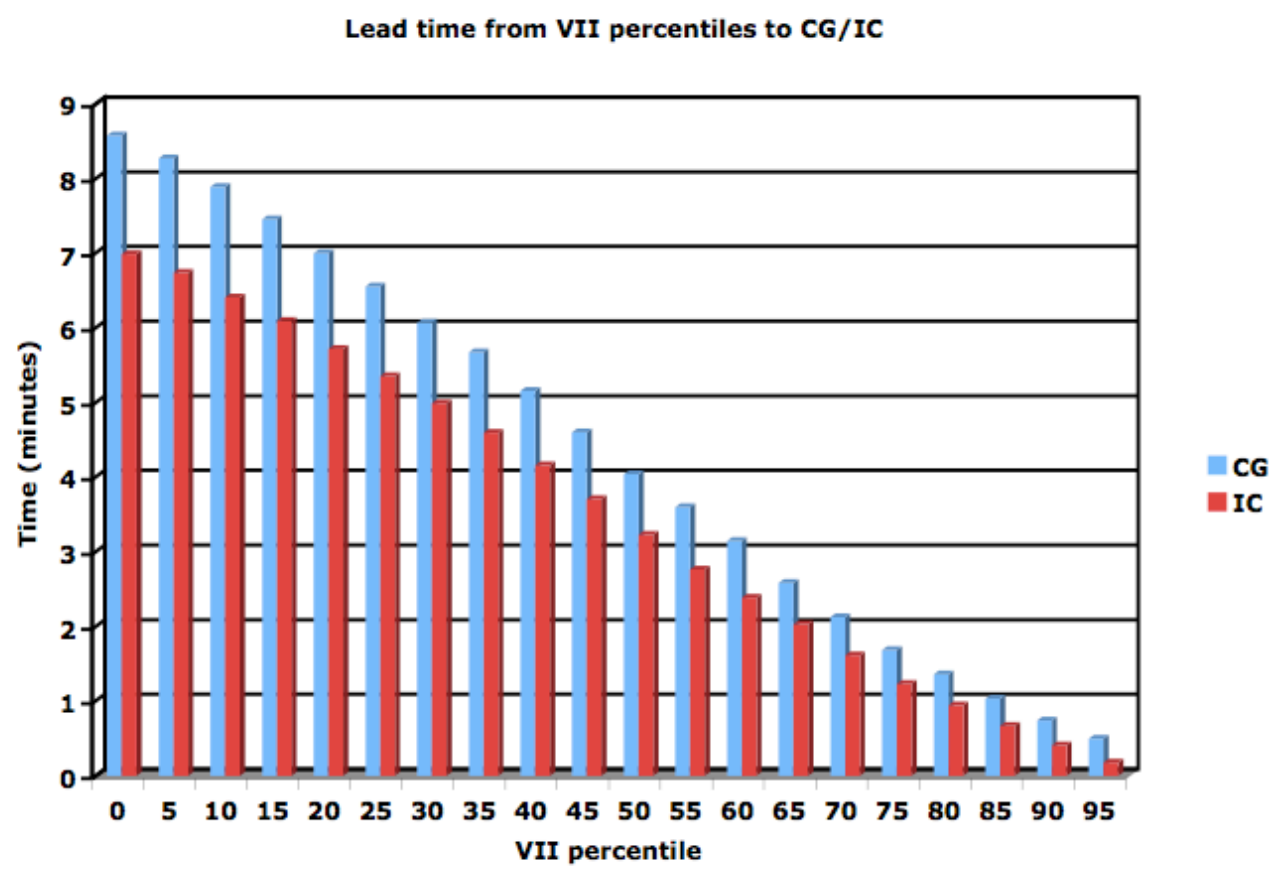

Figure 28. Lead time from VII percentiles to first CG and first IC flash.

\subsubsection{IC as predictor of CG}

\subsubsection{Statistics}

The last predictor of lightning used and analyzed involved using the first IC flash as a predictor of the first $\mathrm{CG}$ flash. Forecast verification statistics for this predictor were calculated in a similar fashion. When comparing CSI to that of the other two best predictors of CG lightning initiation $-25 \mathrm{dBZ}$ at $-20^{\circ} \mathrm{C}$ and VII $30^{\text {th }}$ percentile- , this method outperforms both. CSI for IC as a predictor of CG was 0.55 , whereas CSI for the other two best predictors of CG were 0.469 and 0.467 , respectively. Furthermore, FAR was lower than both ( 0.349 versus 0.46 and 0.444$)$, bias was lower (1.199 versus 1.444 and 
$1.339)$, and POD was equal to or lower ( 0.78 versus 0.78 and 0.745 , respectively). Figure 29 depicts total CSI, POD, FAR, and bias, as well as the time series for each.

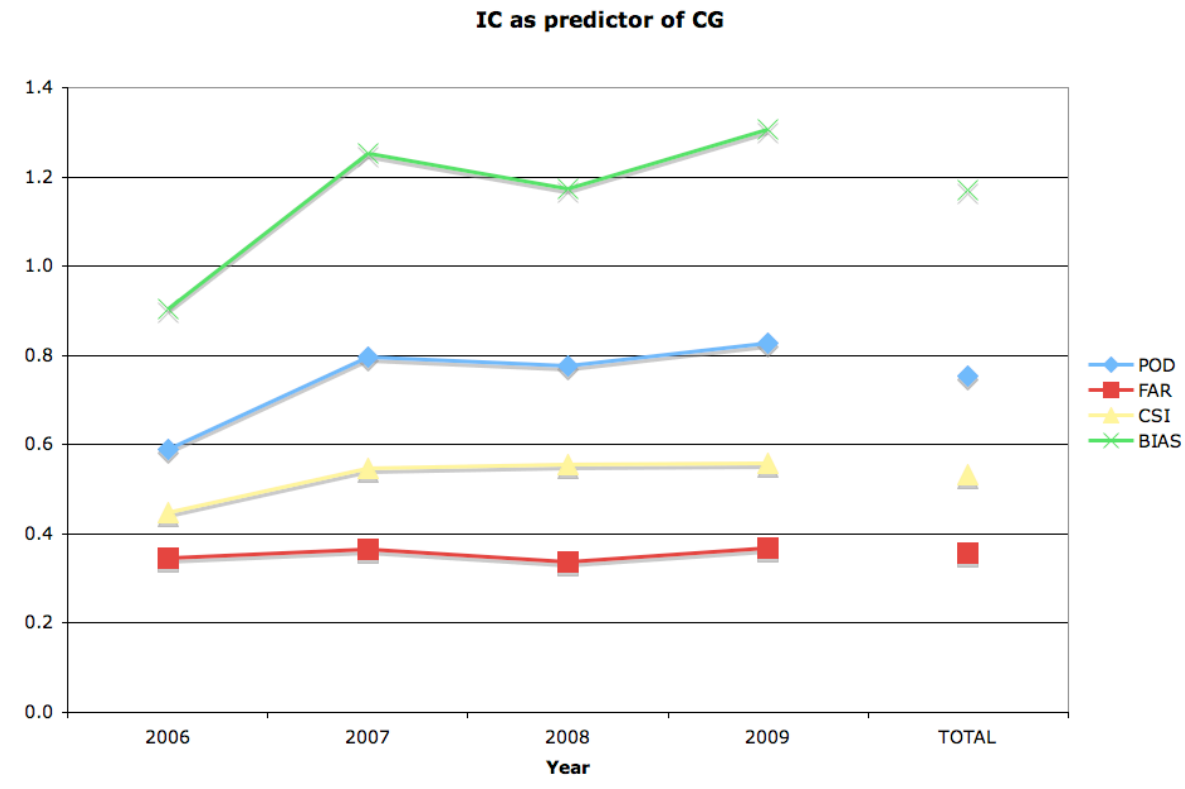

Figure 29. Time series of POD, FAR, CSI, and bias for IC as predictor of CG.

\subsubsection{Lead time}

Average lead time, as calculated and depicted above in Figure 15, was about 2.4 minutes when using the first IC flash as a predictor of CG lightning. Although this lead time is significantly lower than the other two best predictors of CG (6.7 and 6.1 minutes), it is not useless because no algorithm processing or radar scan times are required. Thus, actual lead times may be much more comparable when taking into account automation processing times. 


\subsection{Sensitivity to horizontal resolution}

A cursory examination of $1 \mathrm{~km}$ versus $2 \mathrm{~km}$ horizontal resolution in radar data was performed on a short case in June 2007, as it demonstrated typical scattered convection common over east-central Florida in the summer. It was found that the CAPPI-SCIT algorithm correctly identified two cells in close proximity as two separate cells in the $1 \mathrm{~km}$ resolution data, whereas the cells were often identified as one large cell in the $2 \mathrm{~km}$ resolution radar data. The enhanced $1 \mathrm{~km}$ horizontal resolution radar data is also plotted in Figure 5, showing distinct features and details that would not be resolved in $2 \mathrm{~km}$ horizontal resolution radar data. Therefore, it is suggested that when working with cell identification and tracking algorithms, radar data with $1 \mathrm{~km}$ horizontal resolution could be used as it likely outperforms coarser resolution data. Horizontal interpolation may not create many spurious features, at least up to $1 \mathrm{~km}$ resolution.

\subsection{Sensitivity to range and track count}

Sensitivity tests comparing both range from the LDAR network $(60,80,100 \mathrm{~km})$ and track count $(0,1,2$ radar volumes) were performed. Lead time was found to be higher for cells with a track count of at least 2 volumes within $100 \mathrm{~km}$; average lead time for predicting CG (IC) in these cells was on the order of 9-11 (7-9) minutes for predictors between 20 and $30 \mathrm{dBZ}$ at between -10 and $-15^{\circ} \mathrm{C}$. Similar lead times of 9-11 (7-9) minutes were found for track count of 2 within $100 \mathrm{~km}$ for VII predictors of CG (IC) between the $5^{\text {th }}$ and $30^{\text {th }}$ percentiles.

Comparisons of statistics for radar derived and VII predictors, with regard to range and track count, produced the following results: 
POD slightly higher (on the order of $\sim 0.01$ ) for track count 2 vs. 0; POD actually slightly higher $(\sim 0.01)$ for $100 \mathrm{~km}$ vs. $60 \mathrm{~km}$

FAR lower $(\sim 0.1)$ for track count 2 vs. 0 ; FAR actually slightly lower $(\sim 0.01)$ for CG 100 km vs. 60 km; FAR slightly lower ( 0.01) for IC 60 km vs. $100 \mathrm{~km}$

$>$ CSI higher $(\sim 0.1)$ for track count 2 vs. 0 , CSI generally same for range

Therefore, it is determined that, in general, differences in track count provide greater improvement in forecast statistics, especially CSI, as compared to differences in range, which is consistent with Mosier et al. (2010).

Not surprisingly, highest CSI and POD, and lowest FAR, for IC as a predictor of CG was found for cells with a track count of 2 volumes within $60 \mathrm{~km}$ (CSI: 0.625 , FAR: 0.267, POD: 0.810). Higher LDAR flash detection efficiencies occur at shorter ranges, most likely resulting in better forecast statistics for using IC lightning as a predictor of CG occurrence.

\subsection{More on interannual variation}

Not only are there apparent IC:CG ratio trends during the period of this study, but there also appear to be curious trends in statistical measures calculated for our forecast predictors. A monthly analysis of CG and IC flash counts as well as range from the LDAR networks were presented in Section 3.2. Results indicate that changes in flash detection efficiency from the LDAR-I to LDAR-II system are likely not a significant factor in the upward trending of IC flash totals from 2006 to 2009.

Because our analyses involve the use of radar data, another possible explanation for the trending evident in our forecast statistics are changes in the calibration of the KMLB 
radar. Wang and Wolff (2009) performed analyses comparing the TRMM precipitation radar to ground-based radars, including the KMLB radar, for the period 1998-2007. This analysis was extended to 2009 for KMLB (Wolff, personal communication). Wang and Wolff found that the Melbourne radar had a consistent offset of only 0-2 dB below TRMM reflectivities during JJA 2006-2009, with an offset near 0 or even close to $1 \mathrm{~dB}$ above TRMM reflectivities during JJA 2009. Because the uncertainty in comparing a ground- and space-based radar is on the order of $+/-1 \mathrm{~dB}$, these offsets are relatively minor and cannot fully explain the interannual variation in this study.

Instrumentation changes, i.e. lightning detection system (LDAR, NLDN) changes, and radar calibration changes, are not likely causes in the evident yearly trending in this study. Natural variability, specifically observational rain gauge data, may be a remaining factor. Precipitation totals for JJA 2006-2009 over Florida were plotted to show the aerial extent to the increases and decreases of rainfall through the years (Figure 30). 

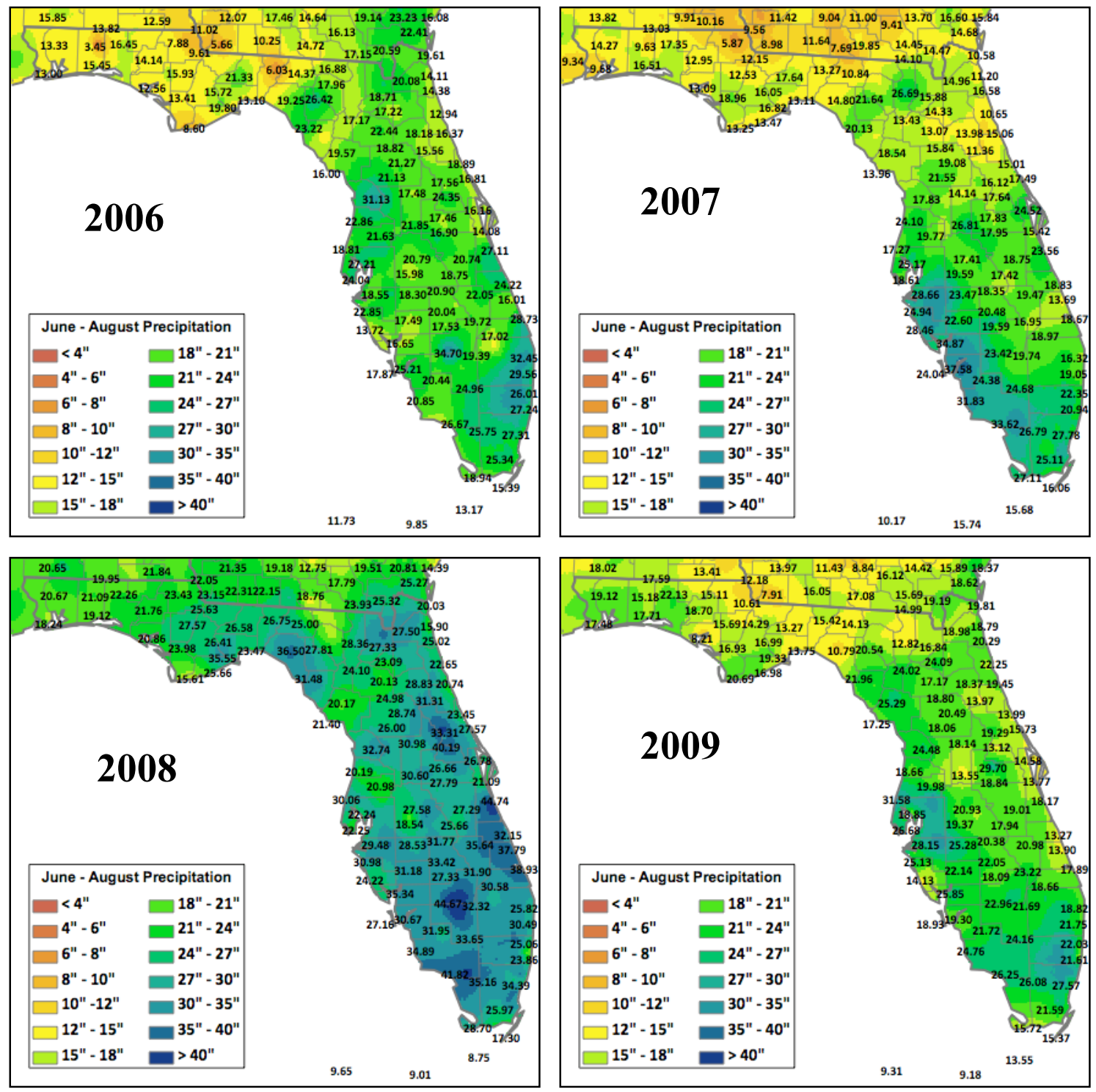

Figure 30. JJA 2006-2009 aerial precipitation for Florida. 
Figure 30 shows no apparent trend in precipitation over the Melbourne, Florida from JJA 2006 to JJA 2009. Precipitation over the area of study is significantly higher during JJA 2008 due to Tropical Storm Fay providing upwards of 20 inches of rain to eastcentral Florida. Nevertheless, trends in rainfall may not necessarily indicate trends in lightning, as evidenced by Figure 31. This scatter plot depicts monthly (JJA) precipitation totals (inches) for the six closest available observation stations to the area of study versus number of monthly (JJA) total lightning (IC+CG) flashes within $100 \mathrm{~km}$ of the LDAR network center. Note that August 2008 for Melbourne, Orlando Sanford, and Sanford were omitted due to the effects of Tropical Storm Fay on precipitation totals for those months. Only a slight positive trend, or no significant trend at all, is apparent, indicating that the amount of lightning may not be directly related to rainfall totals over a certain area. Differences in synoptic weather patterns, such as the prevailing wind direction and thus direction of the sea breeze, may play a key role in the variation of precipitation as well as changes in lightning totals from month to month and year to year. 


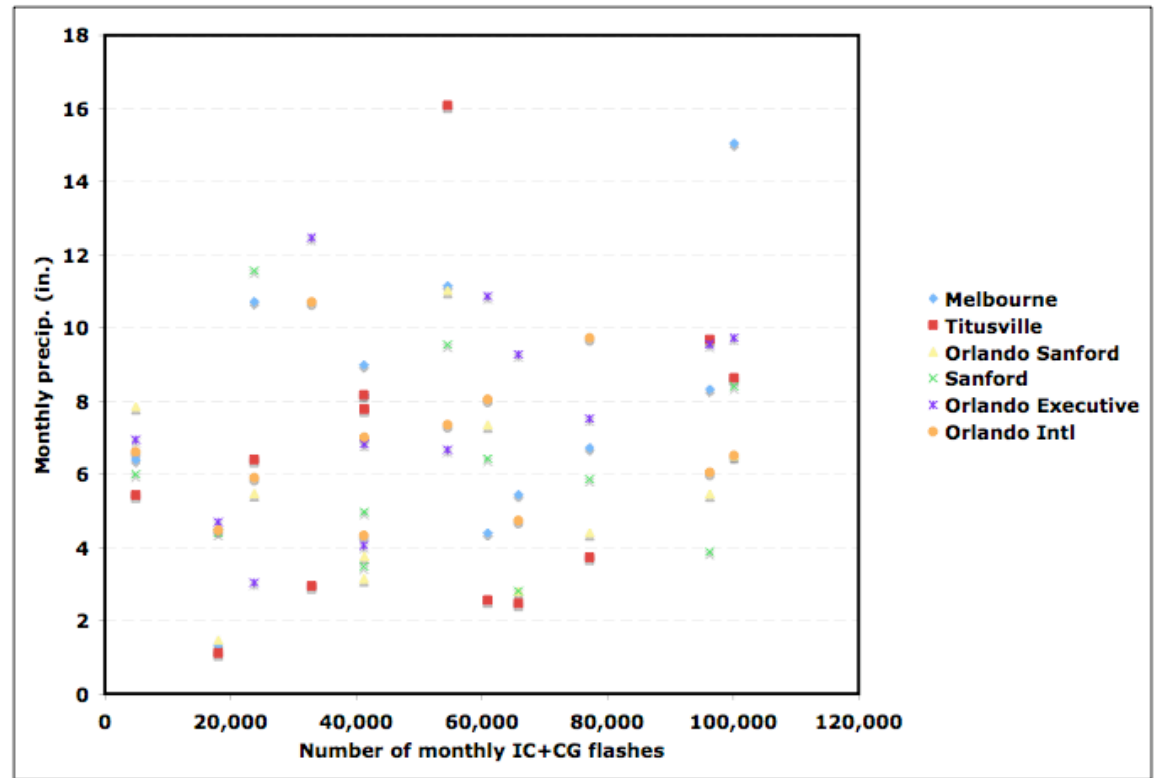

Figure 31. Monthly (JJA) precipitation totals (inches) for the six closest available observation stations to the area of study versus number of monthly (JJA) total lightning $(\mathrm{IC}+\mathrm{CG})$ flashes within $100 \mathrm{~km}$ of the LDAR network center. 


\section{CONCLUSIONS AND FUTURE WORK}

\subsection{Conclusions}

This research is distinct from other past lightning forecasting studies in several ways. First, through the use of automation, we have been able to analyze more than 17,000 individual cells, more than 300 times as many cells as numerous prior studies. By investigating such a large number of storms, we are able to arrive at statistically significant results. Second, this study examines total lightning in the hopes of optimizing both IC and CG flash forecasting — something that has not been greatly pursued in the past. Finally, while many previous studies have focused on lightning - and specifically CG-initiation, we have presented diagnostic comparisons between initiation and cessation for both flash types.

While the great majority of storms with lightning (nearly $90 \%$ ) contained at least one IC flash, still over 700 cells (4\%) contained only CG lightning. A brief analysis of IC:CG ratio over our database showed numbers consistent with previous papers concerning this ratio: 2.64 for our data, while Boccippio et al. (2001a) found between 2 and 2.5 for Central Florida.

Vertically integrated ice at both CG and IC initiation was higher than at both CG and IC cessation, and this difference was statistically significant. Because VII is a proxy for ice mass accumulation in a storm, this result supports the hypothesis that a large amount of ice mass buildup is necessary for a storm to produce charge separation and thus lightning at initiation. Once sufficient charge separation has occurred, however, it is 
possible that lightning can continue to strike, even if VII has lowered during storm dissipation.

The best radar-derived predictor of CG lightning for this study over Melbourne, Florida was found to be $25 \mathrm{dBZ}$ at $-20^{\circ} \mathrm{C}$, while the best reflectivity at isothermal predictor for IC was $25 \mathrm{dBZ}$ at $-15^{\circ} \mathrm{C}$. Meanwhile, the best VII predictor of CG lightning was the $30^{\text {th }}$ percentile $\left(0.840 \mathrm{~kg} \mathrm{~m}^{-2}\right)$, while the best VII predictor of IC was the $5^{\text {th }}$ percentile $\left(0.143 \mathrm{~kg} \mathrm{~m}^{-2}\right)$, or nearly 6 times lower than for CG! CSI was also found to be higher overall for IC lightning forecasts, for both reflectivity and VII methods, than for CG forecasts. However, lead times were consistently lower. Nevertheless, it turns out that using the best (highest CSI) VII percentile predictor for IC prediction provides a slightly longer lead time (6.4 minutes) than using the best VII percentile predictor for CG prediction (6.1 minutes).

VII was found to be lower at IC occurrence, including at initiation, than at CG occurrence, providing evidence that intracloud flashes can occur in storms with lower vertically integrated ice, and thus lower overall charge separation. One possible reason could be that IC flashes occur in storms with less vertical depth and thus less vertically integrated ice.

In our general database overview of cells, we found that $76 \%$ of cells had IC initiation before CG initiation, while $63 \%$ of cells had IC cessation last. Clements and Orville (2008) stated that using total lightning VHF sources provides little utility in CG forecasting — only about a 3-minute warning time. Previously, however, studies have empirically shown the utility of IC as a warning indicator of CG flashes (Murphy and 
Cummins, 2000, Weber et al., 1998). When we looked more closely at our data, we found that, in fact, using the first IC flash as a predictor of CG occurrence statistically outperforms other predictors of CG lightning. CSI for this method (0.55) was higher than CSI for both the best reflectivity method (0.469) and the best VII percentile method (0.467) (each with a track count of 0 within $100 \mathrm{~km}$ ). Furthermore, when considering only those cells with a track count of 2 and within $60 \mathrm{~km}$ of the LDAR network, IC as a predictor of CG still outperforms the other predictors of CG (CSI of 0.625 vs. 0.53 and 0.51). Even though average lead time for using IC as a predictor of CG was only 2.4 minutes, when taking into account automation processing and radar scan time for the other two methods, lead times are much more comparable. Furthermore, IC as a predictor of CG could be the most useful method for the general public, as almost anyone who is outside can spot the first IC flash in a storm and take the necessary safety precautions. While the radar reflectivity and VII percentile methods could be useful for the experienced forecaster, using the first IC flash could turn out to provide the simplest and most practical method for predicting CG lightning initiation.

Horizontal resolution sensitivity tests on radar data resulted in the suggestion that when working with cell identification and tracking algorithms, radar data with $1 \mathrm{~km}$ horizontal resolution could be used as it likely outperforms coarser resolution data. Although interpolation of the radar data is expected, it was found that using $1 \mathrm{~km}$ horizontal resolution most likely does not result in many fabricated features in the radar return. 
Instrumentation changes, including within the lightning detection systems (LDAR, NLDN) used in this study, and radar calibration changes, are not likely causes in the evident yearly trending in this research. Synoptic weather patterns, such as prevailing wind direction and sea breeze formation, may play a key role in the interannual variation of lightning as well as precipitation within this study. Future work focusing on different synoptic weather blueprints and the resulting precipitation and lightning will provide climatological insight into the general long-term patterns of severe storm formation and dissipation over Florida.

\subsection{Future work}

Future work should address using similar approaches in forecasting the cessation of lightning within storms. Although this study provided a cursory glance into this issue, more research is necessary to more accurately predict when the last flash occurs in a storm. Methods like maximum time interval between flashes, used in Stano et al. (2010), should be investigated. In addition, the utility of VII, which has continued to show promise, should be examined not only for forecasting initiation and cessation, but also for predicting the probability of a certain CG or IC flash rate within storms. Finally, polarimetric radar, which should be operational in the U.S. in the near future, will provide further insight into mixed-phase composition and thus proxies for charge separation and lightning formation and dissipation within storm clouds. 


\section{REFERENCES}

Barnes, S. L., 1980: Report on a meeting to establish a common Doppler radar data exchange format, Bull. Am. Meteorol. Soc., 61, 1401 - 1404.

Biagi, C. J., K. L. Cummins, K. E. Kehoe, and E. P. Krider, 2007: National Lightning Detection Network (NLDN) performance in southern Arizona, Texas, and Oklahoma in 2003 - 2004. J. Geophys. Res., 112, D05208, doi: 10.1029/2006JD007341.

Boccippio, D. J., K. L. Cummins, H. J. Christian, and S. J. Goodman, 2001a: Combined satellite- and surface-based estimation of the intracloud-cloud-to-ground lightning ratio over the continental United States. Mon. Wea. Rev., 129, 108-122.

, D. J., S. Heckman, and S. J. Goodman, 2001b: A diagnostic analysis of the Kennedy Space Center LDAR network 1. Data characteristics, J. Geophys. Res., 106, 47694786

, D. J., S. Heckman, and S. J. Goodman, 2001c: A diagnostic analysis of the Kennedy Space Center LDAR network 2. Cross-sensor studies, J. Geophys. Res., 106, 47874796.

Buechler, D. E. and S. J. Goodman, 1990: Echo size and asymmetry - impact on NEXRAD storm identification. J. Appl. Meteor., 29, 962-969.

Carey, L. D., and S. A. Rutledge, 1996: A multiparameter radar case study of the microphysical and kinematic evolution of a lightning producing storm. Meteorology and Atmospheric Physics, 59, 33-64.

Clements, N. C. and R. E. Orville, 2008: The warning time for cloud-to-ground lightning in isolated, ordinary thunderstorms over Houston, Texas. $3^{\text {rd }}$ Conference on Meteorological Applications of Lightning Data, New Orleans, LA, Amer. Meteor. Soc. [Available online at ams.confex.com/ams/pdfpapers/132309.pdf.]

Cressman, G. P., 1959: An operational objective analysis system. Mon. Wea. Rev., 87:367374.

Cummins, K. L., M. J. Murphy, E. A. Bardo, W. L. Hiscox, R. B. Pyle, and A. E. Pifer, 1998: A Combined TOA/MDF Technology Upgrade of the U.S. National Lightning Detection Network, J. Geophys. Res., 103(D8), 9035-9044.

Curran, E.B., R. L. Holle, R. E. Lopez, 2000: Lightning casualties and damages in the United States from 1959 to 1994. J. Climate, 13, 3448-3464. 
Gauthier, M. L., W. A. Petersen, L. D. Carey, and H. J. Christian Jr., 2006: Relationship between cloud-to-ground lightning and precipitation ice mass: A radar study over Houston, Geophys. Res. Lett., 33, L20803, doi:10.1029/2006GL027244.

Goodman, S. J., D. E. Buechler, P. D. Wright, and W. D. Rust, 1988: Lightning and precipitation history of a microburst-producing storm. Geophys. Res. Lett., 15, 1185-1188.

Gremillion, M. S. and R. E. Orville, 1999: Thunderstorm characteristics of cloud-toground lightning at the Kennedy Space Center, Florida: A study of lightning initiation signatures as indicated by the WSR-88D. Wea. Forecasting, 14, 640-649.

Hodanish, S., D. W. Sharp, W. Collins, C. Paxton, and R. E. Orville, 1997: A ten-year monthly lightning climatology of Florida: 1986 through 1995. Wea. Forecasting, 12, 439-448.

Holle, R. L., R. E. López, R. Ortiz, A. I. Watson, D. L. Smith, D.M. Decker, and C.H. Paxton, 1992: Cloud-to-ground lightning related to deaths, injuries, and property damage in central Florida. Intl. Conf. on Lightning and Static Electricity, Atlantic City, NJ, FAA Report No. DOT/FAA/CT-92/20, 66-1-66-11.

Hondl, K. D. and M. D. Eilts, 1994: Doppler radar signatures of developing thunderstorms and their potential to indicate the onset of cloud-to-ground lightning. Mon. Wea. Rev., 122, 1818-1836.

Johnson, J. T., P. L. MacKeen, A. Witt, E. D. W. Mitchell, G. J. Stumpf, M. D. Eilts, and K. W. Thomas, 1998: The Storm Cell Identification and Tracking algorithm: An enhanced WSR-88D algorithm. Wea. Forecasting, 13, 263-276.

Lambert, W. C., M. Wheeler, and W. P. Roeder, 2005: Objective lightning forecasting at Kennedy Space Center and Cape Canaveral Air Force Station using Cloud-toGround Lightning Surveillance System data. $1^{\text {st }}$ Conference on Meteorological Applications of Lightning Data, San Diego, CA, Amer. Meteor. Soc. [Available online at ams.confex.com/ams/pdfpapers/85944.pdf.]

McNamara, T. M., 2002: The horizontal extent of cloud-to-ground lightning over the Kennedy Space Center, M.S. Thesis, Air Force Institute of Technology, WrightPatterson Air Force Base, OH 114 pp.

Michimoto, K, 1991: A study of radar echoes and their relation to lightning discharge of thunderclouds in the Hokuriku district. Part I: Observations and analysis of thunderclouds in summer and winter. J. Meteor. Soc. Japan, 69, 327-335. 
Mohr, C. G., L. J. Miller, R. L. Vaughn, and H. W. Frank, 1986: On the merger of mesoscale data sets into a common Cartesian format for efficient and systematic analysis. J. Atmos. Oceanic Technol., 3, 143 - 161.

Montgomery, D. C. and G. C. Runger, 2006: Applied Statistics and Probability for Engineers. John Wiley \& Sons, 784 pp.

Mosier, R. M., C. Schumacher, R. E. Orville, and L. D. Carey, 2010: Radar nowcasting of cloud-to-ground lightning over Houston, Texas, Accepted, Wea. Forecasting.

Motley, S. M., 2006: Total lightning characteristics of ordinary convection. M.S. thesis, Dept. of Atmospheric Sciences, Texas A\&M University, College Station, TX, 165 pp.

Murphy, M. J., 2006: When flash algorithms go bad. 1st International Lightning Meteorology Conference, Tucson, AZ, 26-27, 6 pp.

, M. J., and K.L. Cummins, 2000: Early detection and warning of cloud-to-ground lightning at a point of interest. 2nd Symposium on Environmental Applications, Amer. Meteorol.. Soc., Long Beach, CA, pp. 172-177.

, M. J., K.L. Cummins, and L. M. Maier, 2000: The analysis and interpretation of three-dimensional lightning flash information. 16th International Conference on Interactive Information and Processing Systems (IIPS) for Meteorology, Oceanography, and Hydrology, Long Beach, CA, 102-105.

, M. J., K.L. Cummins, N. W. S. Demetriades, and W. P. Roeder, 2008: Performance of the new Four-Dimensional Lightning Surveillance System (4DLSS) at the Kennedy Space Center/Cape Canaveral Air Force Station complex. $13^{\text {th }}$ Conference on Aviation, Range and Aerospace Meteorology, New Orleans, LA, Amer. Meteor. Soc. [Available online at ams.confex.com/ams/pdfpapers/131130.pdf.]

Nelson, L. A., 2002: Synthesis of 3-dimensional lightning data and radar to determine the distance that naturally occurring lightning travels from thunderstorms, M.S. Thesis, Air Force Institute of Technology, Wright-Patterson Air Force Base, OH, 85 pp.

OFCM, 2008: Federal Meteorological Handbook No. 11 Doppler Radar Meteorological Observations Part A: System Concepts, Responsibilities, and Procedures. FCMH11A-2008, 53 pp. [Available online at http://www.roc.noaa.gov/WSR88D/PublicDocs/PartA_FMH11_05_09_OFCM_fin al.pdf.] 
Orville, R. E., G. R. Huffines, W. R. Burrows, and K. L. Cummins, 2010: The North American Lightning Detection Network (NALDN): Analysis of flash data-20012009. Accepted to Mon. Wea. Rev.

Oye, D. and M. Case, 1995: REORDER: A Program for Gridding Radar Data. Installation and Use Manual for the UNIX Version. NCAR Atmospheric Technology Division, Boulder, CO, 19pp.

Rakov, V. A. and M. A. Uman, 2003: Lightning: Physics and Effects. Cambridge University Press, 687 pp.

Roeder, W. P., 2010: The Four Dimensional Lightning Surveillance System. $21^{\text {st }}$ International Lightning Detection Conference, Orlando, FL. [Available online at http://www.vaisala.com/Vaisala\%20Documents/Scientific\%20papers/4.RoederThe\%20Four\%20Dimensional.pdf.]

Stano, G. T., H. E. Fuelberg, and W. P. Roeder, 2010: Developing empirical lightning cessation forecast guidance for the Cape Canaveral Air Force Station and Kennedy Space Center. J. of Geophys. Res., 115, D09205.

Vincent, B. R., L. D. Carey, D. Schneider, K. Keeter, and R. Gonski, 2003: Using WSR88D reflectivity for the prediction of cloud-to-ground lightning: A Central North Carolina study. Natl. Wea. Dig., 27, $35-44$.

Wang, J., and D. B. Wolff, 2009: Comparisons of reflectivities from the TRMM precipitation radar and ground-based radars. J. Atmos. Oceanic Technol., 26, 857875.

Weber, M. E., E. R. Williams, M. M. Wolfson, and S. J. Goodman, 1998: An assessment of the operational utility of a GOES lightning mapping sensor. MIT/Lincoln Laboratory Project Rep. NOAA-18, 108 pp. [Released to sponsor only.]

Wilks, D. S. 1995: Statistical Methods in the Atmospheric Sciences. Academic Press, 467 pp.

Wolf, P., 2006: Anticipating the initiation, cessation, and frequency of cloud-to-ground lightning, utilizing WSR-88D reflectivity data. NWA Electronic Journal of Operational Meteorology, December 2006. [Available online at http://www.nwas.org/ej/pdf/2007-EJ1.pdf.] 


\section{APPENDIX A}

\section{STATISTICAL DEFINITIONS}

Hits $(H)$ : events that are both forecast and observed Misses (M): events that are not forecast but observed False alarms (FA): events that are forecast but not observed No forecasts $(N F)$ : events that are not forecast and not observed

Probability of detection (POD): the probability that an event would be forecast, given that it occurred

$$
P O D=\frac{H}{H+M}
$$

False alarm ratio (FAR): the fraction of forecast events that turn out to be incorrect

$$
F A R=\frac{F A}{H+F A}
$$

Critical success index (CSI): the ratio of the number of correctly forecasted events to the sum of the predicted events plus the incorrectly predicted nonevents

$$
C S I=\frac{H}{H+M+F A}
$$

Bias: the ratio of the number of yes forecasts to the number of yes observations; bias greater than one indicates overforecasting, while bias less than one indicates underforecasting

$$
B I A S=\frac{H+F A}{H+M}
$$




\section{APPENDIX B \\ REMAINING FIGURES FROM STATISTICAL ANALYSIS}

\section{B.1 Radar reflectivity method}

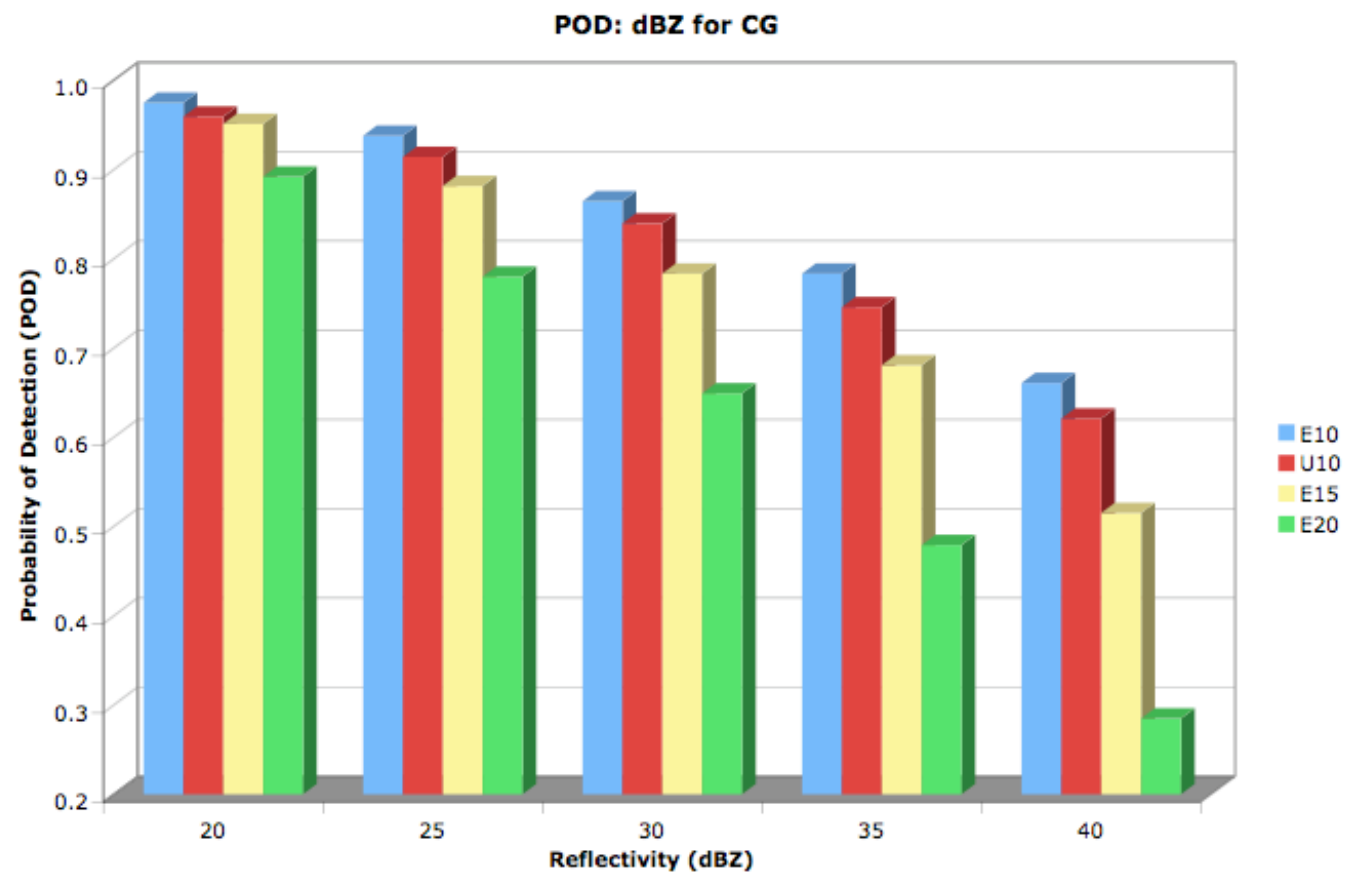

Figure B1. Probability Of Detection (POD) for the five best dBZ group predictors of CG. 


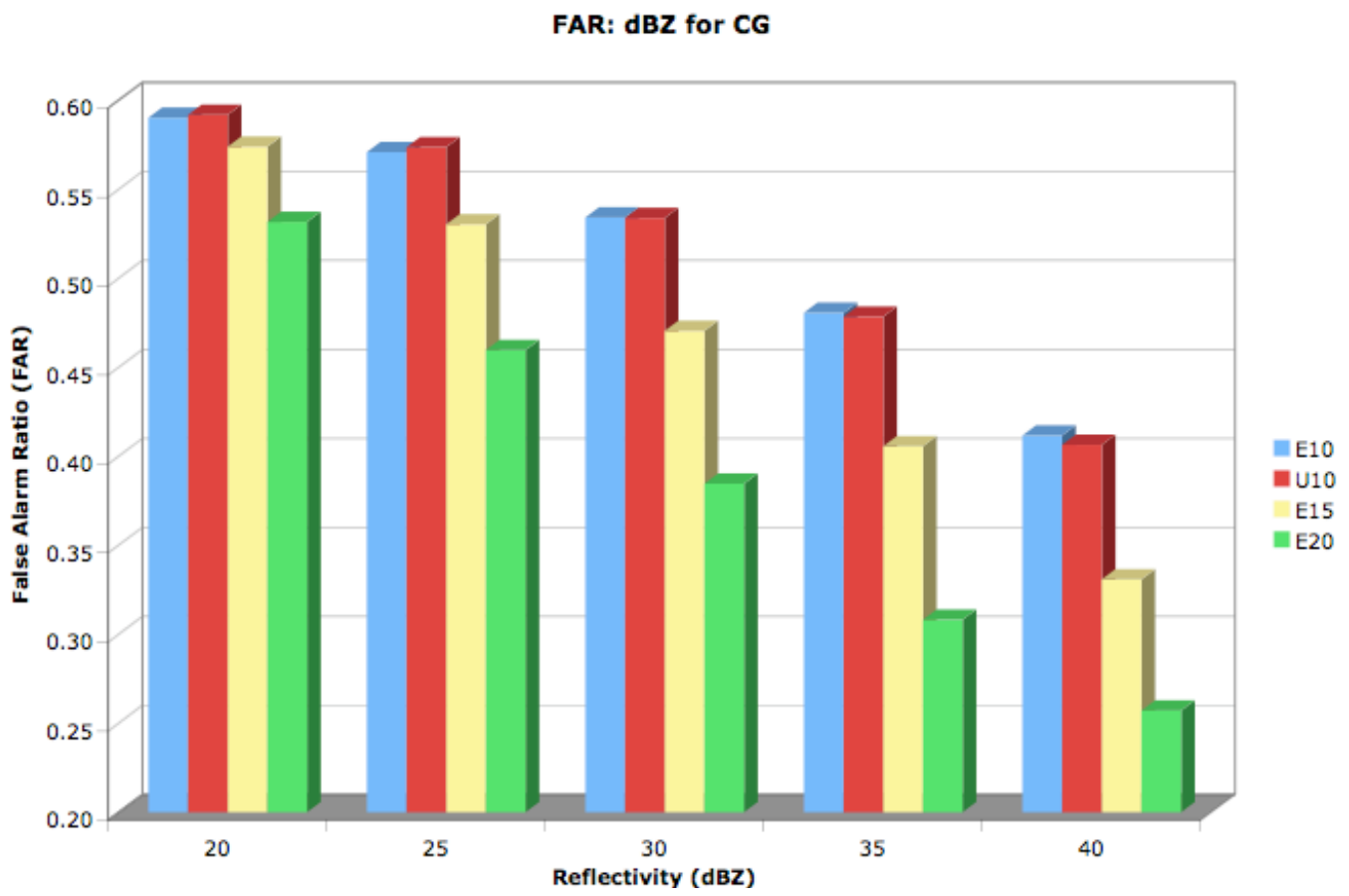

Figure B2. False Alarm Ratio (FAR) for the five best dBZ group predictors of CG. POD: $\mathrm{dBZ}$ for IC

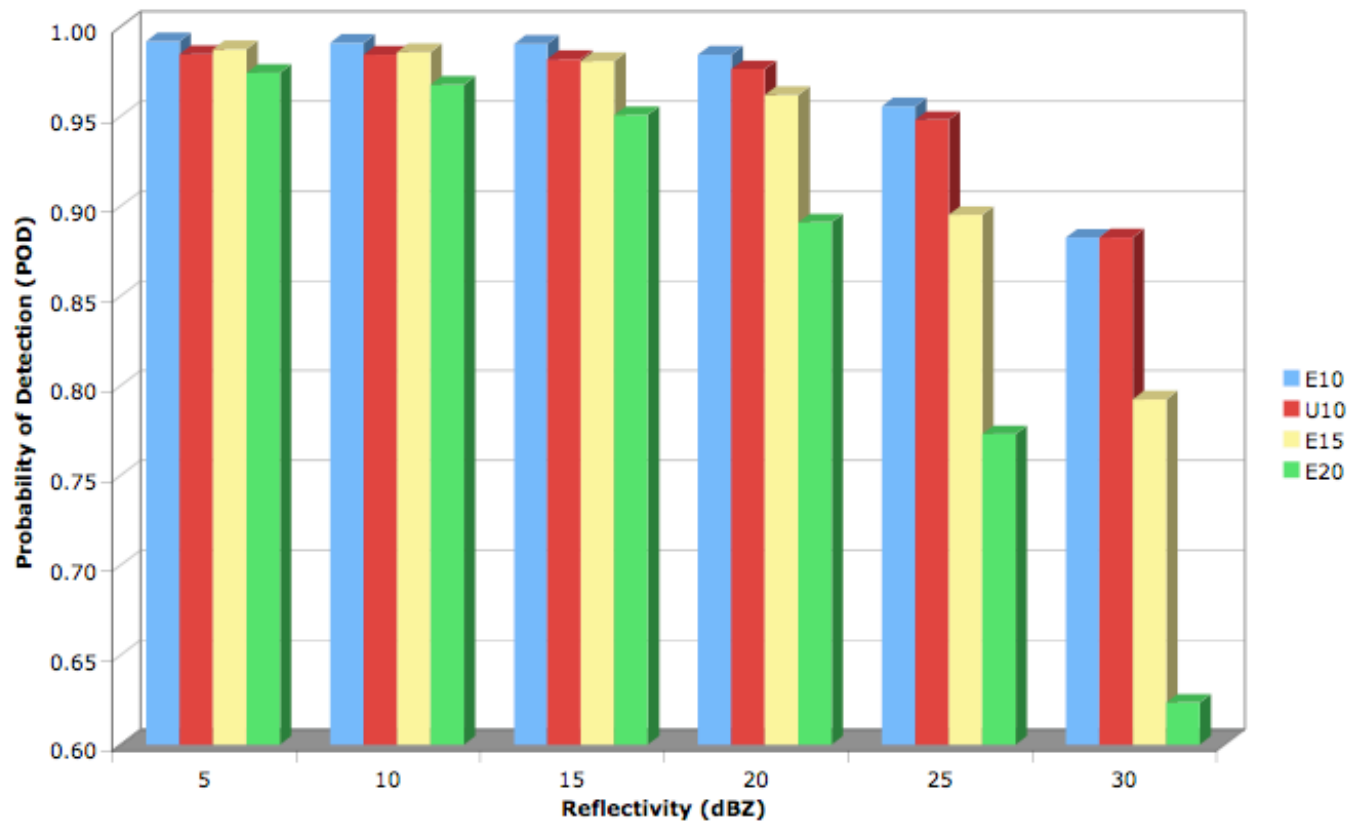

Figure B3. Probability Of Detection (POD) for the six best dBZ group predictors of IC. 


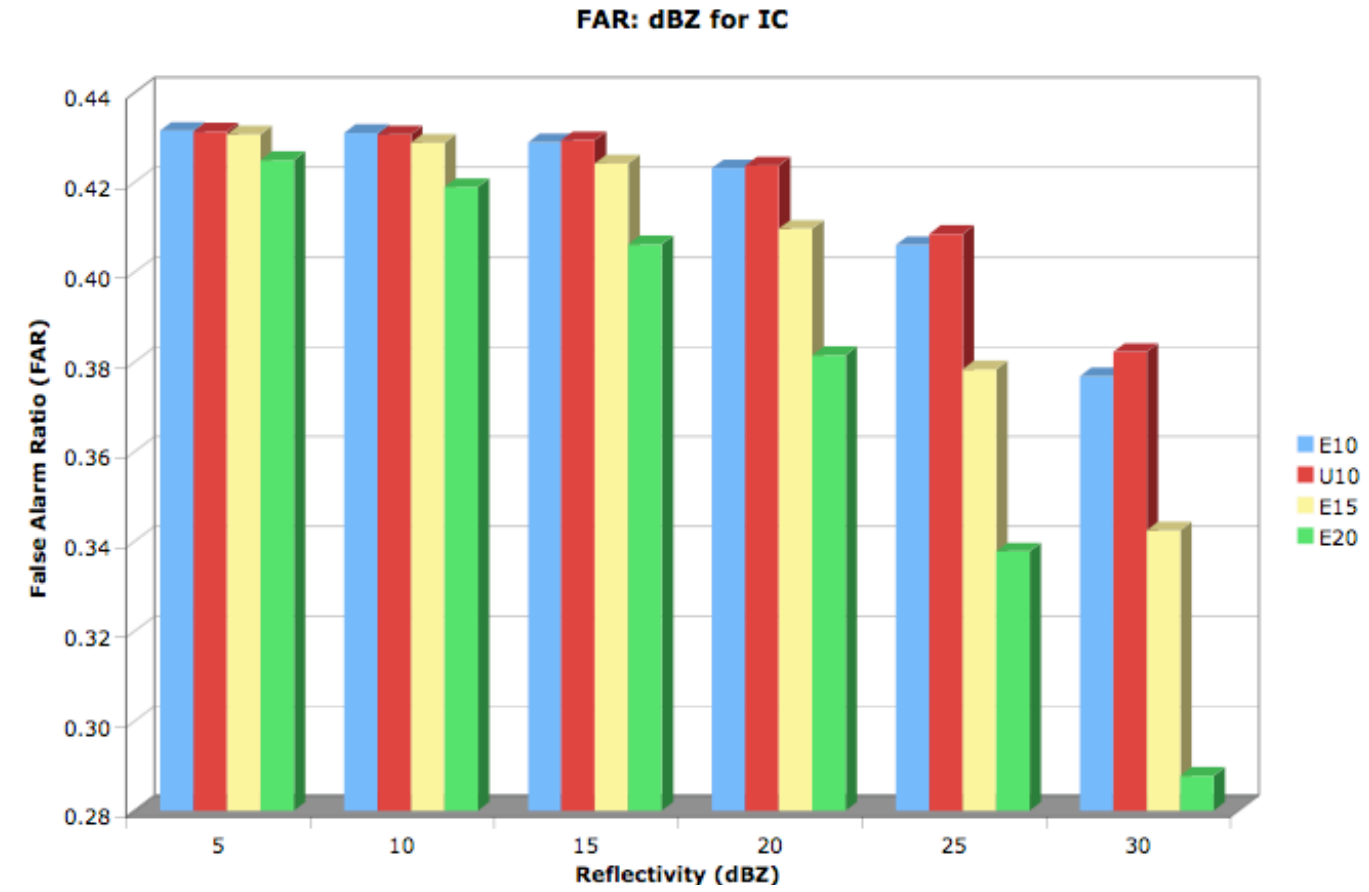

Figure B4. False Alarm Ratio (FAR) for the six best dBZ group predictors of IC. 


\section{B.2 VII percentile method}

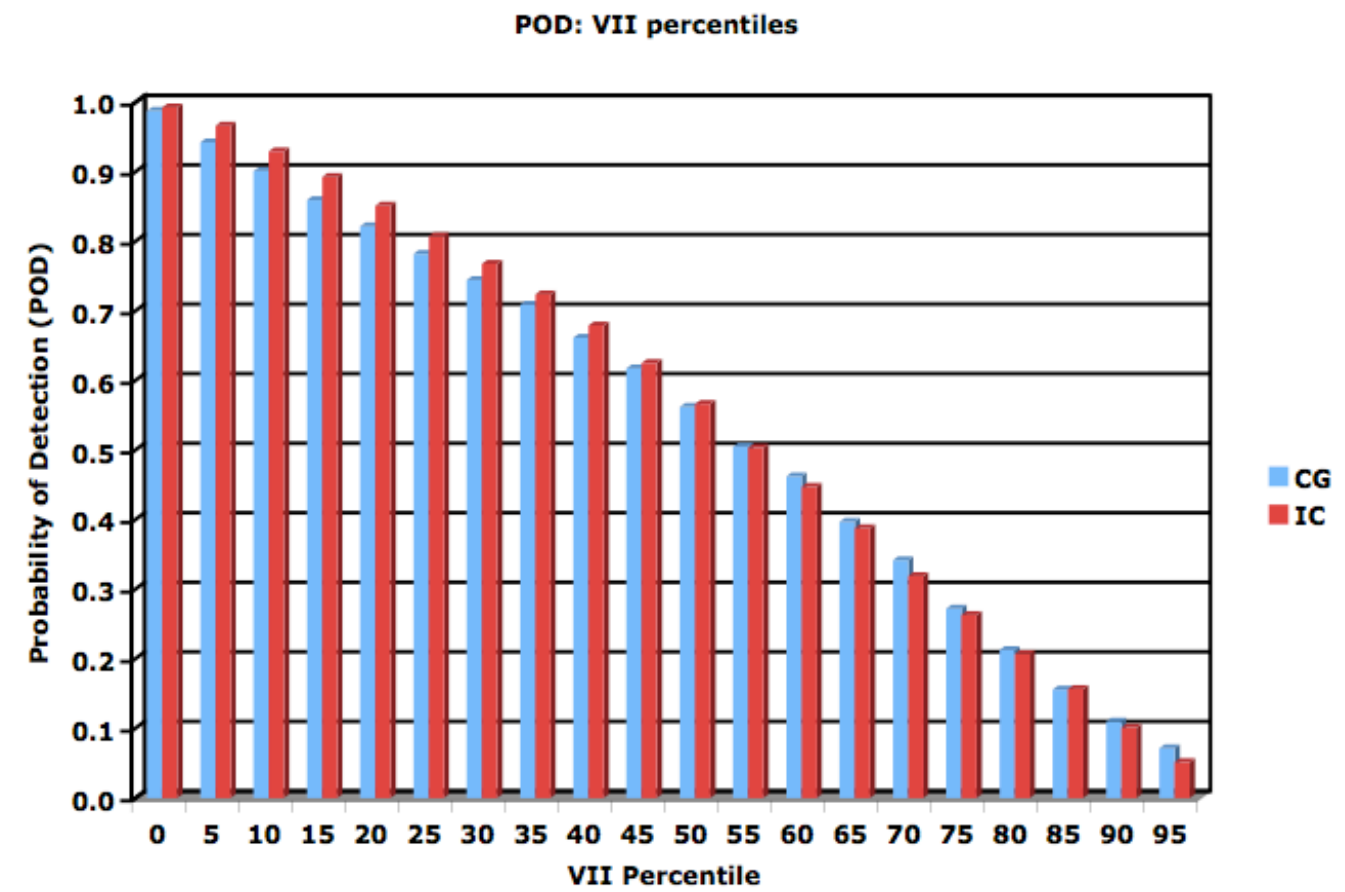

Figure B5. Probability Of Detection (POD) for VII percentiles for both CG and IC. 


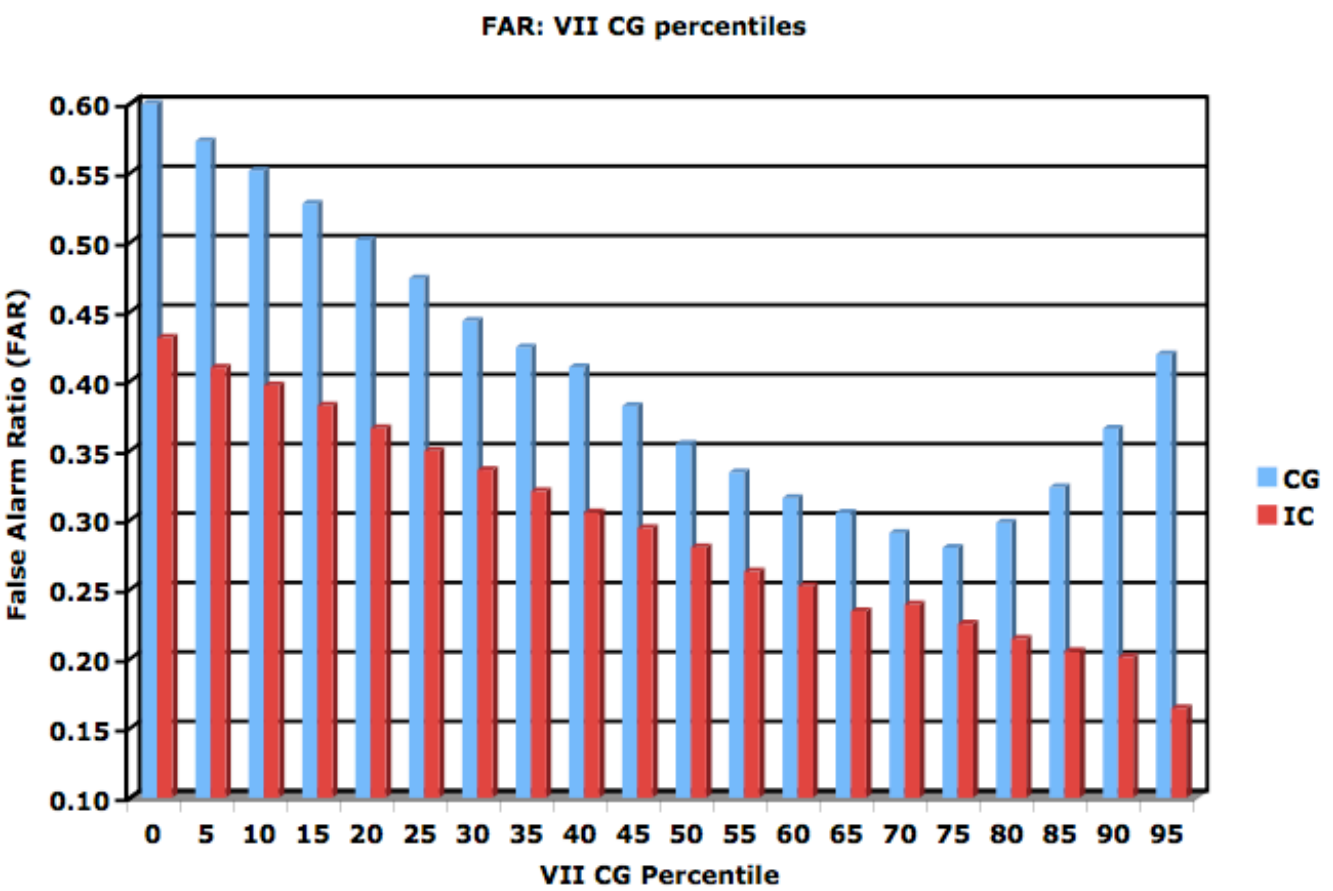

Figure B6. False Alarm Ratio (FAR) for VII percentiles for both CG and IC. 


\section{VITA}

Name: $\quad$ Gregory Nicholas Seroka

Address: $\quad$ Rutgers, the State University of New Jersey

71 Dudley Road

New Brunswick, NJ 08901

Email Address: greg.seroka@gmail.com

Education: $\quad$ B.S., Meteorology, Pennsylvania

State University, 2008

M.S., Atmospheric Sciences, Texas

A\&M University, 2011 